\title{
Revision of North American species of Clistopyga (Hymenoptera: Ichneumonidae: Pimplinae)
}

\author{
Santiago Bordera, Alejandra González-Moreno, ${ }^{1}$ Andrey I. Khalaim, llari E. Sääksjärvi
}

\begin{abstract}
Based on a large number of specimens deposited in many collections, and on material collected in a sampling program in Yucatán Peninsula, Mexico, 19 North American species of Clistopyga Gravenhorst, 1829 (Hymenoptera: Ichneumonidae) are reported. Five species, C. aenigmatica, C. arizonica, C. juliana, C. maya, and C. oaxacana, are described as new. Clistopyga covarrubiasi Khalaim and Hernández, 2008 is synonymysed with C. recurva (Say, 1835) and C. sauberi Brauns, 1898 is once again re-synonymysed with C. canadensis Provancher, 1880. Data on diagnosis, variation, distribution, and hosts of all species are provided. All previously known species are re-described. The present revision extends the distributional range of the Neotropical species C. calixtoi Gauld, 1991, C. fernandezi Gauld, 1991, and C. henryi Gauld, Ugalde, and Hanson, 1998 to the southern part of the Nearctic Region (northern Mexico), and the area of the Nearctic species C. manni Cushman, 1922 to the northern part of the Neotropical region (southern Mexico). An illustrated identification key to all North American Clistopyga species is provided.
\end{abstract}

\begin{abstract}
Résumé-Le présente étude est basée sur un grand nombre de spécimens dans de nombreuses collections importantes d'Ichneumonidae, et le matériel recueilli sur un programme d'échantillonnage effectué dans la péninsule du Yucatán (Mexique). Dans cet article, 19 espèces nordaméricaines de Clistopyga Gravenhorst, 1829 (Hymenoptera: Ichneumonidae), sont signalées. Cinq nouvelles espèces ( $C$. aenigmatica, $C$. arizonica, $C$. juliana, $C$. maya et $C$. oaxacana) sont décrites. L'espèce C. covarrubiasi Khalaim et Hernández (2008) est mise en synonymie avec C. recurva (Say, 1835); C. sauberi Brauns, 1898, est à nouveau considérée en synonymie avec C. canadensis Provancher, 1880. Les données sur le diagnostic, la description, la variation, la distribution et l'hôte de toutes les espèces sont fournies. Dans cette étude, toutes les espèces nord-américaines connues sont à nouveau redécrites. La présente révision étend la zone de distribution des espèces néotropicales C. calixtoi Gauld 1991, C. fernandezi Gauld, 1991, et C. henryi Gauld, Ugalde et Hanson, 1998, dans le sud de la région néarctique (régions du nord du Mexique) et la zone de l'espèce néarctique C. manni Cushman, 1922, à la partie du nord de la région néotropicale (régions du sud du Mexique). Cette étude fournit également une clé d'identification illustrée de toutes les espèces nord-américaines.
\end{abstract}

\section{Introduction}

Clistopyga Gravenhorst, 1829 (Hymenoptera: Ichneumonidae) is a moderately large and widely distributed genus of the biologically diverse subfamily Pimplinae, adapted to many environmental conditions (Porter 1979). In fact, Clistopyga species have been found almost all over the world, the Australian region being the only major exception (Gauld 1991).

Received 25 January 2013. Accepted 5 August 2013.

S. Bordera, Instituto de Investigación CIBIO (Centro Iberoamericano de Biodiversidad), Universidad de Alicante, Apdo. Corr. 99, 03080 Alicante, Spain

A. González-Moreno, ${ }^{1}$ Cuerpo Académico de Ecología Tropical, Campus de Ciencias Biológicas y Agropecuarias, Universidad Autónoma de Yucatán, Mexico

A.I. Khalaim, Zoological Institute, Russian Academy of Sciences, 1 Universitetskaya Emb., St. Petersburg 199034, Russia; División de Estudios de Postgrado e Investigación, Facultad de Ingeniería y Ciencias,

Universidad Autónoma de Tamaulipas, Cd. Victoria 87149, Mexico

I.E. Sääksjärvi, Department of Biology, Zoological Museum, Section of Biodiversity and Environmental Sciences, FIN-20014 University of Turku, Finland

${ }^{1}$ Corresponding author (e-mail: jandra28@yahoo.com).

Subject editor: Bradley Sinclair

doi: $10.4039 /$ tce. 2013.74

http://zoobank.org/urn:Isid:zoobank.org:pub:1109A2F4-A49E-4701-8B28-5FC2A2B0855A 
In earlier papers, most authors (Townes and Townes 1960; Townes 1969; Kasparyan 1981; Gauld 1984) classified Clistopyga, Tromatobia Förster, 1869 and Zaglyptus Förster, 1869 within the tribe Ephialtini, with other spider-attacking pimplines assigned to the tribe Polysphinctini. Gauld (1991) included these three genera in the Tromatobia genus-group within the tribe Ephialtini. In a further phylogenetic analysis of Pimplinae (Gauld et al. 2002) the genera Clistopyga, Tromatobia, and Zaglyptus were included within the Sericopimpla genus-group, together with several other ephialtine genera and all genera traditionally classified in the tribe Polysphinctini.

According to a recent phylogenetic analysis (Gauld and Dubois 2006) the genus Clistopyga is most closely related to Zaglyptus, with these two genera forming a sister lineage to the monophyletic Polysphincta genus-group (=tribe Polysphinctini), with the genus Tromatobia at the base of this clade (Gauld 1991; Gauld and Dubois 2006).

Very little is known about the hosts of Clistopyga but the limited information is of great interest in evolutionary biology, because the genus may represent a kind of transitional form from idiobiont to koinobiont pimpline parasitoids. Gauld (1991) proposed that species of the genus might be idiobiont ectoparasitoids of adult spiders, but some species have been reported to parasitise spider egg-sacs (like Tromatobia) (Townes and Townes 1960; Fitton et al. 1988; Gauld et al. 1998); some species have been observed attacking spiders protecting their eggs (like Zaglyptus) and other Clistopyga species attacking adult spiders hiding in nest, placing their eggs to prosoma and developing as koinobionts (Gauld et al. 1998). The first evidence that Clistopyga attacks spider egg-sacs was recorded by Nielsen (1929) who reared the European species Clistopyga incitator Fabricius, 1793 (the type species of the genus) from an egg sac of Segestria senoculata (Linnaeus, 1758) (Araneae: Segestriidae); later Townes and Townes (1960) recorded the North American species C. manni Cushman, 1922 from the egg nest of Agelenopsis Giebel, 1869 (Araneae: Agelenidae), and another European species, C. rufator Holmgren, 1856, was recorded from the egg nest of Clubiona Latreille, 1804
(Araneae: Clubionidae) (Fitton et al. 1988). However, in all cases it is not clear whether the adult ichneumonid kills the spider or if the ichneumonid larvae consume part of the spider (Gauld 1991). Porter (1979) reported observing specimens of the North American C. recurva (Say, 1835) running on tree trunks, possibly searching for spider nests concealed within the tunnels occupied earlier by siricids and beetles. $\mathrm{He}$ also observed one female of this species walking on a tree trunk with a dead or paralysed spider adult still attached to her ovipositor. Gauld (1991) recorded that the North American species C. manni had been reared from an egg nest of a salticid spider, with evidence that ichneumonid larva had partially eaten the opisthosoma and one specimen of Clistopyga was mentioned as reared in a nest of Sphecidae provisioned with spiders (Gauld et al. 1998). Biologically, Clistopyga is thus highly fascinating from an evolutionary point of view.

Before this study, the genus comprised 34 described species, occurring in the following regions: five are exclusively from the Nearctic region north of Mexico, 15 are exclusivelly from the Neotropical region (including Mexico), eight are exclusively Palaearctic, two from the Oriental region, and one exclusively from the Afrotropical region. In addition, one species has an Afrotropical and Palaearctic distribution: C. incitator (Fabricius, 1796), another is Holarctic: C. canadensis Provancher, 1880 and one has Nearctic and Neotropical distribution: C. nigrifrons Cushman, 1922 (Yu et al. 2012). Within these 34 species, 14 have been reported from North America including Mexico (Townes and Townes 1960; Ruíz-Cancino et al. 2002; Khalaim and Hernández 2008). In the current study, five new species are described and two are synonymised, raising the total species number of Clistopyga to 37.

The fauna of the United States of America and Canada has been revised by Townes and Townes (1960). Recently three species were described by Khalaim and Hernández (2008) from northern Mexico. The Neotropical species reported from North America have been described by Morley (1914), Blanchard (1941), Porter (1979), Graf (1985), Gauld (1991), and Gauld et al. (1998).

The aim of the present study is to revise the North American species of the genus, including 
Fig. 1. Measurements: (A) clypeus: a, length, b, width; (B) head, dorsal view: a, head width, b, interocellar distance, c, maximum diameter of ocellus, d, eye-ocellus distance, e, length of eye, $f$, length of gena, $g$, head length; (C) malar space length in relation to basal width of mandible: a, malar space, $b$, basal width of mandible; (D) metapleuron: a, length, b, depth; (E) propodeum: a, length, b, width.
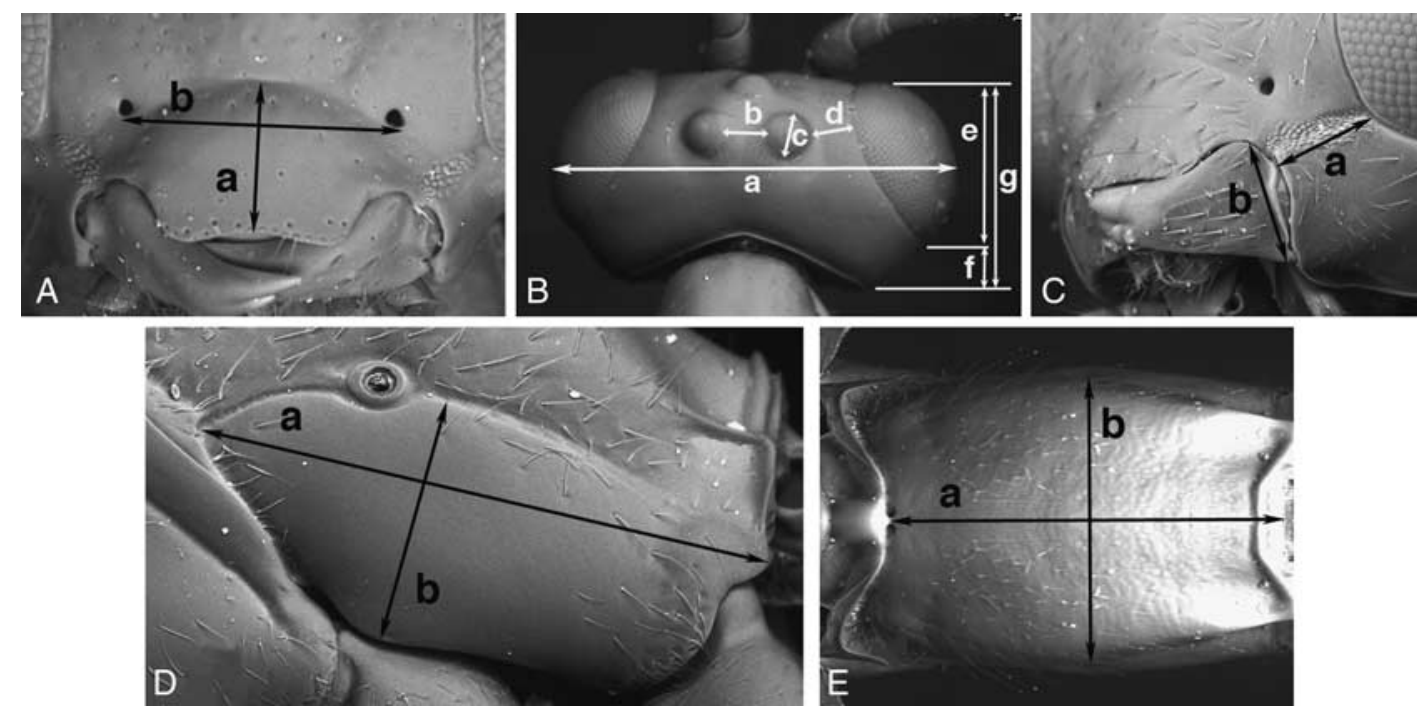

all Mexican species. We provide an identification key and detailed illustrations and descriptions of all species. In addition, new data on the distribution and morphological features of the genus are provided.

\section{Materials and methods}

In total about 900 specimens of Clistopyga were examined from the American Entomological Institute, Gainesville, Florida, United States of America (AEIC); Natural History Museum, London, United Kingdom (BMNH); Colección Entomológica Regional de la Universidad Autónoma de Yucatán, Mérida, Yucatán, Mexico (CER-UADY); Colección Entomológica de la Universidad de Alicante, Alicante, Spain (CEUA); Canadian National Collection of Insects, Arachnids, and Nematodes, Ottawa, Canada (CNCI); Essig Museum of Entomology, University of California, Berkeley, California, United States of America (EMEC); Florida State Collection of Arthropods, Gainesville, Florida, United States of America (FSCA); Instituto Nacional de Biodiversidad, Santo Domingo de Heredia, Costa Rica (INBio); Insect Museum of Universidad Autónoma de
Tamaulipas, Cuidad Victoria, Tamaulipas, Mexico (UAT); Entomology Research Museum, University of California, Riverside, California, United States of America (UCRC); University Laval, Department de Biologie Faculte des Sciences, Québec, Canada (UL); Universidad Nacional Autónoma de México, D.F., Mexico (UNAM); National Museum of Natural History, Smithsonian Institute, Washington, DC, United States of America (USNM); and Zoological Institute, Russian Academy of Sciences, St. Petersburg, Russia (ZISP).

Type specimens of all treated species have been studied. Additionally, North American material was compared with species of Clistopyga from the New World south of Mexico, deposited in the above-mentioned institutions and the Zoological Museum, University of Turku, Finland (ZMUT).

Specimens of $C$. maya new species were collected by Malaise trapping in a savanna of the Ría Lagartos Biosphere Reserve (Reserva de la Biósfera Ría Lagartos), approximately $21^{\circ} 36^{\prime} \mathrm{N}$, $88^{\circ} 10^{\prime} \mathrm{W}$ in northeastern Yucatán, Mexico. Malaise trap collecting jars were replaced every second week from June 2008 to August 2009. Additional information on this fieldwork has been described by González-Moreno and Bordera (2011). 
Morphological terminology mostly follows that of Gauld (1991). Measurements used in descriptions were as illustrated in Figure 1. Flagellomere width was measured from the middle of the flagellomere, in dorsal view, and excluding the anellus. Body length is measured without ovipositor. Terminology used for describing sculpture is based on Eady (1968). Terms for the inner structures of the ovipositor follow Quicke et al. (1992).

Most of the layer photos were taken in ZMUT using an Olympus (Tokyo, Japan) SZX16 stereomicroscope attached to an Olympus E520 digital camera. Some photographs (Figs. 3A-F, 14D, 19B, 19D-F) were taken at ZISP with a DFC 290 digital camera attached to a Leica (Solms, Germany) MZ16 stereomicroscope. Digital photographs were combined using Helicon Focus (Helicon Soft Limited), Deep Focus 3.1, QuickPhoto Camera 2.3 and Combine ZP programmes. The scanning electron microscope (SEM) images were taken using a Hitachi (Tokyo, Japan) S-3000N in low vacuum mode in the University of Alicante.

Type specimens of the new species described in the present study are deposited in CER-UADY, CEUA, and AEIC.

\section{Results}

\section{Genus Clistopyga Gravenhorst, 1829}

Clistopyga Gravenhorst, 1829: 132. Type species: Ichneumon incitator Fabricius, by subsequent designation, Westwood 1840: 59.

Ichneumonoglypta Blanchard, 1941: 9. Type species: Ichneumonoglypta lopezrichinii Blanchard, by original designation.

Hymenomacrophyga Uchida, 1941: 116. Type species: Hymenomacrophyga latifrontalis Uchida, by original designation.

Diagnosis. Clistopyga can be distinguished from females of all other genera of Ephialtini by the following combination of characters: fore wing with vein $3 r s-m$ absent (without an enclosed areolet) (e.g., Fig. 8C); posterior tarsomere 5 not broadened, with arolium not projecting clearly beyond claws; occipital carina always present and evenly convex or rarely weakly dipped (protuberant in some mainly tropical species) (Fig. 4A); mandible not twisted, with dorsal tooth longer than the length of the ventral tooth and never upcurved; epicnemial carina present and usually strong (Fig. 6A-C); propodeum smooth or finely microsculptured and moderately long, never with conspicuous posterolateral swellings, with most of the carinae reduced, usually only with lateral longitudinal carina shortly present posteriorly (Fig. 9A, 9E). Female tarsal claws with a pointed basal lobe; subgenital plate large and projecting, evenly sclerotised and slightly convex (e.g., Fig. 7A-D), ovipositor evenly or abruptly upcurved in apical $0.3-0.5$ (rarely robust, straight, or slightly down-curved) and apex of ovipositor with at most small teeth on dorsal surface of ventral valve (Fig. 2C). Male ventral part of gena sometimes with a strong longitudinal concavity (Fig. 16A, 16B) and subgenital plate slightly elongate and posteriorly rounded (e.g., Fig. 17C). Whenever possible, the generic identification of the males, especially of those without longitudinal concavity at ventral part of gena, should be confirmed by comparison to females.

Description (modified from Townes and Townes 1960; Townes 1969; Gauld 1991). Small to moderately sized long and slender wasps (fore wing length of 3.2-11.0 mm) which are black, brown, orange, or yellow, sometimes strikingly patterned, with the wings varying from more or less hyaline (most species) to almost completely black (some undescribed tropical species), many species with face, clypeus and facial orbits at least partly white. Antenna filiform. Face evenly convex (e.g., Fig. 20A-D). Clypeus shiny, with very sparse setiferous punctures in its dorsal part, not divided into basal and apical parts, with ventral margin thin and truncate or concave, clypeal suture strongly marked (e.g., Fig. 20A-D). Mandibles not twisted, strongly tapered in apical half, with dorsal tooth about twice the length of the ventral tooth, never upcurved. Occipital carina mediodorsally evenly convex or rarely weakly dipped (e.g., Fig. 19D) (rarely protuberant, mainly in some rare tropical species), sometimes ventrally reduced. Dorsal part of gena smooth. Ventral part of gena with (several males) or without (all females and some males) a strong longitudinal concavity (Fig. 16A, 16B). Epomia present in most species (rarely absent), from long to short 
Fig. 2. Ovipositor structure: (A) relative position of valvilli (arrow); (B) valvilli; (C) apical teeth.
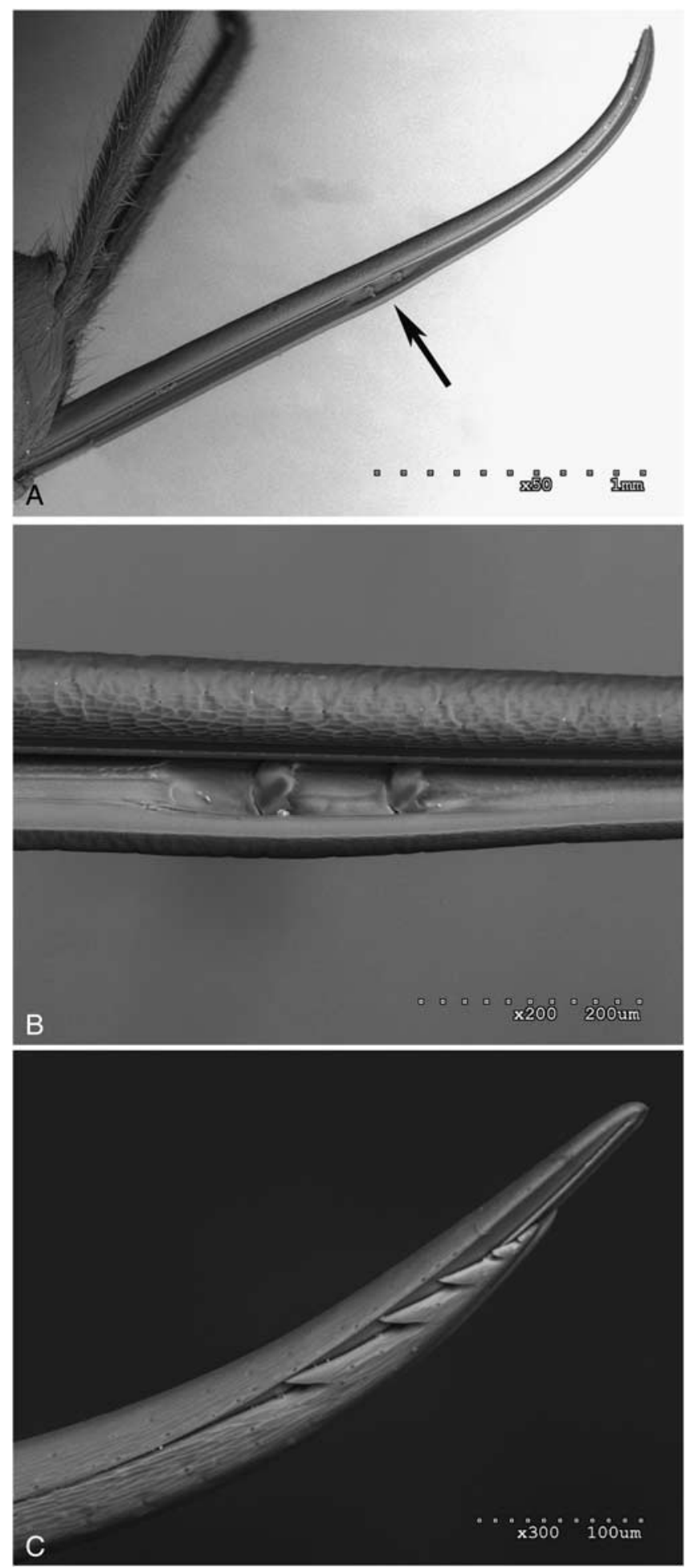
(e.g., Fig. 9A-B). Mesoscutum smooth to variously punctate, with notauli strongly impressed anteriorly and median lobe relatively protuberant anteriorly. Scutellum smooth and shiny, with sparse punctures. Epicnemial carina present and usually strong (e.g., Fig. 9A-B). Mesopleural suture weakly angled centrally. Propodeum smooth or finely microsculptured on a shiny, slightly granulate, or rugulose background, moderately long, evenly convex in lateral view, never with conspicuous posterolateral swelling, with most of the carinae reduced, lateromedian longitudinal carinae weak or absent, lateral longitudinal carina shortly present posteriorly, pleural carina discernible or absent, being replaced by narrow, deep groove. Submetapleural carina from complete to incomplete or entirely absent (e.g., Figs. 6C, 11C). Propodeal spiracle subcircular or circular at or close to pleural carina or groove (e.g., Fig. 11G-H). Fifth posterior tarsomere not broadened, with arolium not projecting beyond claws. Female tarsal claws with a pointed basal lobe, male tarsal claws simple. Fore wing without vein 3rs-m (areolet open) (e.g., Fig. 8C). Hind wing with distal abscissa of $C u 1$ present and joining $c u$ - $a$ much closer to $1 A$ than to $M$ or absent.
Metasoma depressed or more or less cylindrical. First tergite with lateromedian and lateral longitudinal carinae present or absent. Second tergite with long sharp oblique grooves delineating anterolateral corners, joining weaker oblique grooves that delineate posterolateral corners (these grooves bounding a subrhombic central raised area usually strongly sculptured) (Fig. 5A-C). Third and following tergites with basolateral and apicolateral grooves shallower than tergite 2, progressively less microsculptured towards posterior part of metasoma. Female subgenital plate large, evenly sclerotised and slightly convex (e.g., Fig. 7A-D). Ovipositor sheath 1.1-2.8 times as long as hind tibia, with dark setae and basally (ventral side) with or without denticles (Fig. 12A-D). Ovipositor surface coriaceous, matt (most species) or rarely smooth and shiny (some mainly tropical species). Ovipositor slender or stout, evenly or abruptly up-curved in apical $0.3-0.5$ (rarely thick and robust, straight, or slightly down-curved), centrally with at most a slight thickening (not an obvious swelling), which corresponds internally with the location of valvilli (Fig. 2A-B), ventral valve apically with at most fine teeth (Fig. 2C). Males with subgenital plate elongate, posteriorly rounded.

\section{Key to North American species of Clistopyga}

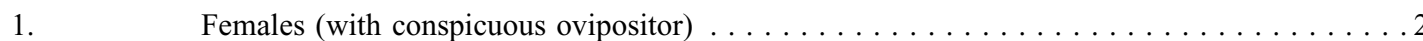

- Males (males of C. aenigmatica, C. arizonica, C. juliana, C. nigrifrons, and C. oaxacana unknown)

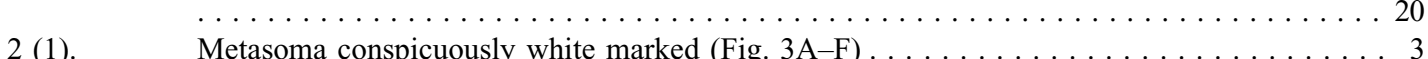

Metasoma orange-brown to red or black, without conspicuous white marks but sometimes tergites with narrow light coloured posterior margins (Figs. 7A-D, 8A-D, 10A-E, 13A-B) . . . . 8

3 (2). Ovipositor long and straight, 2.7-2.8 times as long as hind tibia (C. henryi species-group) (Fig. 3A) . . . . . . . . . . . . . . . . . . . . . . C. henryi Gauld, 1991 Ovipositor at most 2.4 times as long as hind tibia and distinctly up-curved (Fig. 3B-F) . . . 4

4 (3). Occipital carina complete, strong and raised dorsomedially in a flange-like protuberance (Fig. 4A). Submetapleural carina complete and strongly raised (C. chaconi species-group) (Fig. 4C) C. chaconi Gauld, 1991 Occipital carina usually complete, sometimes weak or absent laterally, never raised into a flangelike protuberance (Fig. 4B). Submetapleural carina complete or incomplete, weak to moderately

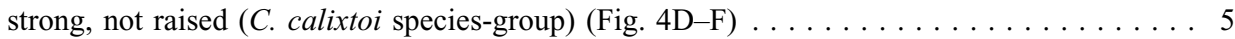

5 (4). Metasomal tergites shiny with shallow punctures on a granulate-rugulose background (Fig. 5A). Mesoscutum entirely red (Fig. 3C). Submetapleural carina complete but sometimes weak posteriorly (Fig. 4D). . . . . . . . . . . . . . . . . . . . C. maya new species Metasomal tergites finely punctate on a smooth and shiny background (Fig. 5B, 5C). Mesoscutum black with white or red marks (Fig. 3D-F). Submetapleural carina entirely absent or present as

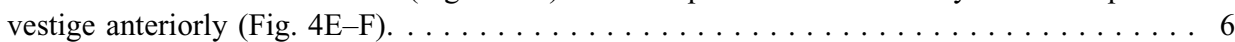


6 (5). Central area of tergites 2 and 3 sparsely punctate (Fig. 5B), distance between punctures about 3.0-4.0 times diameter of puncture. Hind femur white or light cream, widely dark brown basally, with two conspicuous preapical dark brown marks on anterior and posterior sides (Fig. 3D). Tergites 2 and 3 brown with anterior corners and posterior margin widely white, and with a pair of lateral black marks on posterior margin (Fig. 5B); following tergites mostly red with evanescent white and black marks posteriorly (Fig. 3D) . . . . . . . . C. aenigmatica new species Central area of tergites 2 and 3 densely punctate, distance between punctures at most equal to diameter of puncture (Fig. 5C). Hind femur white or light cream, basally and dorsally light brown to black, usually with a light brown to dark brown long stripe on posterior side, but lacking two conspicuous, preapical dark brown marks (Fig. 3E-F). Metasoma with tergite 2 and following tergites red with posterior margins usually narrowly banded with white, tergite 2 and sometimes

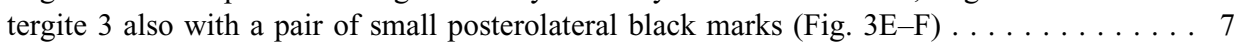

7 (6). Ovipositor sheath 1.9-2.2 times as long as hind tibia. Lateral lobes of mesoscutum black (Fig. 3E) . . . . . . . . . . . . . . . . . . . . . . . . . . C. calixtoi Gauld, 1991 Ovipositor sheath 1.7-1.8 times as long as hind tibia. Lateral lobes of mesoscutum red, peripherally black (Fig. 3F) . . . . . . . . . . . . . . . . C. fernandezi Gauld, 1991

8 (2). Submetapleural carina complete (Figs. 6A-C, 9A-B, 9E-F) $\ldots \ldots \ldots \ldots \ldots \ldots$

- $\quad$ Submetapleural carina absent or present only anteriorly (Fig. 11A, 11C, 11G-H) . . . . . 14

9 (8). Distal 0.3 of ovipositor strongly up-curved (Fig. 7A-D) $\ldots \ldots \ldots \ldots \ldots \ldots \ldots \ldots$

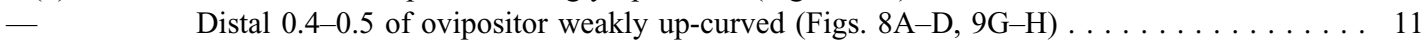

10 (9). Ventral half of mesopleuron with fine, shallow, and sparse setiferous punctures (Fig. 6A). Propodeum laterally (Fig. 6A), tergites 2-4 (Fig. 7E) and ovipositor sheath with long and moderately sparse setae. Central region of tergites $2-4$ with large, shallow, and dense punctures (Fig. 7E). Mesoscutum, propodeum, and metasomal tergites orange-brown (Fig. 7A) . . . . . . . . . . . . . . . . . . . C. californica Khalaim and Hernández, 2008 Ventral half of mesopleuron with fine, sharp, and dense setiferous punctures (Fig. 6B-C). Propodeum laterally (Fig. 6B-C), tergites 2-4 (Fig. 7F) and ovipositor sheath with shorter and denser setae. Central region of tergites 2-4 with smaller, deep, and dense punctures (Fig. 7F). Mesoscutum, propodeum, and metasomal tergites mostly dark brown to black (Fig. 7B, 7D), rarely red (in C. pulchripicta holotype) (Fig. 7C) . . . . . . . . . . C. recurva (Say, 1835)

11 (9). Mesopleuron (except in dorsoanterior part), mesosternum, and metapleuron orange (Fig. 8A-B) . . 12 Mesopleuron, mesosternum, and metapleuron entirely black to dark brown (Fig. 8C-D) . . 13

12 (11). Mesosoma (Fig. 9A) and metasomal tergites (Fig. 9C) punctate on a coarsely granulate background. Propodeum and tergites 1-5 of metasoma orange (Fig. 8A). Face entirely black

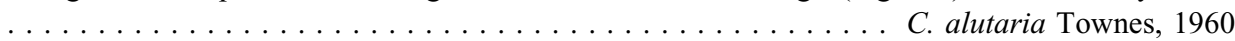
Mesosoma punctate on a smooth and shiny background (Fig. 9B). Central lobes of metasomal tergites shiny, coarsely and densely punctate (Fig. 9D). Propodeum and metasomal tergites entirely black or dark brown (Fig. 8B). Face brown with two yellow stripes below antennal insertions and yellow marks on facial orbits. . . . . . . . C. maculifrons Cushman, 1922

13 (11). Metapleuron shiny and impunctate, sometimes with fine and sparse punctures in its posterior half (Fig. 9E). Ovipositor stout (Fig. 9G) . . . . . . . . . . . C. canadensis Provancher, 1880 Metapleuron entirely coarsely punctate (Fig. 9F). Ovipositor slender (Fig. 9H)

14 (8). A A $\quad$ Apical $0.3 \ldots \ldots \ldots \ldots \ldots \ldots \ldots \ldots \ldots \ldots \ldots \ldots \ldots \ldots$. atrata Cushman, 1922 Apical 0.3 of ovipositor strongly and abruptly up-curved (Figs. 10A-B, 11B, 11D) . . . 15 Metapleuron 2.2-2.3 times as long as deep (Fig. 11A). Propodeum 1.1-1.2 times as long as medially wide. Ovipositor stout, parallel-sided in basal third, dark brown (Figs. 10A, 11B) $\ldots \ldots \ldots \ldots \ldots \ldots \ldots \ldots \ldots \ldots \ldots \ldots \ldots \ldots \ldots \ldots \ldots \ldots \ldots \ldots \ldots$ arizonica new species Metapleuron longer, 2.5-2.6 times as long as deep (Fig. 11C). Propodeum 1.3-1.4 times as long as wide. Ovipositor slender, tapered from base towards apex, light brown (Figs. 10B, 11D)

C. juliana new species

16 (14). Ventral margin of ovipositor sheath basally without denticles (Fig. 12A). Ovipositor slender (Fig. 11E) . . . . . . . . . . . . . . . . . . . . . . . . C. manni Cushman, 1922 Ventral margin of ovipositor sheath basally with denticles (Fig. 12B-D). Ovipositor stout (Fig. 11F)

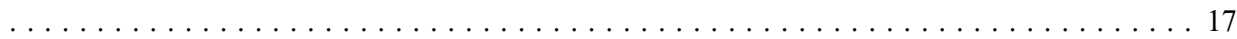


17 (16). Submetapleural carina strong on anterior 0.4-0.5 of metapleuron (Fig. 11G). Ovipositor sheath

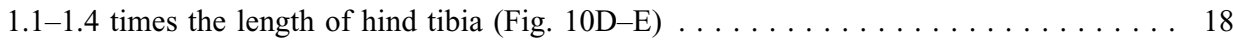
Submetapleural carina absent or at most as weak tubercle on anterior part of metapleuron (Fig. 11H). Ovipositor sheath longer, 1.5-1.7 times the length of hind tibia (Fig. 13A-B) . . . . 19 18 (17). Epomia absent (Fig. 11G). Metapleuron 2.3 times as long as deep (Fig. 11G). Propodeum 1.1 times as long as wide. Ovipositor sheath 1.4 times as long as hind tibia (Fig. 10D). Hind coxa light brown, partially white. Hind femur white with a light brown stripe on its posterior side (Fig. 10D) $\ldots \ldots \ldots \ldots \ldots \ldots \ldots \ldots \ldots \ldots \ldots \ldots \ldots \ldots \ldots \ldots \ldots \ldots \ldots$ oaxacana new species Epomia as strong long carina. Metapleuron shorter, 1.8-2.0 times as long as deep. Propodeum shorter, 0.8-0.9 times as long as wide. Ovipositor sheath 1.2-1.3 times as long as hind tibia (Fig. 10E). Hind coxa entirely orange. Hind femur entirely orange with apex white (Fig. 10E) $\ldots \ldots \ldots \ldots \ldots \ldots \ldots \ldots \ldots \ldots \ldots \ldots \ldots \ldots \ldots$. nigrifrons Cushman, 1922

19 (17). Mesopleuron mostly red with a black spot dorsoposteriorly (Fig. 13A). Head black with facial, frontal and vertical orbits and two small spots below antennal sockets white (Fig. 13C, 13E). Hind femur white with brown marks (Fig. 13A). First tergite 1.2-1.4 times as long as posteriorly broad . . . . . . . . . . . . . . . . . . . . . C. moraviae Gauld, Ugalde, and Hanson, 1998 Mesopleuron red with a large subsquare black mark dorsoposteriorly (Fig. 13B). Head black, with four white spots in dorsal part of face (below antennal sockets and at inner eye orbits) (Fig. 13F), and a pair of white spots on vertex at top of eyes (Fig. 13D). Hind femur reddish brown, white at extreme base and apex (Fig. 13B). First tergite about 1.1 times as long as posteriorly broad

$\ldots \ldots \ldots \ldots \ldots \ldots \ldots \ldots \ldots \ldots \ldots \ldots . \ldots \ldots$. serricauda Khalaim and Hernández, 2008

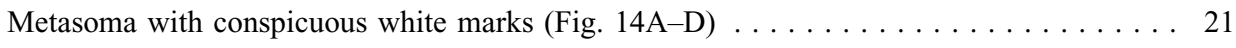
Metasoma orange-brown to red or black, without white marks (Figs. 15A-D, 17A-C, 19A-B) . . 24 21 (20). Submetapleural carina complete and strongly raised (as in Fig. 4C). Occipital carina complete, strong, raised into a flange-like protuberance (as in Fig. 4A). Ventral part of gena without longitudinal concavity. .................... Chaconi Gauld, 1991 Submetapleural carina incomplete or absent. Occipital carina complete never strongly raised into a flange-like protuberance (as in Fig. 4B). Ventral part of gena with a conspicuous longitudinal or

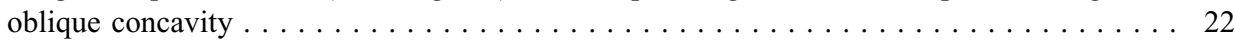

22 (21). Mesopleuron white with black marks (Fig. 14B). Mesoscutum black with a pair of white stripes interrupted at level of notauli . . . . . . . . . . . . . . . C. calixtoi Gauld, 1991 Mesopleuron orange (Fig. 14C) or white with light brown marks (Fig. 14D). Mesoscutum almost

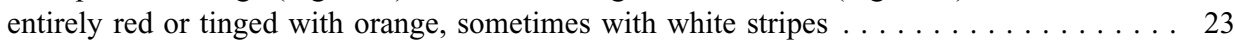

23 (22). Metasoma almost entirely black with small white marks posterolaterally. Metapleuron widely red. Propodeum almost entirely black or brown, rarely with two small posterolateral white marks

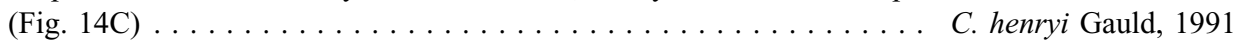
Metasoma black or brown, with tergite 1 laterally, posterior margins of all tergites centrally and anterolateral corners of tergites 2-4(5) white. Metapleuron widely white. Propodeum laterally extensively white (Fig. 14D) . . . . . . . . . . . . . . C. fernandezi Gauld, 1991

24 (20). Submetapleural carina complete (Fig. 18A, 18C, and as in Figs. 4C-D, 6A-C, 9A-B, 9E-F)

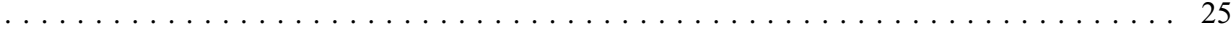
Submetapleural carina absent or only present anteriorly (as in Figs. 4E-F, 11A, 11C, 11G-H) . . 31 Face white, sometimes with longitudinal black mark along midline or surrounding clypeus

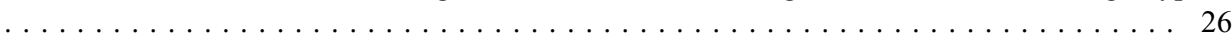
Face entirely black or dark brown, sometimes with white marks below antennal sockets and/or on

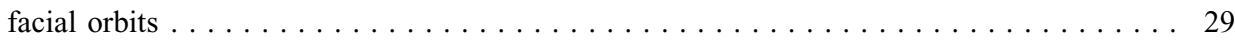

26 (25). Gena with deep longitudinal concavity near ventral part of eye (Fig. 16A) . . . . . . . $\ldots \ldots \ldots \ldots \ldots \ldots \ldots \ldots \ldots \ldots \ldots \ldots \ldots \ldots \ldots \ldots$. maculifrons Cushman, 1922 Gena without a longitudinal concavity near ventral part of eye (as in Fig. 16C) . . . . . . 27 27 (26). Mesoscutum smooth and glabrous. Tergites slightly rugulose on a strongly granulate background (as in Fig. 5A). Propodeum black with a pair of white elongate marks dorsolaterally (Fig. 15B)

C. maya new species Mesoscutum with more or less dense setiferous punctures. Tergites distinctly punctate on a smooth background (Fig. 15E-F). Propodeum black or orange-brown, without white marks (Fig. 15C-D)

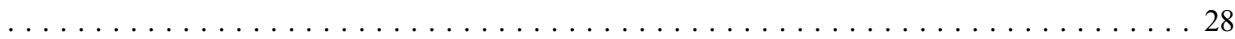


28 (27). Central lobes of tergites 2-4 coarsely and densely punctate (Fig. 15E). Mesoscutum red, median lobe partly or entirely black (Fig. 15C), sometimes with a pair of longitudinal white dashes centrally. Propodeum black with dorsolateral red marks. Metasoma entirely black, sometimes with

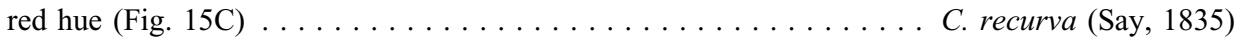
Central lobes of tergites 2-4 with large and shallow punctures (Fig. 15F). Mesoscutum entirely orange-brown (Fig. 15D). Propodeum orange-brown, slightly darkened anteriorly and posteriorly. Metasoma almost entirely orange-brown with first tergite slightly darkened basally (Fig. 15D) . . . . . . . . . . . . . . . . . . C. californica Khalaim and Hernández, 2008

29 (25). Gena with deep longitudinal concavity near ventral part of eye (Fig. 16B) . . . . . . . $\ldots \ldots \ldots \ldots \ldots \ldots \ldots \ldots \ldots \ldots \ldots$. canadensis Provancher, 1880 Gena without a longitudinal concavity near ventral part of eye (Fig. 16C). . . . . . . . 30 Propodeum (Fig. 18A) and metasomal tergites centrally (Fig. 18B), finely and sparsely punctate on a strongly granulate background. Metapleuron granulate (Fig. 18A). Mesopleuron (except in dorsal anterior part), mesosternum and metapleuron orange. Tergites 2-4(5) of metasoma orange (Fig. 17B) . . . . . . . . . . . . . . . . . . . . . . . . . . C. alutaria Townes, 1960 Propodeum (except transversely striate posterior part) (Fig. 18C) and metasomal tergites centrally with coarse and dense punctures (Fig. 18D). Metapleuron coarsely punctate on a smooth and shiny background (Fig. 18C). Mesosoma and metasoma entirely black to dark brown (Fig. 17C)

31 (24). First tergite ruguloso-punctate, laterally sometimes punctulate, with lateromedian longitudinal carinae sharp on basal half. Submetapleural carina strong, present on anterior $0.3-0.4$ of metapleuron. Face and ventral part of gena white . . . . . . . . C. manni Cushman, 1922 First tergite smooth and shiny, laterally sometimes with very sparse setiferous punctures, with lateromedian longitudinal carinae absent or vestigial, reaching at most 0.2 length of tergite. Submetapleural carina usually absent or as a short anterior vestige. Face and ventral part of gena

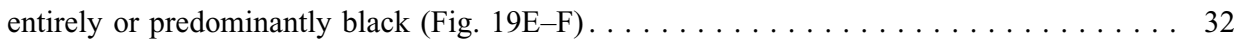

32 (31). Mesopleuron mostly red with a black spot on the dorsoposterior part (Fig. 19A). Head black with facial, frontal, and vertical orbits, and two small spots below antennal sockets white (Fig. 19C, 19E). Hind femur mostly white with brown marks (Fig. 19A) . . . . . . . . . . . . . . . . . . . . . . . . . . . . . C. moraviae Gauld, Ugalde, and Hanson, 1998 Mesopleuron red with a large sub-square black mark dorsoposteriorly (Fig. 19B). Head black, with four white spots in dorsal part of face (below antennal sockets and at inner eye orbits) (Fig. 19F), and a pair of white spots on vertex at top of eyes (Fig. 19D). Hind femur reddish brown, white at extreme base and apex (Fig. 19B) . . . . . . . . . . . . C. serricauda Khalaim and Hernández, 2008

\section{Clistopyga aenigmatica Bordera and González-Moreno, new species}

(Figs. 3D, 5B)

Material examined. Holotype female. UNITED STATES OF AMERICA. Texas: Galveston (No. 5611), "S.S. Miraflores", "Mexico in cargo", Div. I.D. No. 39-18479, 6.XII.1939 (USNM, 2053570).

Etymology. From the Latin "aenigmaticus" (enigmatic) in reference to the mystery regarding its origin.

Diagnosis. Female of $C$. aenigmatica can be distinguished from all other females of North American species by combination of the following characters: tergites 2 and 3 brown with anterior corners and posterior margin widely white and with a pair of black marks on hind margin laterally (Fig. 5B), following tergites mostly red with white and black marks becoming evanescent towards apex of metasoma (Fig. 3D); hind femur white, widely dark brown at base, with two conspicuous preapical dark brown marks on anterior and posterior lateral sides (Fig. 3D); occipital carina complete, not forming a flange dorsomedially; submetapleural carina vestigial on anterior part of metapleuron; central area of metasomal tergites sparsely punctulate on a smooth and shiny background, distance between punctures about 3.0-4.0 times puncture diameter (Fig. 5B); ovipositor stout, weakly and evenly up-curved in apical $0.4-0.5$ (Fig. 3D), shiny, 2.4 times as long as hind tibia. 
Fig. 3. Female habitus, lateral view: (A) Clistopyga henryi; (B) Clistopyga chaconi; (C) Clistopyga maya (holotype); (D) Clistopyga aenigmatica (holotype); (E) Clistopyga calixtoi (paratype); (F) Clistopyga fernandezi (paratype).
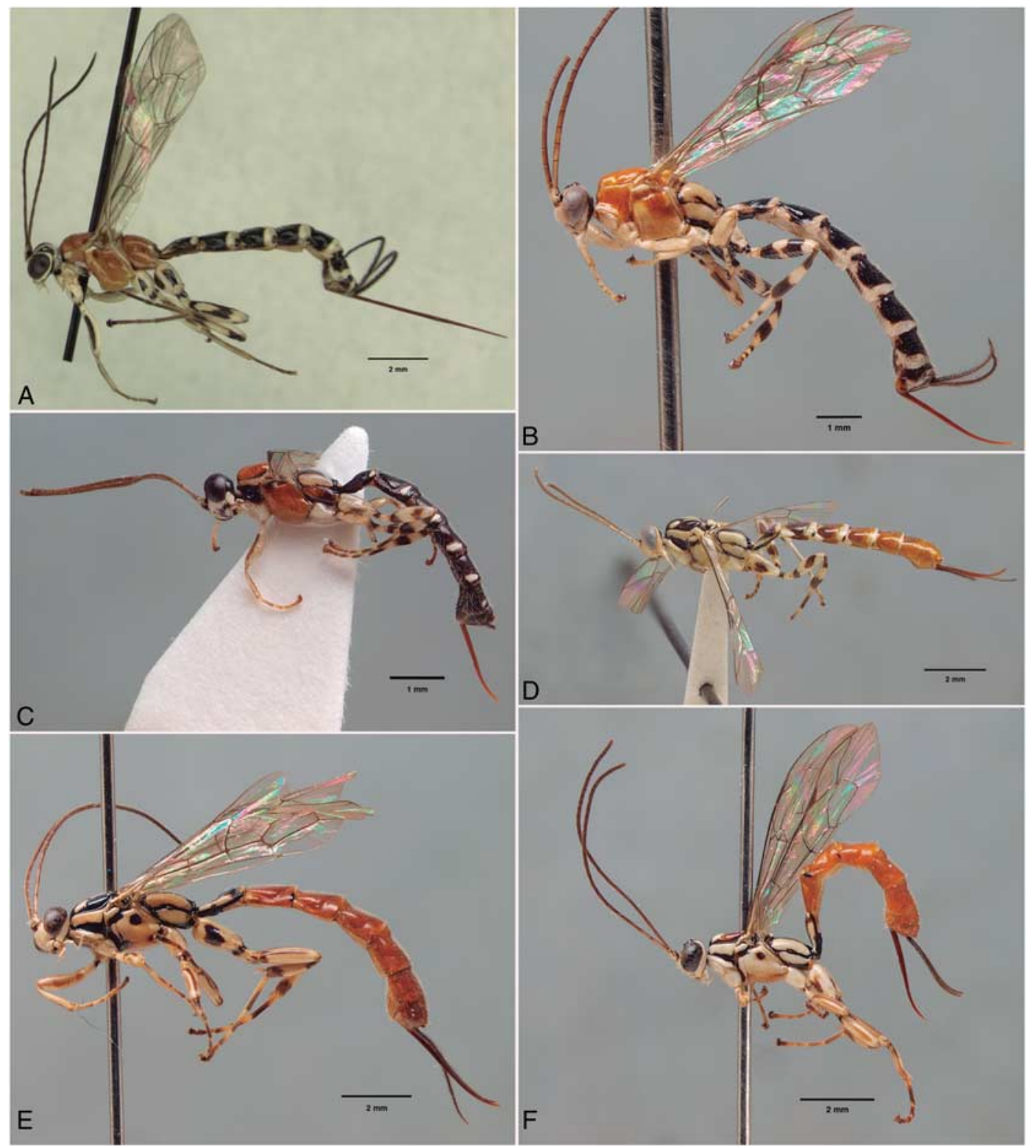

Description. Female. Body length $8.5 \mathrm{~mm}$. Fore wing length $6.0 \mathrm{~mm}$.

Head. In dorsal view, strongly narrowed behind eyes. Gena in anterior view long, straightly and moderately constricted below eyes. Gena sparsely and finely punctate, in dorsal view 0.3 times as long as eye. Frons smooth and shiny. Posterior ocellus separated from eye by 1.0 times its maximum diameter. Distance between posterior ocelli 0.9 times maximum diameter of posterior ocellus. Occipital carina weak, not forming a flange dorsomedially. Occiput in dorsal view slightly concave. Face finely and very sparsely punctate; distance between punctures more than 
Fig. 4. Morphology of females, lateral view: (A-B) head and anterior part of mesosoma; (A) Clistopyga chaconi; (B) Clistopyga calixtoi (paratype); (C-F) propodeum and metapleuron: (C) Clistopyga chaconi; (D) Clistopyga maya (paratype); (E) Clistopyga calixtoi (paratype); (F) Clistopyga fernandezi.
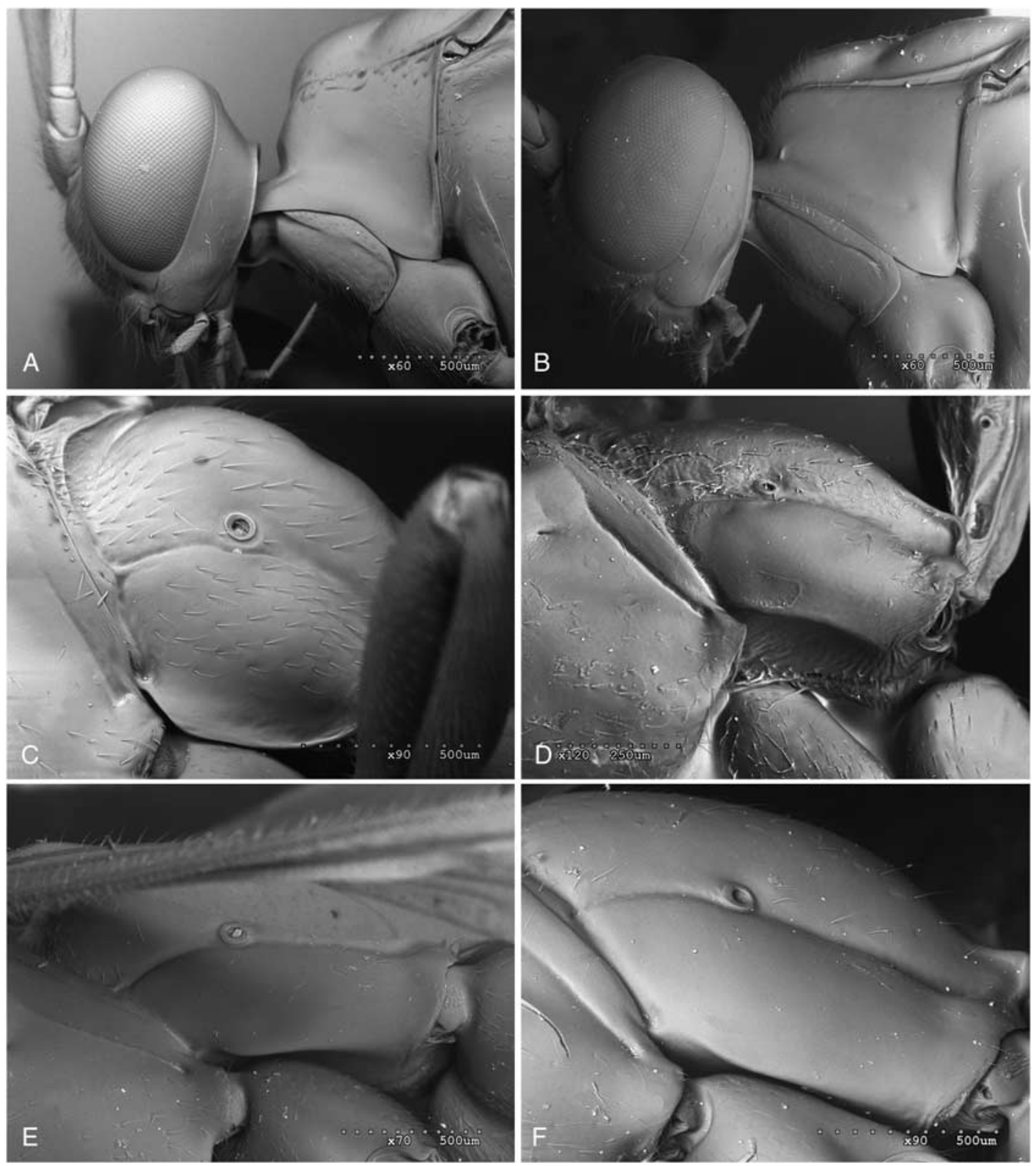

twice length of diameter of puncture. Clypeal suture straight. Clypeus 2.1 times as broad as medially long, weakly convex. Malar space smooth, with a narrow sulcus between eye and mandible, 0.7 times as long as basal mandibular width. Antenna with 27 flagellomeres, first about 6.2 times as long as wide.
Mesosoma. Pronotum smooth and shiny. Epomia strong and short. Median lobe of mesoscutum smooth and shiny, with moderately dense punctures tending to be more sparse or absent on lateral lobes and posteriorly. Notauli deep, reaching about half the length of mesoscutum. Mesopleuron shiny, mostly smooth with very 
Fig. 5. Second and third metasomal tergites of females, dorsal view: (A) Clistopyga maya (holotype); (B) Clistopyga aenigmatica (holotype); (C) Clistopyga calixtoi (paratype).
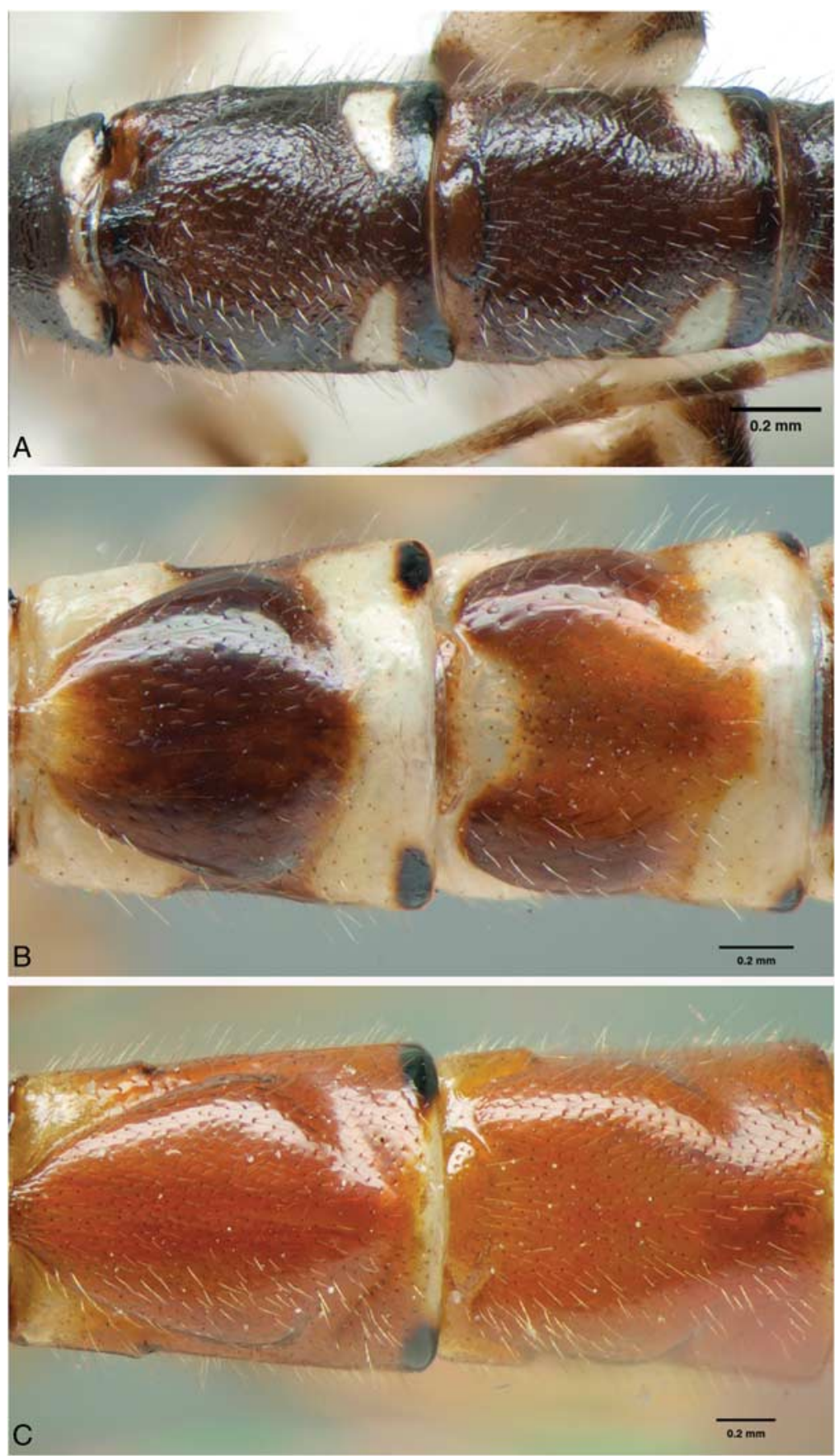

sparse and inconspicuous setiferous punctures in ventral and anterior part. Epicnemial carina strong, slightly curved backward, ending moderately far from anterior margin of mesopleuron at level of centre of pronotum. Metapleuron smooth and shiny, 2.7 times as long 
Fig. 6. Mesosoma of females, lateral view: (A) Clistopyga californica (holotype); (B) Clistopyga recurva (Clistopyga covarrubiasi paratype); (C) Clistopyga recurva.
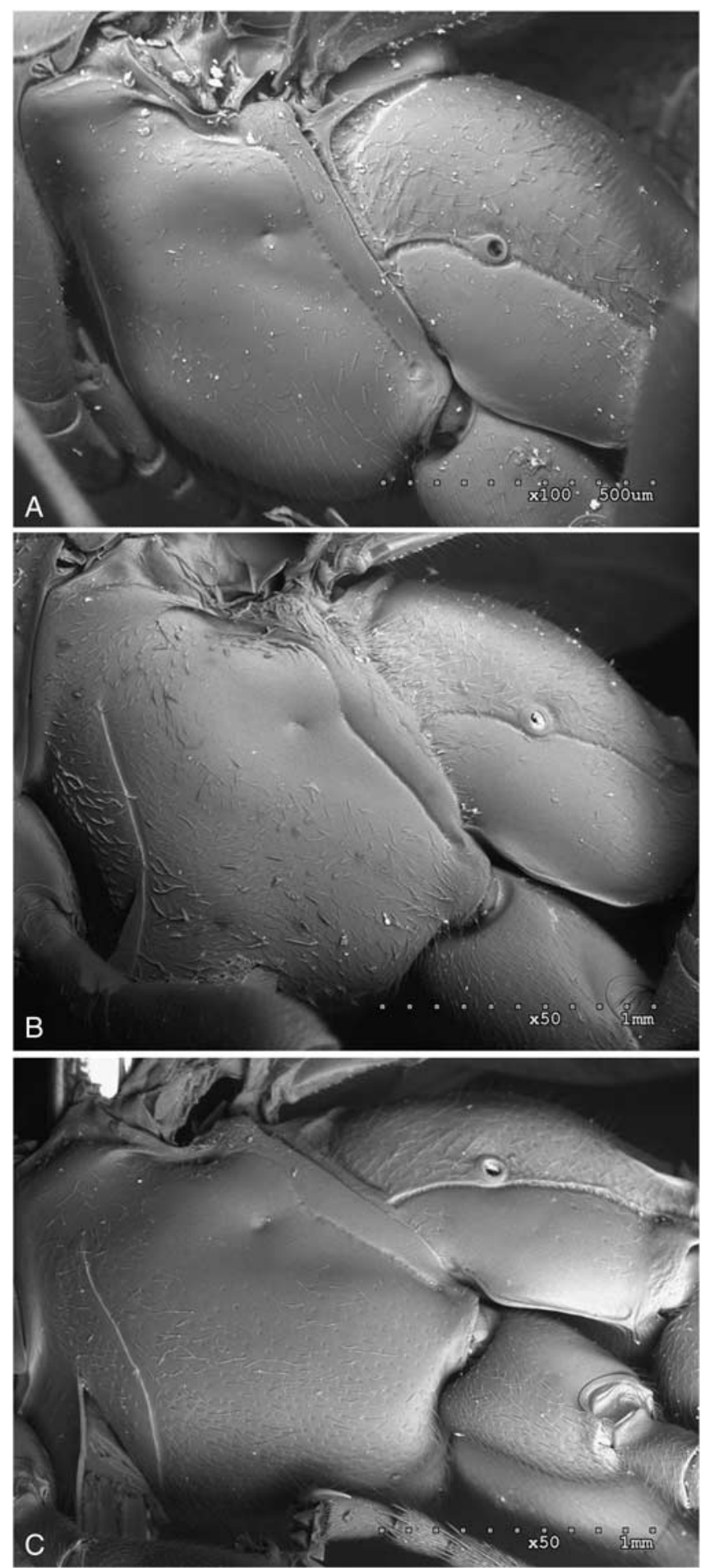
Fig. 7. Morphology of females: (A-D) habitus, lateral view; (A) Clistopyga californica (holotype); (B) Clistopyga recurva (Clistopyga annulipes, holotype); (C) Clistopyga recurva (Clistopyga pulchripicta, holotype), (D) Clistopyga recurva (Clistopyga covarrubiasi, paratype); (E-F) second and third tergites, dorsal view: (E) Clistopyga californica (holotype); (F) Clistopyga recurva.

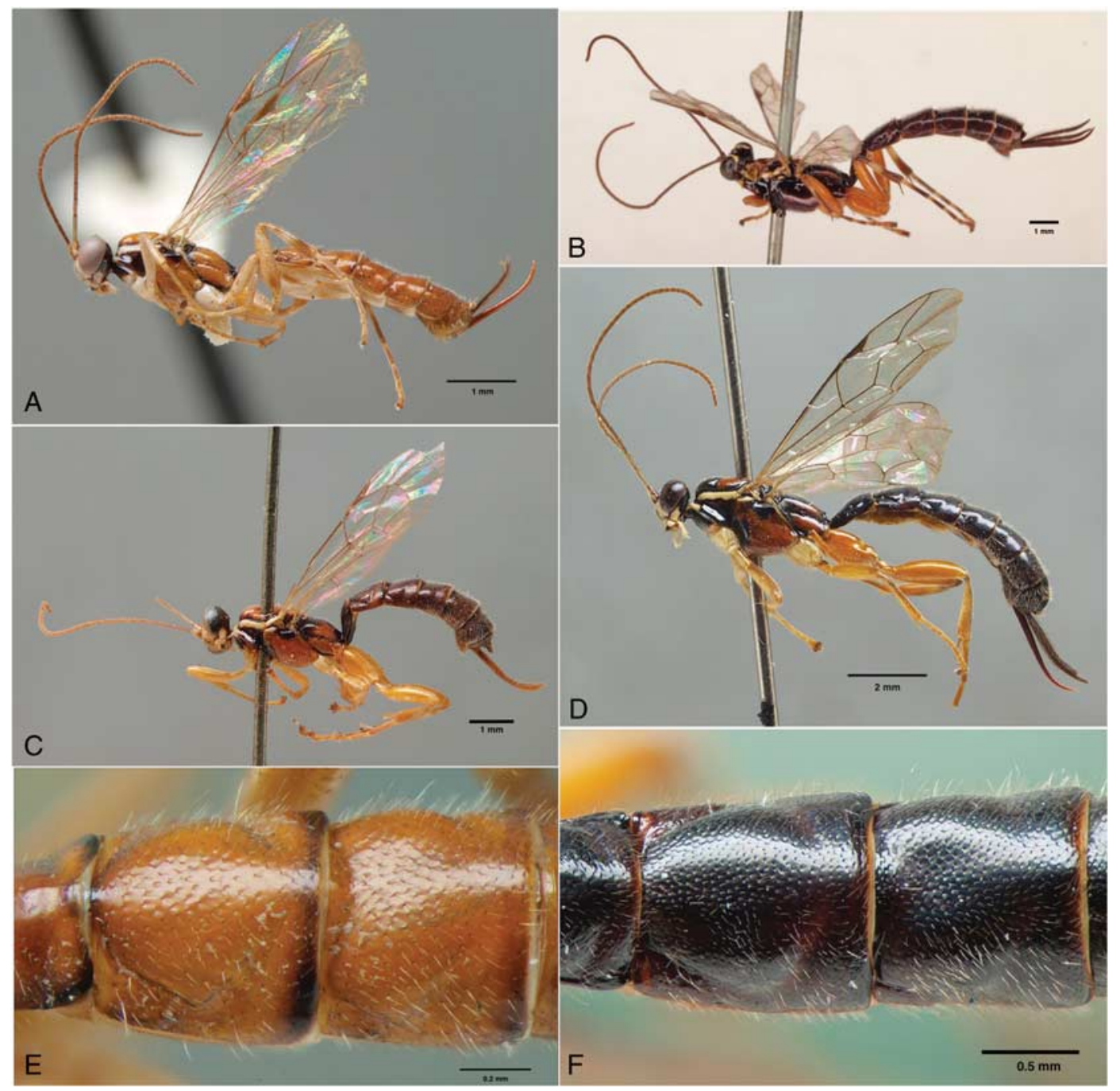

as deep. Submetapleural vestigial on anterior part of metapleuron. Propodeum smooth and shiny, with very sparse setiferous punctures anteriorly and laterally, without lateromedian longitudinal carina, in dorsal view 1.2-1.3 times as long as medially wide. Propodeal spiracle situated on groove separating propodeum and metapleuron. Hind leg with femur as long as tibia. Fore wing with vein $C u$ - $a$ almost opposite vein $R s \& M$. Vein $2 r s-m$ about half length of abscissa of $M$ between $2 r s-m$ and $2 m-c u$. Abscissa of $\mathrm{Cu} 1$ between $1 m-c u$ and $C u 1 a$ about 1.3 times as long as $C u 1 b$. Hind wing with vein $C u-a 0.3$ times as long as abscissa of $M+C u$ between $M$ and $C u 1$. Vein $C u 1$ weakly pigmented. Metasoma. First tergite 1.5 times as long as posteriorly broad, smooth and shiny with very sparse setiferous punctures laterally; spiracle near basal 0.3. Lateromedian and lateral longitudinal carinae absent. Sternite 1 extending 
Fig. 8. Female habitus, lateral view: (A) Clistopyga alutaria; (B) Clistopyga maculifrons; (C) Clistopyga canadensis (lectotype); (D) Clistopyga atrata (holotype).
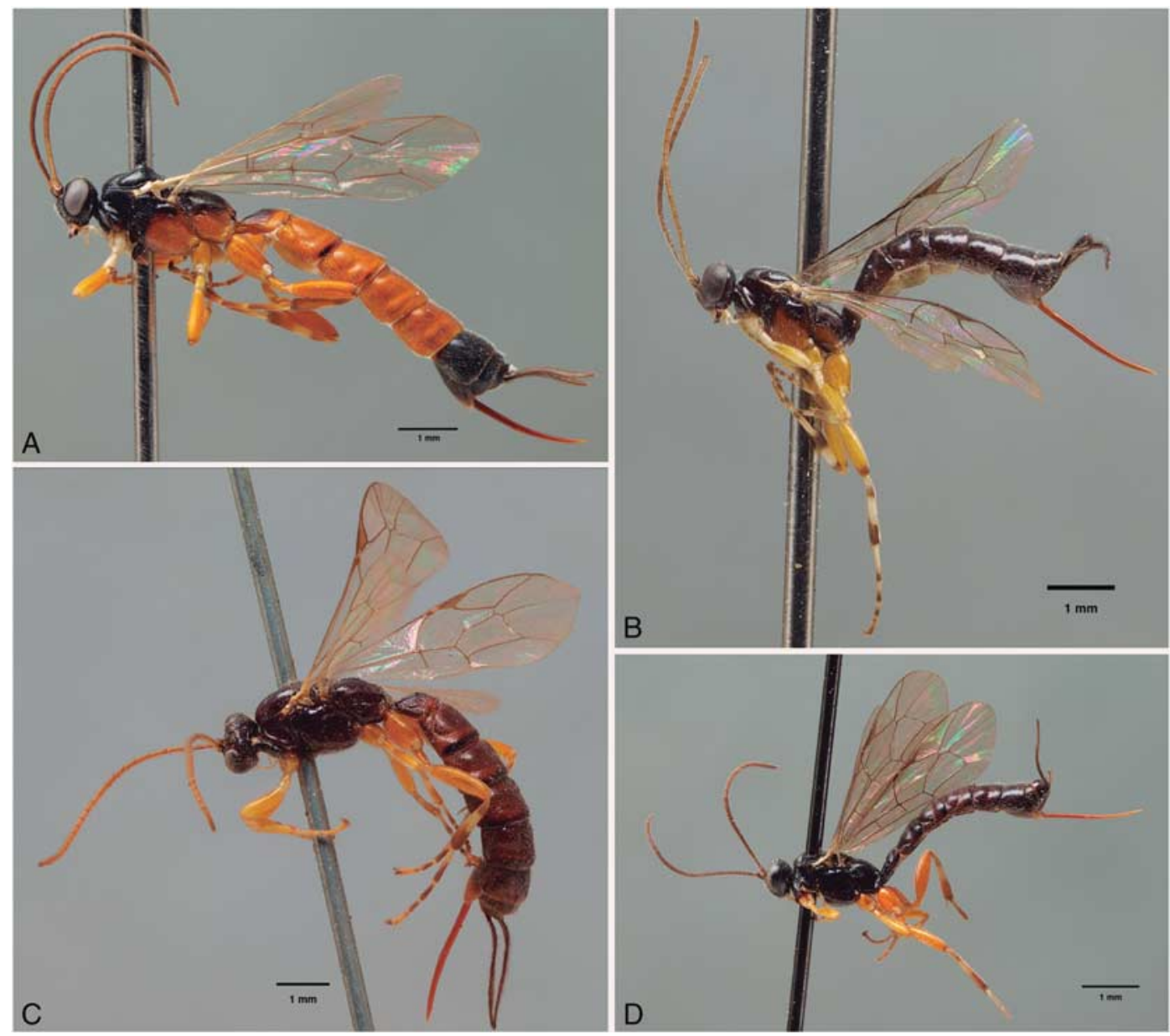

back about half of length of tergite. Second tergite 1.1 times as long as posteriorly broad, central region with very shallow and sparse setiferous punctures (Fig. 5B). Ovipositor stout, weakly, and evenly up-curved in apical $0.4-0.5$, shiny, 2.4 times as long as hind tibia (Fig. 3D). Ovipositor sheath twice as long as hind tibia, without denticles on basal ventral margin, with numerous oblique black setae, which are longer than sheath width.

Colouration. Body white, black and orange (Fig. 3D). Antenna brown with scape, pedicel and two basal flagellomeres white beneath. Head white; frons centrally, ocellar area, area adjacent to occipital carina and occiput black. Face, clypeus and palpi white. Mandible white with teeth black. Propleuron white. Pronotum bicoloured, mostly white with a wide band medially and collar black. Mesopleuron white with black stripe below subalar prominence and with brown hue on its ventral part. Metapleuron white with submetapleural carina black. Mesoscutum dark brown with two interrupted notaular white stripes. Scutellum and postscutellum white. Metanotum brown with white margins. Propodeum white with wide median longitudinal brown band, posterior margin black. Fore leg entirely white except dorsal longitudinal brown stripe. Mid leg mostly white with trochanter, dorsal longitudinal stripe on femur, base and 
Fig. 9. Morphology of females, lateral view: (A-B) mesosoma: (A) Clistopyga alutaria; (B) Clistopyga maculifrons; (C-D) tergites 1-3: (C) Clistopyga alutaria; (D) Clistopyga maculifrons; (E-F) posterior part of mesosoma: (E) Clistopyga canadensis; (F) Clistopyga atrata; (G-H) ovipositor: (G) Clistopyga canadensis (lectotype); (H) Clistopyga atrata (holotype).

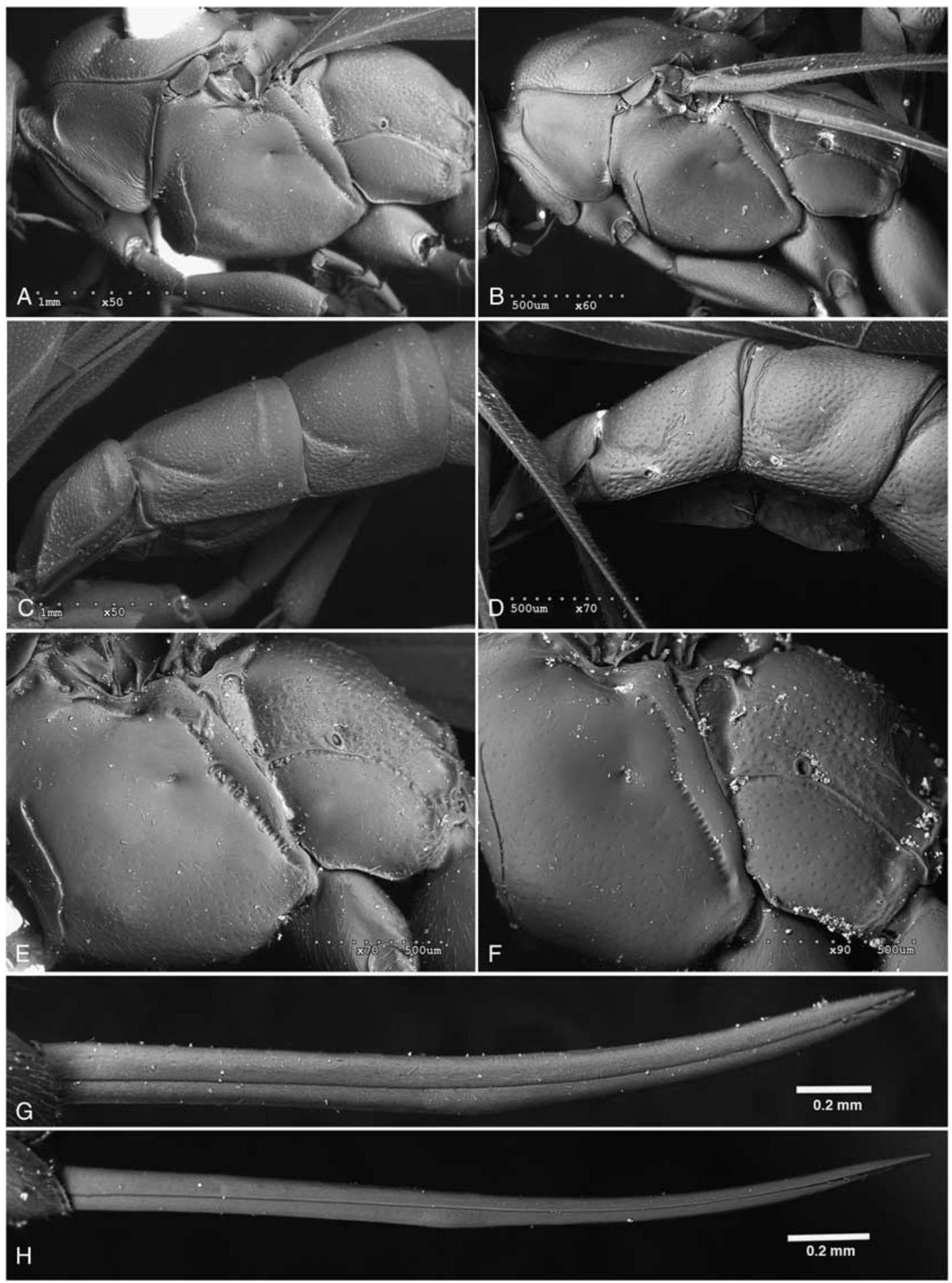


Fig. 10. Clistopyga species, female habitus, lateral view: (A) Clistopyga arizonica (holotype); (B) Clistopyga juliana (paratype); (C) Clistopyga manni (holotype); (D) Clistopyga oaxacana (holotype); (E) Clistopyga nigrifrons (holotype).
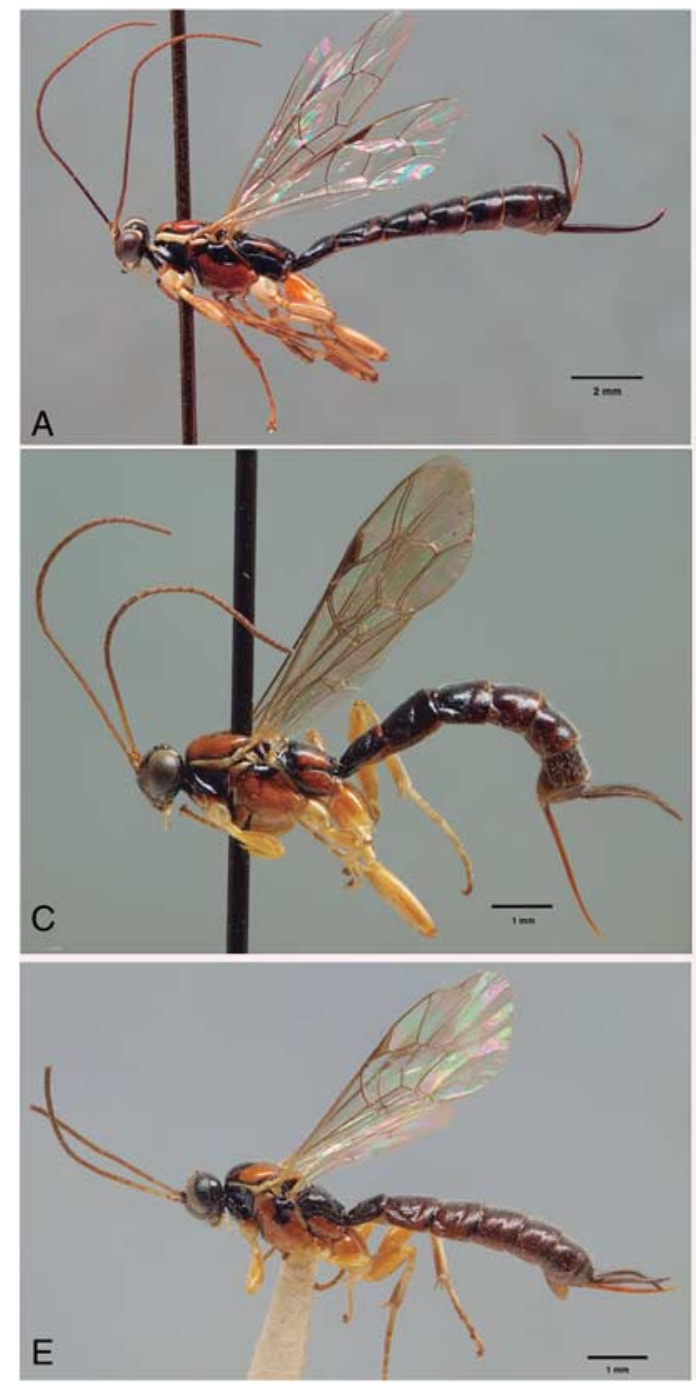

apex of tibia and apices of tarsomeres brown. Hind leg with coxa with two lateral marks anteriorly and posteriorly, and trochanter, brown; trochantellus white, basally dark brown; femur white, basally dark brown, with two conspicuous preapical dark brown marks on anterior and posterior sides; tibia white, basally and apically brown; tarsomeres white, apically brown. Tergite 1 mostly brown with lateral sides and posterior margin white. Tergites 2 and 3 brown with anterior corners and posterior margins
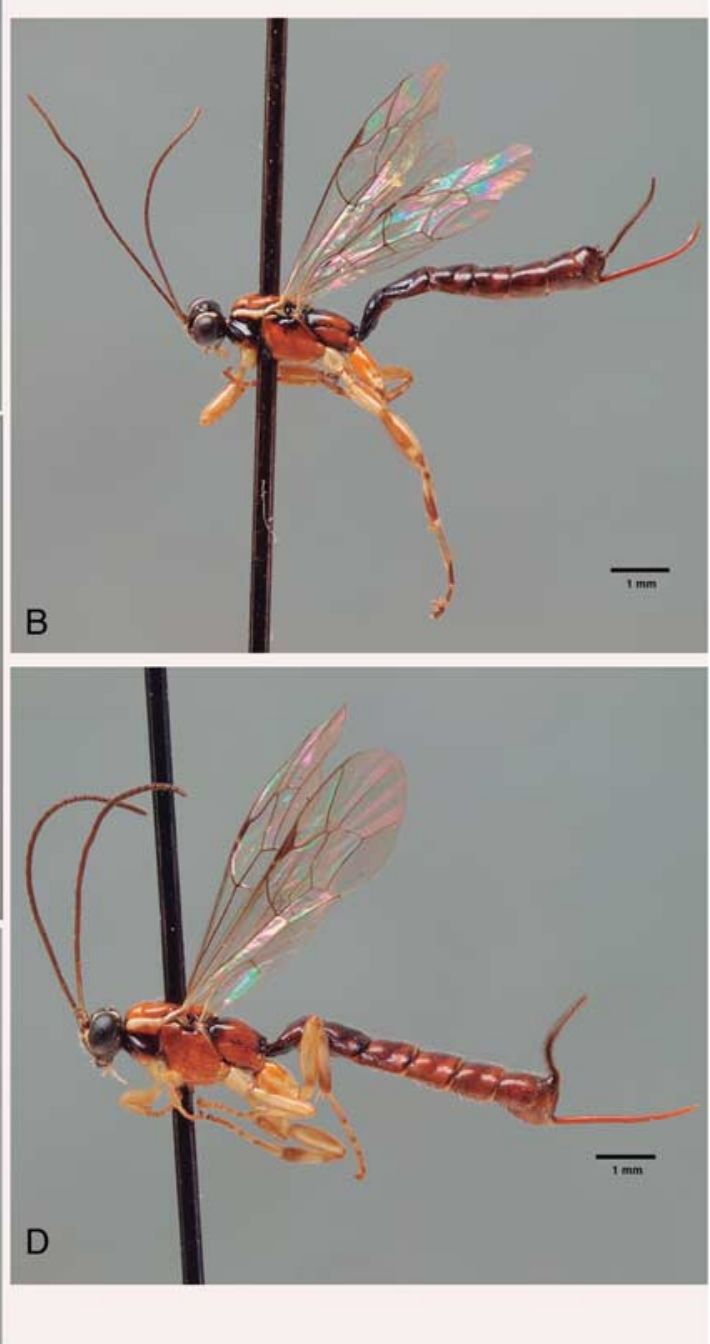

widely white and with a pair of lateral black marks on posterior margins, following tergites mostly red with white and black marks becoming evanescent towards apex of metasoma. Ovipositor light brown. Ovipositor sheath brown.

Male. Unknown.

Hosts. Unknown.

Distribution. The origin of the unique specimen is uncertain. Although the specimen was probably collected in Galveston (Texas, United States of America), the labels refer to the cargo 
Fig. 11. Morphology of females, lateral view: (A-B) Clistopyga arizonica (paratype); (A) posterior part of mesosoma; (B) ovipositor; (C-D) Clistopyga juliana (paratype); (C) posterior part of mesosoma; (D) ovipositor; (E-F) ovipositor; (E) Clistopyga manni (holotype); (F) Clistopyga oaxacana (holotype); (G-H) mesosoma; (G) Clistopyga oaxacana (holotype); (H) Clistopyga moraviae.
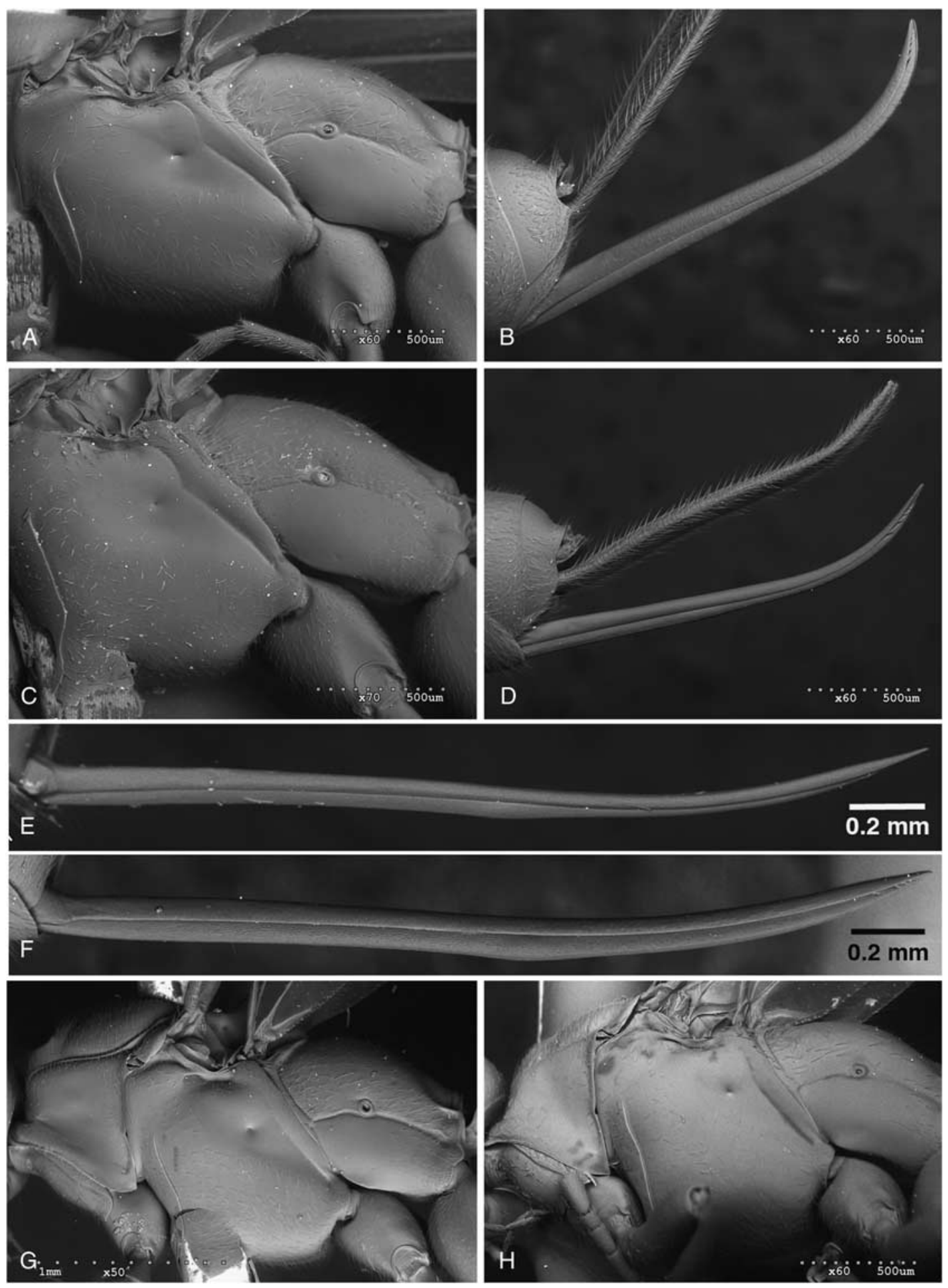

(C) 2014 Entomological Society of Canada 
Fig. 12. Base of ovipositor sheaths (arrows show ventral row of denticles): (A) Clistopyga manni (holotype); (B) Clistopyga oaxacana (holotype); (C) Clistopyga nigrifrons (holotype); (D) Clistopyga moraviae.
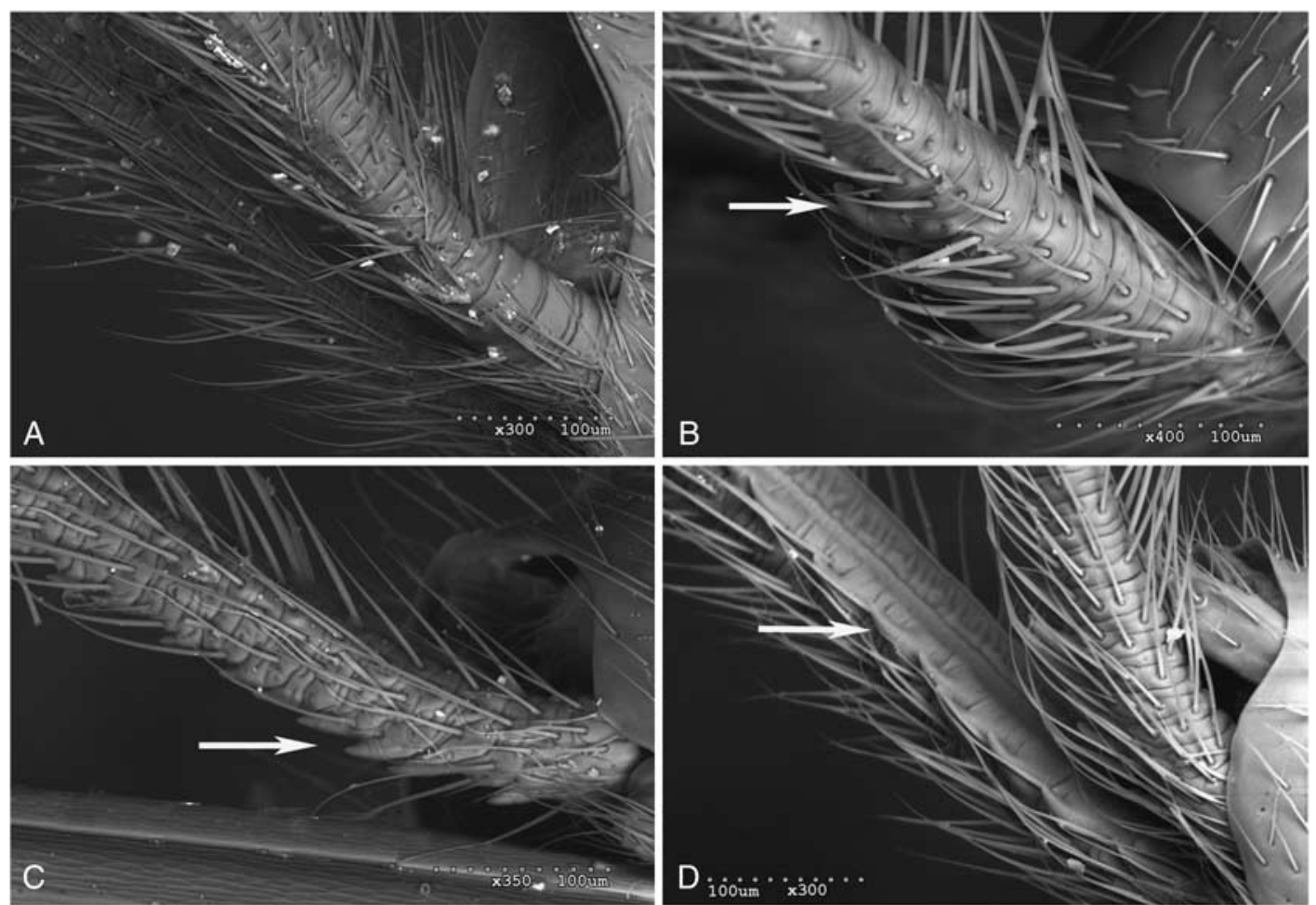

ship SS Miraflores, which in 1939 usually docked in the port of Galveston with fruit cargoes from Mexico, Central America, and the Caribbean Islands (http://www.wrecksite.eu/wreck.aspx?17171 and http://atlanticdivers.websitetoolbox.com/post? $\mathrm{id}=3134237 \&$ goto $=$ nextoldest); therefore, the specimen could possibly have originated in any of these areas.

\section{Clistopyga alutaria Townes, 1960}

(Figs. 8A, 9A, 9C, 16C, 17B, 18A-B)

Clistopyga alutaria Townes in Townes and Townes, 1960: 200. Holotype: + , United States of America (USNM).

Material examined. Holotype female, UNITED STATES OF AMERICA. Delaware: Newark, from wheat stubble, E.D. Eaton, Cage Erd2 (antennae missing) (USNM). Paratypes. CANADA. Ontario: Marmora, 10.VII.1952, coll.

J.R. Vockeroth (Paratype $\left.\mathrm{N}^{\circ} 7432\right), 1$ (CNCI). UNITED STATES OF AMERICA. Florida: Sarasota, 3.III.1937, 1 q (USNM, 2053217). Non-type material. UNITED STATES OF AMERICA. Florida: Levy, 14.III.1958, 1 q (AEIC); same locality, 24.III.1959, 1 đิ (AEIC). Michigan: Ann Arbor, 6.IX.1965, 1 ㅇ (AEIC); same locality, VII.1976, coll. I.D. Gauld, 1 (BMNH); Gun Lake, VIII.1976, coll. I.D. Gauld, 1 o, 1 o (BMNH); same locality and collector, Malaise trap, VII-VIII.1976, 1 के (BMNH); Lake Odessa, VIII.1976, coll. I.D. Gauld, 1 oे (BMNH); Lake Saddlebag, VII.1976, coll. I.D. Gauld, 2 के $\widehat{\delta}$ (BMNH). New Jersey: Oceanville, 4.X.1945, 1 $\widehat{ }$ (AEIC); same locality, 20.VII.1950, 1 ㅇ (AEIC). North Carolina: Panicum, Bogue Banks, 24.V.1960, coll. L. Davis, 1 ㅇ (USNM, 2053570).

Diagnosis. Clistopyga alutaria can be recognised from all other North American species by complete submetapleural carina (Figs. 9A, 18A); face entirely black or dark brown; mesopleuron (except in dorsal anterior part), 
mesosternum and metapleuron orange, in combination with the following characters: female with propodeum and tergites $1-5$ of metasoma orange (Fig. 8A); mesosoma and metasomal tergites punctate on a coarsely granulate background (Fig. 9A, 9C), and ovipositor weakly up-curved from $0.4-0.5$ to apex. Male with tergites 2-4(5) of metasoma orange (Fig. 17B); ventral part of gena weakly convex or flat (Fig. 16C); metapleuron granulate (Fig. 18A); propodeum and metasoma finely and sparsely punctate on a strongly granulate background (Fig. 18A-B).

Description. Female. Body length $6.3-7.0 \mathrm{~mm}$. Fore wing length $3.7-4.8 \mathrm{~mm}$.

Head. In dorsal view, weakly narrowed behind eyes. Gena, in anterior view, straightly and moderately constricted below eyes. Gena densely and finely punctate, in dorsal view $0.4-0.5$ times as long as eye. Frons shiny, with transverse striae. Posterior ocellus separated from eye by 1.4 times its maximum diameter. Distance between posterior ocelli 1.2 times maximum diameter of posterior ocellus. Occipital carina strong, not forming a flange dorsomedially. Occiput in dorsal view almost flat. Face strongly and densely punctate, distance between punctures less than twice length of diameter of puncture. Clypeal suture slightly rounded. Clypeus 1.7-1.8 times as broad as medially long, weakly convex in dorsal half and flat in ventral half. Malar space with a granulate stripe between eye and mandible, 1.1-1.2 times as long as basal mandibular width. Antenna with 21 flagellomeres, first 4.5-5.1 times as long as wide.

Mesosoma. Pronotum shiny, punctate in dorsal half and mostly granulate in ventral part (Fig. 9A). Epomia strong and long (Fig. 9A). Median lobe of mesoscutum densely and finely punctate on a strongly granulate background, lateral lobes and sometimes posterior part of median lobe densely punctate on smooth and shiny background. Notauli deep, extending from anterolateral margin of mesoscutum to about 0.7 its length. Mesopleuron shiny, mostly granulate and moderately strongly and densely punctate, smooth in dorsal posterior part. Epicnemial carina strong, with dorsal end straight or slightly curved backward ending very close to anterior margin of mesopleuron at level of centre of pronotum (Fig. 9A). Metapleuron mostly finely sparsely punctate on granulate background, twice as long as deep (Fig. 9A). Submetapleural carina strong and complete, not raised (Fig. 9A). Propodeum almot matt, strongly granulate, finely and densely punctate anteriorly and laterally, without lateromedian longitudinal carina (Fig. 9A), in dorsal view 1.0-1.1 times as long as medially wide. Propodeal spiracle situated immediately above groove separating propodeum and metapleuron (Fig. 9A). Hind leg with femur 0.9 times as long as tibia. Fore wing with vein $C u-a$ slightly distal to vein $R s \& M$; Vein $2 r s-m$ shorter than half length of abscissa of $M$ between $2 r s-m$ and $2 m-c u$. Abscissa of $C u 1$ between $1 m-c u$ and $C u 1 a$ about 1.6 times as long as $C u 1 b$. Hind wing with vein $C u-a$ 0.4-0.5 times as long as abscissa of $M+C u$ between $M$ and $C u 1$. Vein $C u 1$ weakly pigmented.

Metasoma. First tergite about as long as posteriorly broad, rugulose punctate on granulate background; spiracle near its basal 0.4. Lateromedian longitudinal carinae strong, reaching about mid length of tergite, lateral longitudinal carinae strong and complete. Sternite 1 extending back about half of length of tergite. Second tergite 0.9 times as long as posteriorly broad, central region strongly and densely punctate on granulate background (Fig. 9C). Ovipositor stout, weakly and evenly up-curved in apical 0.4-0.5, matt, 1.7-1.9 times as long as hind tibia (Fig. 8A). Ovipositor sheath 1.2-1.3 times as long as hind tibia, basally with denticles on ventral side, with numerous oblique black setae that are subequal to sheath width.

Colouration. Body primarily orange and black (Fig. 8A). Antenna orange, scape brown, pedicel and basal flagellomeres yellow beneath. Head black with dorsal part of gena with two very small orange spots at level of posterior ocellus. Face black. Clypeus orange. Mandible orange with black teeth. Palpi white. Mesosoma anterodorsally black to dark brown, posteroventrally orange. Propleuron black with ventral margin orange. Pronotum, mesoscutum, scutellum, and metanotum entirely black. Mesopleuron mostly orange with dorsal part and epicnemium black. Metapleuron entirely orange. Propodeum black basally, black dorsolaterally and orange posteriorly. Tegula and base of wings white. Pterostigma pale brown. Legs mainly orange; fore coxa and trochanters white; hind tibia brown 
basally and apically, white centrally; mid tarsomeres and hind tarsomeres brown, pale yellow basally. Tergites 1-5 predominantly orange; tergite 1 brown anterolaterally, tergite 2 with two black stripes posterolaterally, tergite 3 with two black marks on posterior margin, tergites 6-8 entirely black with posterior margin narrowly orange. Ovipositor light brown. Ovipositor sheath brown.

Male. Body length 5.5-6.1 mm. Fore wing length 3.8-4.2 mm. Similar to female in structure and colouration (Figs. 16C, 17B, 18A-B) except characters given below. Flagellomere 1 about 3.7 as long as wide. Malar space 0.9 times as long as basal mandibular width. Ventral part of gena weakly convex or flat (Fig. 16C). Clypeus twice as broad as medially long. Metapleuron 1.8 times as long as deep (Fig. 18A). Tergite 1 with median longitudinal carinae strong, reaching about 0.8 length of tergite. Tergites 3-5 with basolateral and apicolateral grooves stronger than in female.

Colouration. Similar to female (Fig. 17B) but antenna brown beneath, palpi white, clypeus orange with dorsal margin brown, mandible yellow in basal half and black in apical half with teeth orange, legs mainly orange with fore coxae, mid coxae, and trochanters white, tergites 1-5(6) orange, and tergites 6(7)-8 entirely brown.

Variation. Female with epicnemium, propodeum and tergite 1 sometimes entirely orange. Male with brown areas on mesopleuron and propodeum sometimes larger. Tergite 1 sometimes entirely dark brown, black or orange; black marks of tergites sometimes extending across entire posterior margin.

Host. Unknown.

Distribution. Nearctic: Canada (Ontario) and United States of America (Delaware, Florida, Michigan, Wisconsin).

\section{Clistopyga arizonica Bordera and González-Moreno, new species}

(Figs. 10A, 11A-B)

Material examined. Holotype female, UNITED STATES OF AMERICA. Arizona, Parker Canyon Lake, 23.VIII.1974, coll. H. and M. Townes (AEIC). Paratypes. UNITED STATES OF AMERICA. Arizona: Portal,
24.VIII.1974, coll. H. and M. Townes, 1 우 (AEIC); same locality and collectors, 31.VIII.1974, 1 ㅇ (AEIC); same locality and collectors, 12.IX.1987, 1 \& (AEIC); Sierra Vista, Huachuca Mts., 20.VIII.1967, coll. R.F. Sternitzky, 1 \% (CNCI).

Etymology. The name refers to Arizona, the state where all type material was collected.

Diagnosis. Female of $C$. arizonica can be distinguished from all other females of North American species by combination of the following characters: metasoma orange-brown to red or black, without white marks, tergites sometimes with narrowly white posterior margin (Fig. 10A); submetapleural carina weakly present anteriorly (Fig. 11A); ovipositor stout, parallel sided in basal third, abruptly up-curved at apical 0.3 (Fig. 11B), vividly dark brown (Fig. 10A); metapleuron 2.2-2.3 times as long as deep (Fig. 11A); propodeum 1.1-1.2 times as long as medially wide.

Description. Female. Body length $5.8-12.3 \mathrm{~mm}$. Fore wing length $4.7-8.2 \mathrm{~mm}$.

Head. In dorsal view, strongly narrowed behind eyes. Gena in anterior view, straightly and moderately constricted below eyes. Gena with very sparse setiferous punctures, in dorsal view $0.26-0.30$ times as long as length of eye. Frons smooth and shiny. Posterior ocellus separated from eye by $0.8-0.9$ times its maximum diameter. Distance between posterior ocelli 0.9-1.0 times maximum diameter of posterior ocellus. Occipital carina strong, not forming a flange dorsomedially. Occiput in dorsal view moderately concave. Face finely and densely punctate; distance between punctures mostly less than twice length of diameter of puncture. Clypeal suture slightly rounded. Clypeus 1.8 times as broad as medially long, weakly convex, almost flat. Malar space with granulate stripe between eye and mandible, 0.9-1.0 times as long as basal mandibular width. Antenna with 26-33 flagellomeres, first about 5.5 times as long as wide.

Mesosoma. Pronotum smooth and shiny. Epomia strong and short. Median lobe of mesoscutum densely and finely punctate, lateral lobes and posterior part of median lobe more sparsely punctate on smooth and shiny background. Notauli deep, extending from anterolateral margin of mesoscutum to about 0.7 times length of mesoscutum. Mesopleuron shiny, 
Fig. 13. Morphology of females: (A, C, E) Clistopyga moraviae; (A) habitus, lateral view; (C) head, dorsal view; (E) head, anterior view; (B, D, F) Clistopyga serricauda (holotype): (B) habitus, lateral view; (D) head, dorsal view; (F) head, anterior view.
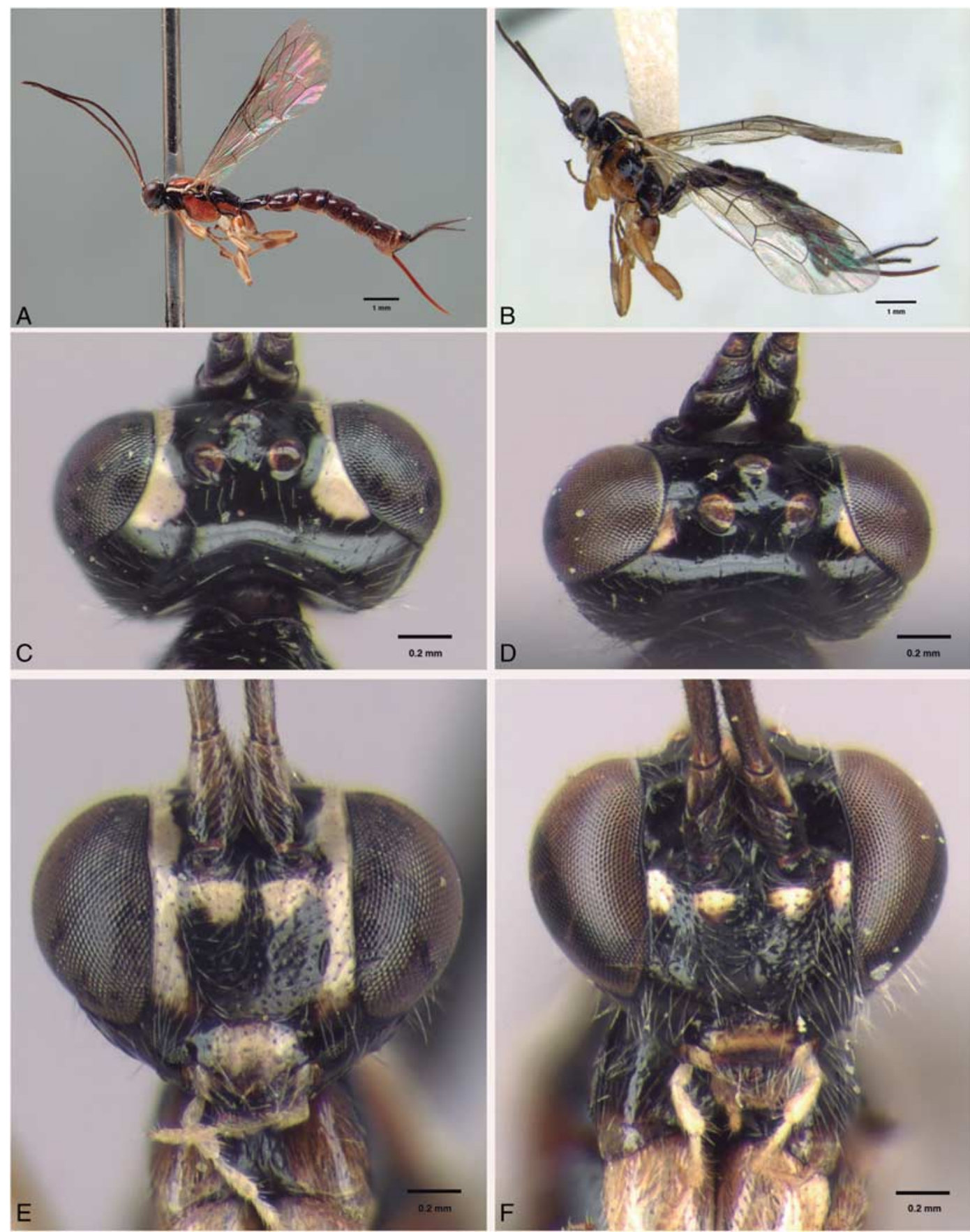
Fig. 14. Male habitus, lateral view: (A) Clistopyga chaconi; (B) Clistopyga calixtoi (paratype); (C) Clistopyga henryi; (D) Clistopyga fernandezi.
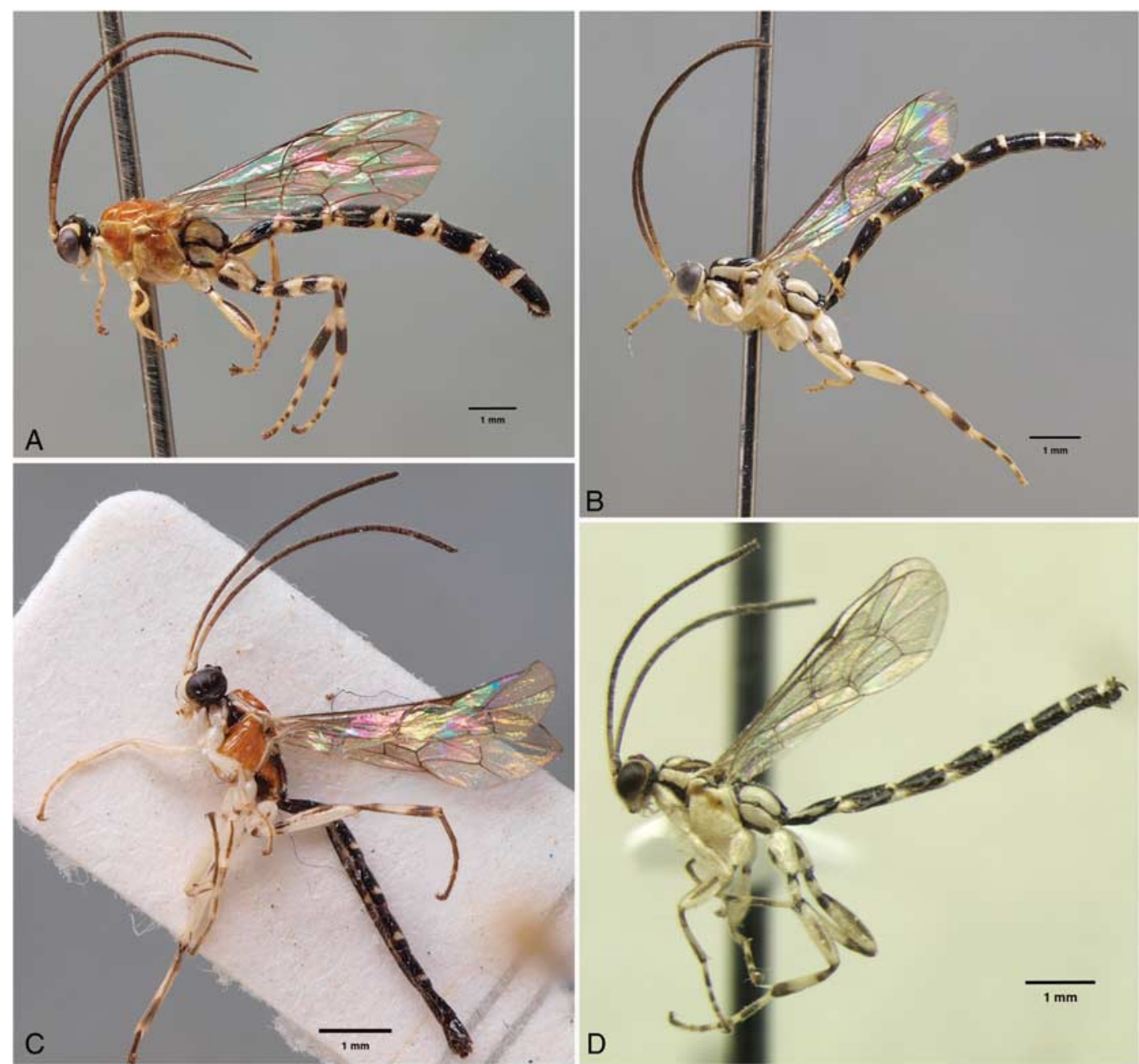

mostly smooth, finely and sparsely punctate in ventral and anterior part (Fig. 11A). Epicnemial carina strong, with dorsal end slightly curved backward, ending so far from anterior margin of mesopleuron at level of centre of pronotum (Fig. 11A). Metapleuron smooth and shiny, 2.2-2.3 times as long as deep (Fig. 11A). Submetapleural carina weakly present on anterior part of metapleuron (Fig. 11A). Propodeum shiny, with dense and moderately strong punctures in anterior half on a smooth background, weakly granulate rugulose in middle part and smooth posteriorly, without lateromedian longitudinal carina; in dorsal view 1.1-1.2 times as long as medially wide. Propodeal spiracle situated immediately above groove separating propodeum and metapleuron. Hind leg with femur 1.0-1.1 times as long as tibia. Fore wing with vein $C u-a$ opposite to vein $R s \& M$. Vein $2 r s-m$ shorter than half length of abscissa of $M$ between $2 r s-m$ and $2 m-c u$. Abscissa of $C u 1$ between $1 m-c u$ and $C u 1 a$ 1.8-2.1 times as long as $C u 1 b$. Hind wing with vein $C u-a$ 0.3-0.6 times as long as abscissa of $M+C u$ between $M$ and $C u 1$. Vein $C u 1$ weakly pigmented.

Metasoma. First tergite 1.0-1.1 times as long as posteriorly broad, smooth and shiny, with fine and moderately dense setiferous punctures; 
Fig. 15. Morphology of males: (A-D) male habitus, lateral view; (A) Clistopyga maculifrons; (B) Clistopyga maya (paratype); (C) Clistopyga recurva; (D) Clistopyga californica (paratype); (E-F) metasomal tergites, dorsal view; (E) Clistopyga recurva; (F) Clistopyga californica (paratype).
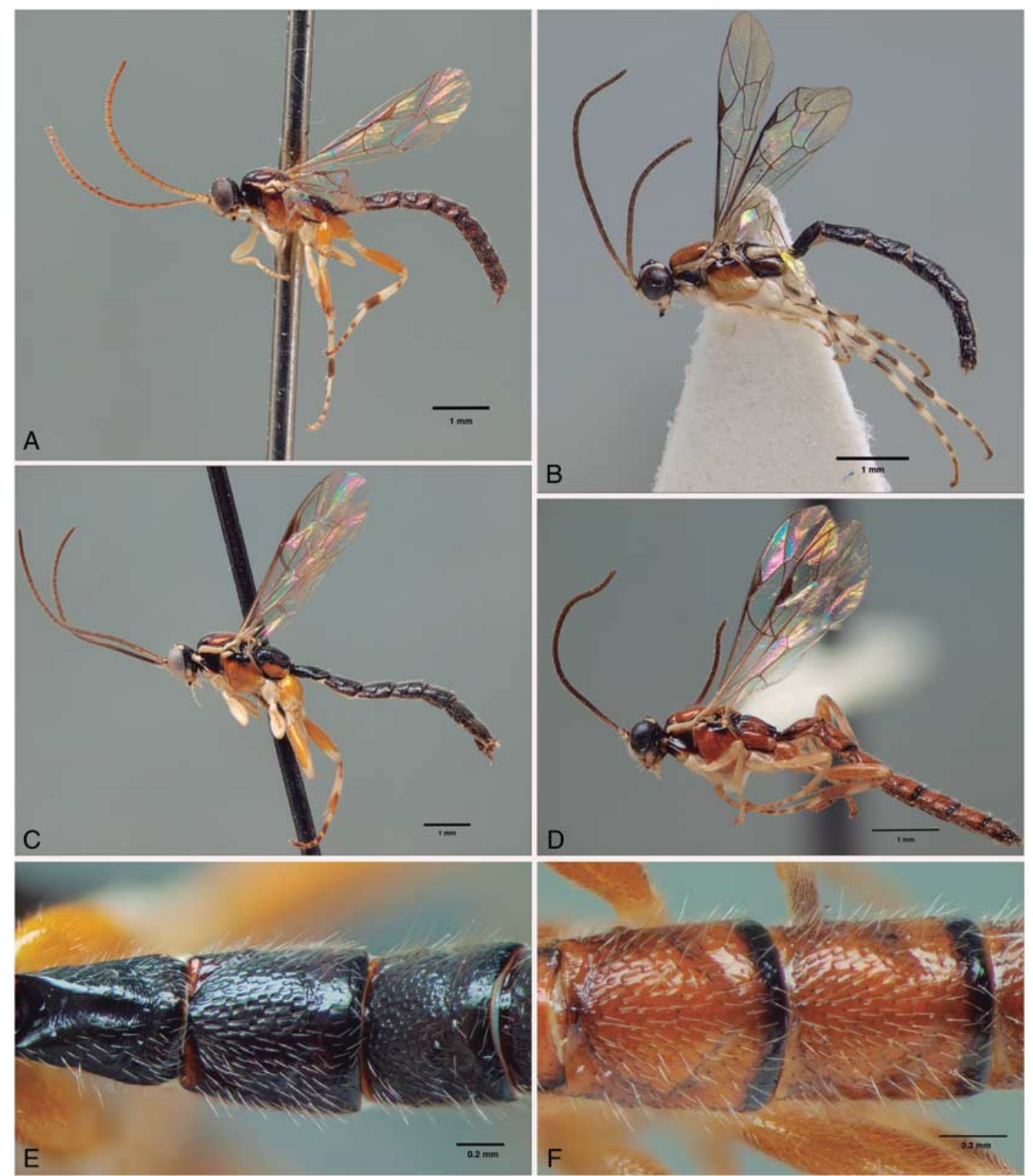

spiracle near its basal 0.3 . Lateromedian longitudinal carina strong and reaching about $0.2-0.3$ length of tergite, lateral longitudinal carina absent. Sternite 1 extending back about 0.3 length of tergite. Second tergite $0.9-1.0$ times as long as posteriorly broad, central region strongly and densely punctate. Ovipositor stout, parallel sided in basal third, abruptly up-curved at apical 0.3, matt, 1.8-1.9 times as long as hind tibia (Fig. 11B). Ovipositor sheath 1.4-1.5 times as 
Fig. 16. Head of males, anterior view: (A) Clistopyga maculifrons; (B) Clistopyga canadensis; (C) Clistopyga alutaria.
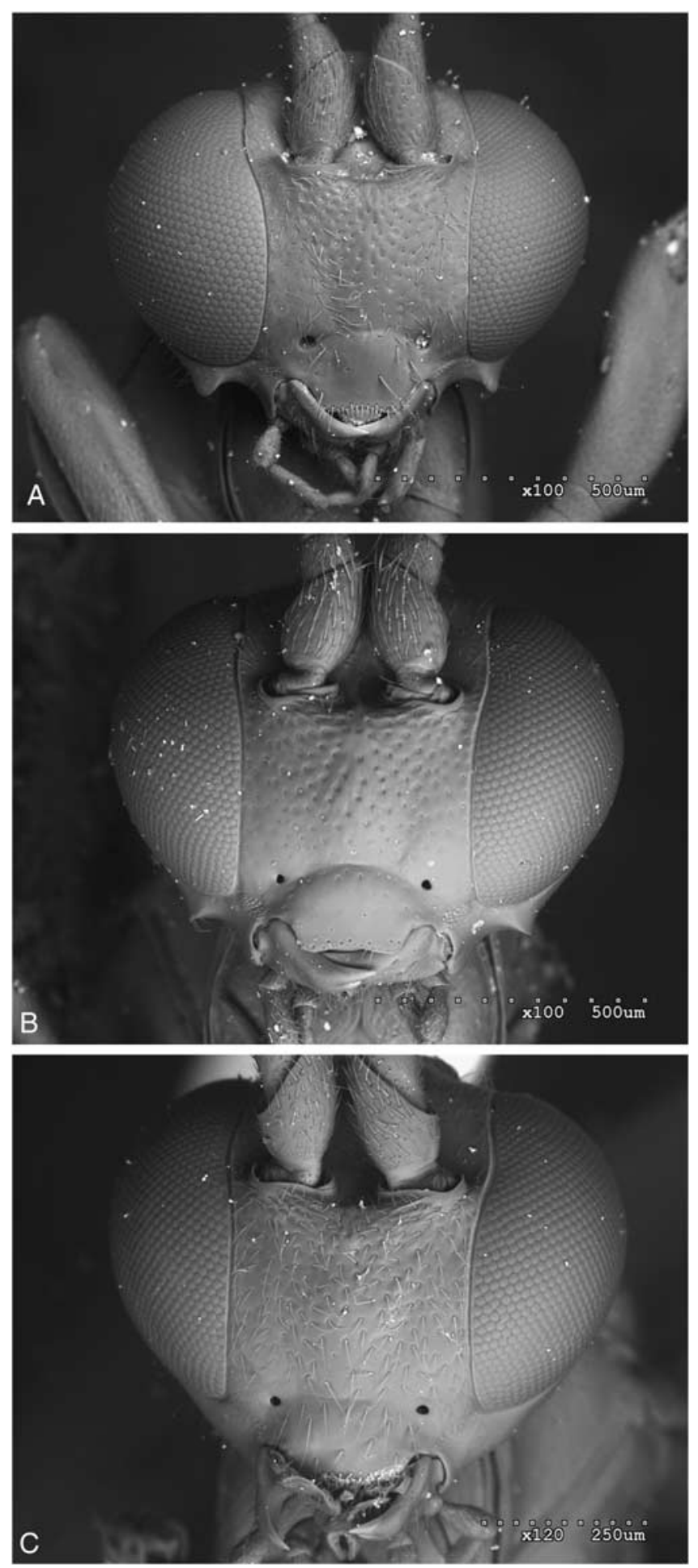
long as hind tibia, without denticles at basal ventral margin, with numerous oblique brown setae that are usually longer than sheath width.

Colouration. Body primarily orange and black (Fig. 10A). Antenna brown with scape, pedicel and basal flagellomeres yellow beneath. Head black, ventral part of gena with yellow stripe next to mandible, inmediately below malar space. Inner orbits yellow. Face white, variably tinged with brown; clypeal suture and malar space brown. Palpi, clypeus and basal half of mandible (teeth black) white. Pronotum black with collar and wide dorsolateral band white. Mesopleuron mostly orange with epicnemium, speculum and area below subtegular ridge black, subalar prominence white. Metapleuron entirely brown. Mesoscutum with median and lateral lobes orange, black peripherally, with two yellow interrupted notaular marks and median lobe posteriorly black. Prescutellar groove black. Scutellum orange, laterally black, with posterior white mark. Metanotum black, with postscutellum white. Propodeum black with a pair of red elongate marks dorsolaterally and two small white spots posterolaterally. Tegula and base of wings white. Pterostigma brown. Fore legs and mid legs predominantly white, trochanters, femora and tibiae with light brown stripes posteriorly. Hind coxa orange, white dorsoapically; trochanters and femur white with anterior and posterior dorsal light brown stripes, tibia light brown basally and apically, white medially, all tarsomeres dark, white basally. Metasoma black with dark brown to red hue. Ovipositor vividly dark brown. Ovipositor sheath black.

Male. Unknown.

Host. Unknown.

Distribution. Nearctic: southeast United States of America (Arizona).

\section{Clistopyga atrata Cushman, 1922}

(Figs. 8D, 9F, 9H, 17C, 18C, 18D)

Clistopyga atrata Cushman, 1922: 14. Holotype: + , United States of America (USNM).

Material examined. Holotype female, UNITED STATES OF AMERICA. California, Berkeley, IX.1914, coll. E.P. van Duzee (USNM). Allotype male, UNITED STATES
OF AMERICA. California, Yosemite Natural Park, taken from gallery of Calopus angustus in Pinus murrayana, 10.VIII.1917, coll. J.E. Patterson (USNM). Non-type material. UNITED STATES OF AMERICA. Arizona: Alpine, 23.V.1947, 1 ㅇ (AEIC). Nevada: Tuscarora, 5.VI.1978, 1 우 (AEIC). Oregon: Yamhill, St Paul, 12.X.1970, coll. C.E. Deonier, 1 (USNM).

Diagnosis. Clistopyga atrata can be distinguished from all other North American species by combination of the following characters: body mostly black or dark brown, sometimes with posterior margin of metasomal tergites narrowly white (Figs. 8D, 17C); submetapleural carina complete (Figs. 9F, 18C). Female with metapleuron entirely coarsely punctate (Fig. 9F), and ovipositor slender, weakly up-curved from basal 0.4-0.5 to apex (Fig. 9H). Male with face entirely black or dark brown, ventral part of gena weakly convex, propodeum (except transversely striate posterior part) and metasomal tergites centrally with coarse and dense punctures (Fig. 18D), metapleuron coarsely punctate on smooth and shiny background (Fig. 18C).

Description. Female. Body length $6.5-7.6 \mathrm{~mm}$. Fore wing length $4.7-5.2 \mathrm{~mm}$.

Head. In dorsal view moderately narrowed behind eyes. Gena in anterior view, straightly and moderately constricted below eyes. Gena densely and finely punctate, in dorsal view half as long as eye. Frons shiny strongly punctate, with very weak wrinkles below antennal sockets. Posterior ocellus separated from eye by 0.7 times its maximum diameter. Distance between posterior ocelli 0.8 times maximum diameter of posterior ocellus. Occipital carina strong, not forming a flange dorsomedially. Occiput in dorsal view slightly concave. Face strongly and densely punctate; distance between punctures less than twice length of diameter of puncture. Clypeal suture rounded. Clypeus 1.5-1.7 times as broad as medially long, weakly convex in dorsal half, flat in ventral half. Malar space with granulate stripe between eye and mandible, 1.1-1.2 times as long as basal mandibular width. Antenna with 22-23 flagellomeres, first about 4.4-5.0 times as long as wide.

Mesosoma. Pronotum mostly smooth and shiny, weakly punctate on posterior corner. Epomia strong and long. Anterior part of median lobe of mesoscutum densely and finely punctate 
Fig. 17. Male habitus, lateral view: (A) Clistopyga canadensis; (B) Clistopyga alutaria; (C) Clistopyga atrata (paratype).
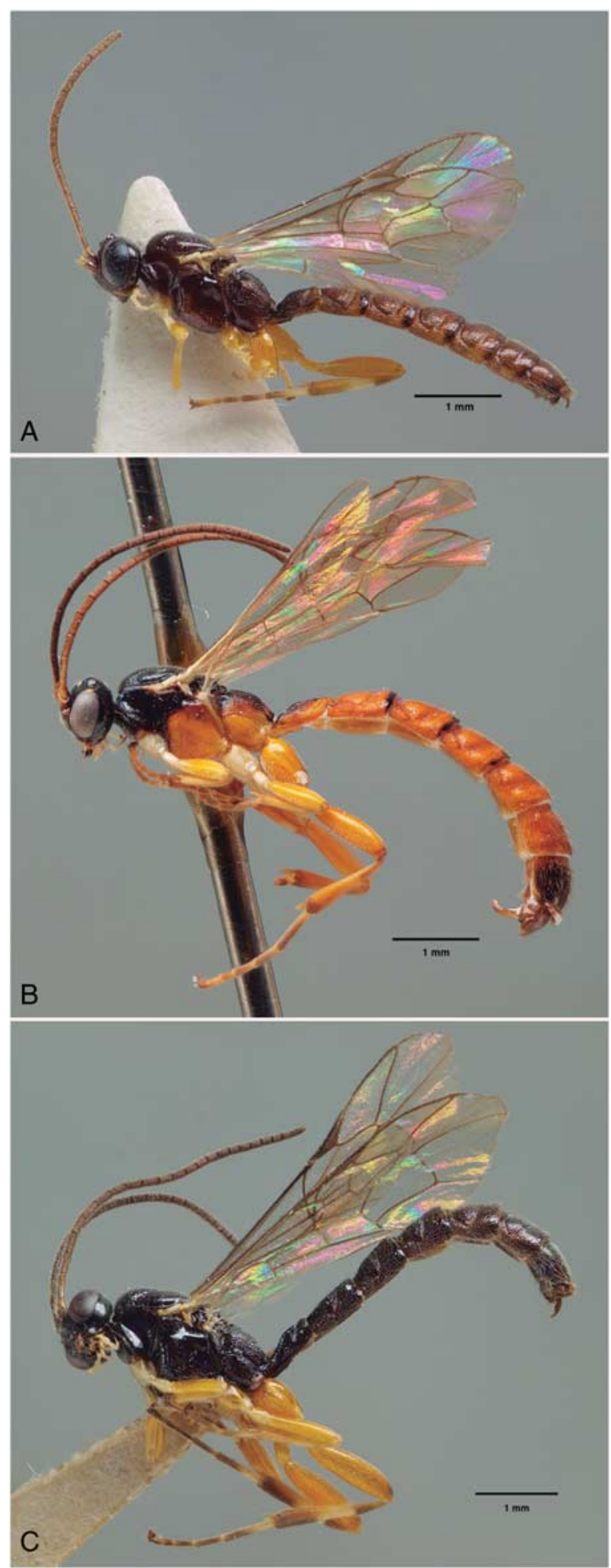
Fig. 18. Morphology of males, lateral view: (A-B) Clistopyga alutaria; (A) posterior part of mesosoma; (B) metasomal tergites 1-3; (C-D) Clistopyga atrata; (C) posterior part of mesosoma; (D) metasomal tergites $1-3$.
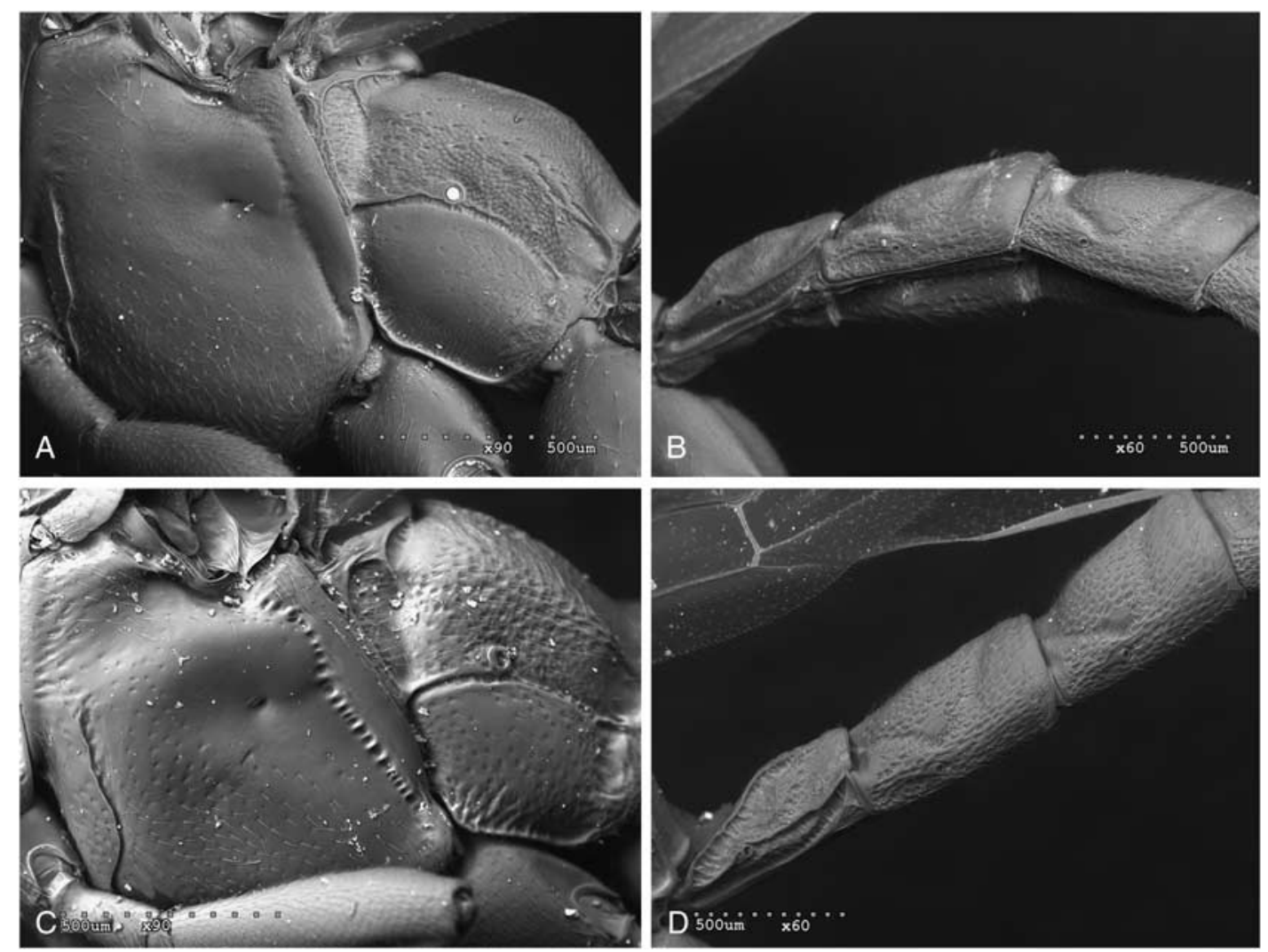

on granulate background, posterior part and lateral lobes punctate on rugulose or smooth and shiny background. Notauli deep, reaching about 0.8 times length of mesoscutum. Mesopleuron shiny, with dense and strong punctures, smooth in dorsal posterior part (Fig. 9F). Epicnemial carina weak, with dorsal end slightly curved backward, ending very close to anterior margin of mesopleuron at level of centre of pronotum. Metapleuron shiny with strong, coarse, and dense punctures in dorsal part, more sparsely in ventral part, 1.8 times as long as deep (Fig. 9F). Submetapleural carina strong and complete, not raised (Fig. 9F). Propodeum shiny, mainly granulate and strongly and densely punctate, dorsoposteriorly smooth to slightly strigose, without lateromedian longitudinal carina; in dorsal view $0.9-1.0$ times as long as medially wide. Propodeal spiracle situated immediately above groove separating propodeum and metapleuron (Fig. 9F). Hind leg with femur 0.9 times as long as tibia. Fore wing with vein $\mathrm{Cu}$ - $a$ very slightly distal to vein $R s \& M$; Vein $2 r s-m$ shorter than half length of abscissa of $M$ between $2 r s-m$ and $2 m-c u$. Abscissa of $C u 1$ between $1 m-c u$ and $C u 1 a$ 1.4-1.5 times as long as $C u 1 b$. Hind wing with vein $C u-a$ 0.3 times as long as abscissa of $M+C u$ between $M$ and $C u 1$. Vein $C u 1$ distinctly pigmented.

Metasoma. First tergite $0.8-0.9$ times as long as posteriorly broad, rugulose, with strong, dense punctures; spiracle near its basal 0.4. Lateromedian longitudinal carina strong and reaching almost posterior end of tergite, lateral longitudinal carinae strong and complete. Sternite 1 extending back about 0.4 length of tergite. Second tergite 0.8 times as long as posteriorly broad, central region very strongly and densely punctate. Ovipositor slender, weakly and 
Fig. 19. Morphology of males: (A, C, E) Clistopyga moraviae; (A) habitus, lateral view; (C) head, dorsal view; (E) head, anterior view; (B, D, F) Clistopyga serricauda (paratype): (B) habitus, lateral view; (D) head, dorsal view; (F) head, anterior view.

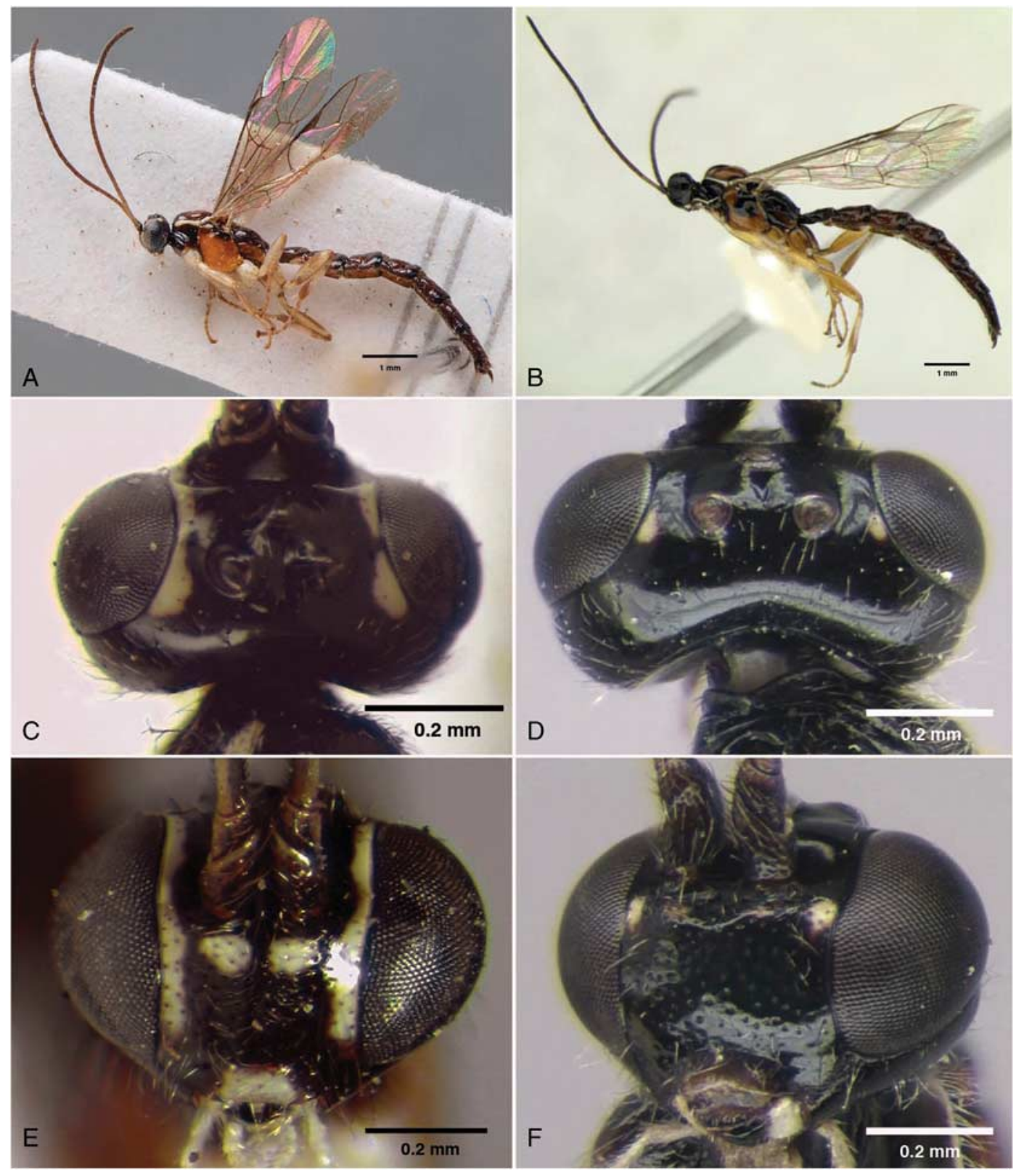

evenly up-curved in apical $0.4-0.5$ (Figs. 8D, 9H), matt, 1.5-1.7 times as long as hind tibia. Ovipositor sheath $1.2-1.3$ times as long as hind tibia, transversely striate, with few small denticles on basal ventral margin and numerous oblique black setae that are about as long as sheath width.

Colouration. Body mainly black, metasoma behind tergite 1 black to dark brown (Fig. 8D). Antenna brown with scape and pedicel black. 
Fig. 20. Variation in Clistopyga recurva, females: (A-D) face colour gradient.
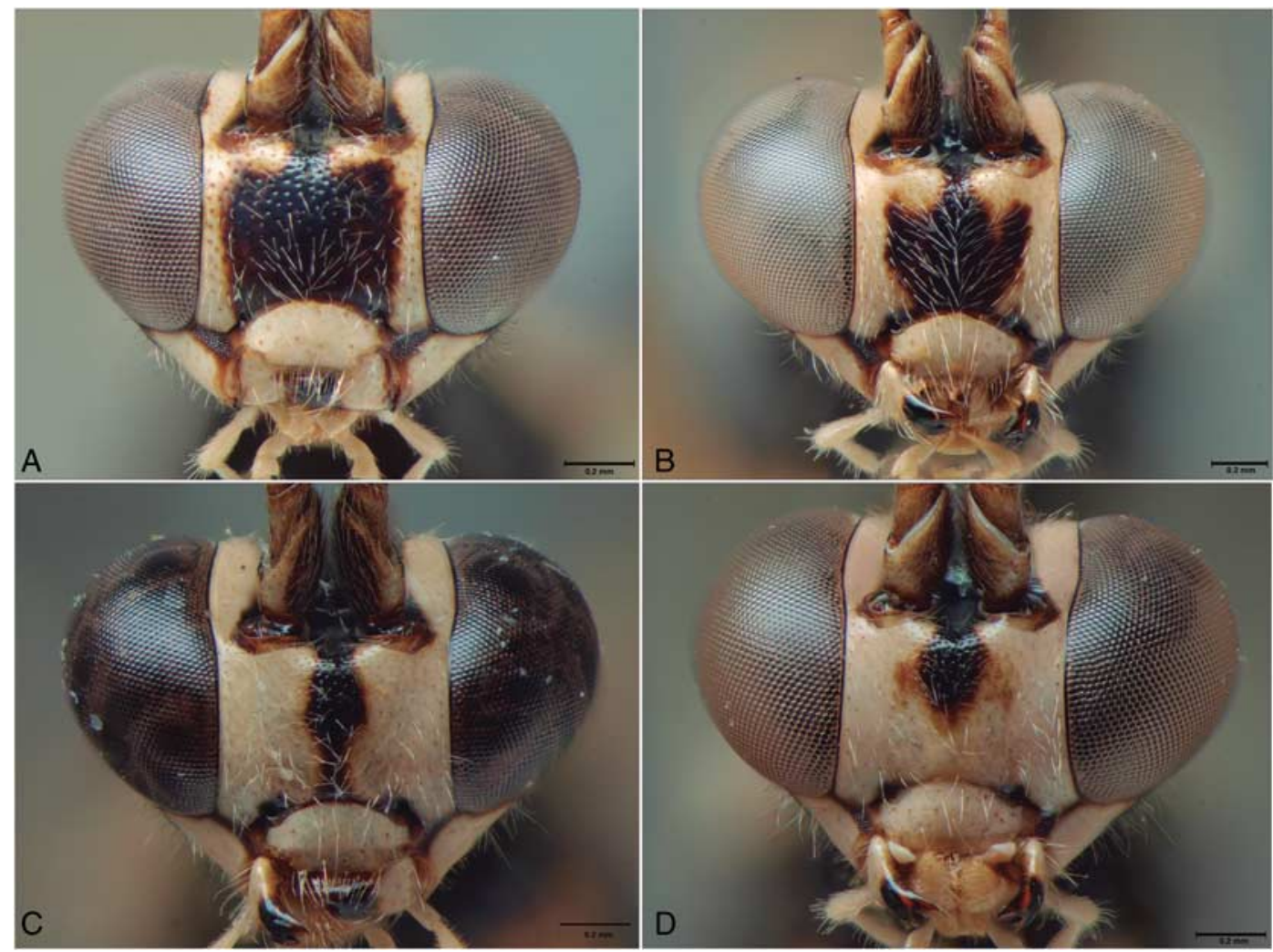

Head black with two small yellow spots at level of posterior ocelli. Face black. Clypeus orange with dorsal margin brown. Basal half of mandible brown and apical half black with orange teeth. Palpi, tegula and posterior lateral corner of pronotum white. Pterostigma pale brown. Legs mainly orange, fore leg with coxa and trochanters white. Mid legs and hind legs with tibiae brown basally and apically, white centrally, and tarsomeres brown, yellow basally. Ovipositor light brown. Ovipositor sheath dark brown.

Male. Body length $6.4 \mathrm{~mm}$. Fore wing length $4.1-4.8 \mathrm{~mm}$. Similar to female in structure and colouration, but differs in characters described below. Posterior ocelli separated from each other and from eye 1.0 times its maximum diameter. Clypeus 1.8 times as broad as medially long. Mandible strongly tapered in apical half, with dorsal tooth sligthly longer than ventral tooth. Malar space as long as basal mandibular width. Gena without longitudinal concavity in ventral part.
Antenna with 22 flagellomeres, first about 4.1 times as long as wide. Propodeum 0.8 times as long as medially wide in dorsal view, strigose punctate on granulate background, tending to be slightly granulate dorsoposteriorly, rugulose punctate laterally; in profile evenly convex. Vein $C u$ - $a$ opposite $R s \& M$. Abscissa of $C u 1$ between $1 m-c u$ and $C u 1 a$ about 1.8 times as long as $C u 1 b$. Hind wing with $C u 1$ very weakly pigmented. First tergite 1.1 times as long as posteriorly broad, strongly and densely punctate on granulate background. Tergites $2-4$ with strong basolateral and apicolateral grooves.

Colouration. Similar to female (Fig. 17C).

Host. Collected from gallery of Calopus angustus LeConte, 1851 (Coleoptera: Oedemeridae) in Pinus contorta murrayana (Balfour) Engelmann (Pinaceae) (Townes and Townes 1960).

Distribution. Nearctic: southeast United States of America (Arizona, California, Nevada). 


\section{Clistopyga californica Khalaim and Hernández, 2008}

\author{
(Figs. 6A, 7A, 7E, 15D-F)
}

\section{Clistopyga californica Khalaim and Hernández, 2008: 316. Holotype: 오, Mexico (UCRC).}

Material examined. Holotype female, MEXICO. Baja California Sur, Las Barracas, Pan trap, 20.XI.1984, coll. P. Debach (UCRC, 88836). Paratype. MEXICO. Baja California: Same data as holotype, 27.IV.1985, 1 of (UCRC, 88837). Non-type material. UNITED STATES OF AMERICA. Arizona: Cochise, $12 \mathrm{~km}$ Sierra Vista, Ramsey Canyon, $1700 \mathrm{~m}$ : 1.V.1986, 1 q ; 21.VI.1986, 2 ㅇ $q$; 30.VI.1986, 3 우; 27.IX.1986, 2 우 (all in AEIC). Portal, 23.VIII.1987, 1 \& (AEIC). Texas: Valverde, 13.V.1946, 1 ô (AEIC).

Diagnosis. Clistopyga californica can be distinguished from all other North American species by combination of the following characters: metasoma mainly orange-brown, without white marks, first tergite slightly darkened basally and submetapleural carina complete (Figs. 7A, 15D). Female with ventral half of mesopleuron with fine, shallow, sparse setiferous punctures; propodeum laterally (Fig. 6A), tergites 2-4 and ovipositor sheath with long and moderately sparse setae; central region of tergites 2-4 with large, shallow, dense punctures (Fig. 7E) and ovipositor strongly up-curved at distal 0.3 (Fig. 7A). Male with face white, sometimes with longitudinal median black mark or black area surrounding clypeus; mesoscutum entirely orange-brown; propodeum orange-brown, slightly darkened anteriorly and posteriorly without white marks (Fig. 15D), gena without longitudinal concavity at its ventral part, mesoscutum with more or less dense setiferous punctures, and central lobes of tergites 2-4 with large, shallow punctures on smooth and shiny background (Fig. 15F).

Description. Female. Body length $5.5 \mathrm{~mm}$. Fore wing length $3.8 \mathrm{~mm}$.

Head. In dorsal view, strongly narrowed behind eyes. Gena in anterior view, straightly and moderately constricted below eyes. Gena with fine and moderately dense setiferous punctures, in dorsal view 0.43 times as long as eye. Frons shiny, with fine punctures. Posterior ocellus separated from eye by 1.1 times its maximum diameter. Distance between posterior ocelli 1.2 times maximum diameter of hind ocellus. Occipital carina weak, not forming a flange dorsomedially. Occiput in dorsal view slightly concave medially. Face with very fine and sparse setiferous punctures; distance between punctures more than twice length of diameter of puncture. Clypeal suture slightly rounded. Clypeus 1.4 times as broad as medially long, flat. Malar space with granulate strip between eye and mandible, 1.0 times as long as basal mandibular width. Antenna with 25 flagellomeres, first flagellomere about 7.0 times as long as wide.

Mesosoma. Pronotum smooth and shiny. Epomia strong and very short. Mesoscutum virtually smooth and shiny anteriorly and laterally, posteriorly with very inconspicuous fine and dense setiferous punctures. Notauli deep anteriorly, reaching the middle of mesoscutum. Mesopleuron shiny, with fine and sparse setiferous punctures in ventral part, smooth in dorsal part (Fig. 6A). Epicnemial carina strong, dorsally almost straight, ending far from anterior margin of mesopleuron at level of centre of pronotum (Fig. 6A). Metapleuron smooth and shiny, 2.3 times as long as deep (Fig. 6A). Submetapleural carina strong and complete, not raised (Fig. 6A). Propodeum, granulate and transversely striate anteromedially, almost matt, finely and sparsely punctate anteriorly, smooth and shiny posteriorly, without lateromedian longitudinal carina; in dorsal view 1.1 times as long as medially wide. Propodeal spiracle on groove separating propodeum and metapleuron (Fig. 6A). Hind leg with femur $0.9-1.0$ as long as tibia. Fore wing with vein $\mathrm{Cu}-a$ opposite vein $R s \& M$. Vein $2 r s-m$ shorter than half length of abscissa of $M$ between $2 r s-m$ and $2 m-c u$. Abscissa of $C u 1$ between $1 m-c u$ and $C u 1 a 1.7$ times as long as $C u 1 b$. Hind wing with vein $C u-a$ 0.3-0.4 times as long as abscissa of $M+C u$ between $M$ and $C u 1$. Vein $C u 1$ absent.

Metasoma. First tergite about 1.3 times as long as posteriorly broad, smooth and shiny, finely and sparsely punctate laterally, posterolaterally slightly granulate; spiracle near its basal 0.4. Lateromedian longitudinal carina weak reaching 0.2 length of tergite, lateral 
longitudinal carina strong reaching 0.2 length of tergite. Sternite 1 extending back about 0.4 of length of tergite. Second tergite about as long as posteriorly broad, central region with large, shallow, dense puctures (Fig. 7E). Ovipositor stout, up-curved in apical 0.4, matt, 1.8-1.9 times as long as hind tibia (Fig. 7A). Ovipositor sheath 1.4 times as long as hind tibia, without denticles on basal ventral side, with numerous oblique black setae that are longer than sheath width.

Colouration. Body orange-brown (Fig. 7A, E). Antenna brown with scape, pedicel and basal flagellomeres white ventrally. Head black, ventral part of gena white. Inner orbits white. Face white with brown median spot in dorsal part. Basal half of mandible, clypeus and palpi white. Propleuron black with ventral margin white. Pronotum bicoloured, mostly black with a white mark anteriorly and in a wide dorsolateral band. Mesopleuron mostly orange-brown with dorsal part black and a white longitudinal mark in dorsal part (below tegula). Metapleuron orangebrown somewhat with ventral part black. Mesoscutum orange-brown, with central lobe black anteriorly. Scutellum red with white mark posteriorly. Postscutellum white. Propodeum orange-brown, slightly darkened anteriorly and posteriorly. Tegula and base of wings white. Wings weakly infumate, pterostigma pale brown. Fore legs and mid legs with coxae entirely white, with femora and tibia white ventrally and brown dorsally, with tarsomeres slightly infuscate. Hind leg with coxa mostly red brown, white dorsally; femur more or less brown, white ventrally in apical half; tibia narrowly light brown basally, widely brown apically, white medially; tarsomeres mostly brown, white basally. Metasoma orange-brown, tergite 1 darkened basally and postero-laterally. Tergite 2 with black posterior rim, tergite 3 with this black mark becoming vestigial. Ovipositor light brown. Ovipositor sheath brown.

Male. Body length $5.8 \mathrm{~mm}$. Fore wing length $3.5 \mathrm{~mm}$. Fore wing length $3.4 \mathrm{~mm}$. Similar to female in structure and colouration but differs in the following characters. Posterior ocelli separated from each other and from eye 1.0 times its maximum diameter. Clypeus 1.3 times as broad as medially long. Malar space 1.2 times as long as basal mandibular width. Gena without longitudinal concavity in ventral part. First flagellomere about 5.0 times as long as wide. Metapleuron 1.9 times as long as deep.

Colouration. Similar in colour to female (Fig. 15D). Face with vestigial brown median mark. Mesoscutum entirely orange-brown. Pterostigma brown. Metasoma with tergites 2-6 with posterior rim black, tergite 7 red darkened anteriorly to black posteriorly.

Host. Unknown.

Distribution. Nearctic: south United States of America (Arizona, Texas), northwest Mexico (Baja California). First record from the United States of America.

\section{Clistopyga calixtoi Gauld, 1991}

(Figs. 3E, 4B, 4E, 5C, 14B)

Clistopyga calixtoi Gauld, 1991: 293. Holotype: + , Costa Rica (INBio).

Material examined. Holotype female, COSTA RICA. Guanacaste Prov., Guanacaste National Park, Santa Rosa Sector, Bosque Húmedo, 300 m, I.1985, coll. D. Janzen and W. Hallwachs (INBio). Paratypes. COSTA RICA. Guanacaste Prov.: Same data as holotype, 1 t , 10-C., 1 ô, 11-0 (AEIC); same data as holotype, 6 ô 0 (INBio). Guanacaste National Park, $560 \mathrm{~m}$, Estación Maritza, Volcano Orosi, 4.V.1989, 1 \& (AEIC); same locality, VII.1989, 1 (AEIC); same locality, IV.1990, 1 q (UAT). Non-type material. MEXICO. Tamaulipas: $15 \mathrm{~km}$ SSE Cd. Victoria, El Madroño, oak-forest, 2.V.2008, coll. A.I. Khalaim, 1 (UAT).

Diagnosis. Clistopyga calixtoi can be distinguished from all other North American species by combination of the following characters: submetapleural carina entirely absent or present as a vestige on anterior third of metapleuron (Fig. 4E), not raised, and occipital carina weak, not forming a flange dorsomedially (Fig. 4B). Female with mesoscutum black with a pair of white longitudinal stripes interrupted by notauli, but lateral lobes always entirely black; hind femur white, basally and dorsally dark brown, posterolateral side usually with a long brown stripe; metasoma with tergite 2 and following, red with posterior margins usually narrowly banded with white, and tergite 2 also with a pair 
of small posterolateral black marks (Fig. 3E); central area of metasomal tergites finely and quite densely punctate on smooth and shiny background, distance between punctures at most 1.0 times diameter of puncture (Fig. 5C); ovipositor sheath 1.9-2.2 times as long as hind tibia. Male with metasoma black with anterior and posterior margins of tergites white; mesoscutum black with a pair of white stripes interrupted at level of notauli; mesopleuron white with black marks (Fig. 14B), and ventral part of gena with conspicuous longitudinal or oblique concavity.

Description. Female. Body length $10.8-12.0 \mathrm{~mm}$. Fore wing length $6.4-8.0 \mathrm{~mm}$.

Head. In dorsal view, strongly narrowed behind eyes. Gena in anterior view, straightly and moderately constricted below eyes. Gena finely and sparsely punctate, in dorsal view 0.36 times as long as eye. Frons smooth and shiny. Posterior ocellus separated from eye by 1.1-1.2 times its maximum diameter. Distance between posterior ocelli 1.0-1.1 times maximum diameter of posterior ocellus. Occipital carina weak, not forming a flange dorsomedially (Fig. 4B). Occiput in dorsal view very slightly concave medially. Face finely and sparsely punctate; distance between punctures usually more than twice length of diameter of puncture. Clypeal suture slightly rounded. Clypeus 1.9-2.0 times as broad as medially long, weakly convex in dorsal half, flat in ventral half. Malar space with deep, narrow groove between eye and mandible, 0.7-0.8 times as long as basal mandibular width. Antenna with 31-32 flagellomeres, first flagellomere 7.1-7.3 times as long as wide.

Mesosoma. Pronotum smooth and shiny (Fig. 4B). Epomia discernible as a strong short tubercle (Fig. 4B). Mesoscutum smooth and shiny, median lobe anteriorly with very fine and dense setiferous punctures. Notauli deep, extending from anterolateral margin of mesoscutum to $0.4-0.5$ its length. Mesopleuron shiny, smooth, with very fine and sparse setiferous punctures in ventral part. Epicnemial carina strong, dorsally almost straight, ending very far from anterior margin of mesopleuron above level of centre of pronotum. Metapleuron smooth and shiny, 2.4-2.7 times as long as deep. Submetapleural carina absent or discernible as vestige in anterior part of metapleuron (Fig. 4E). Propodeum smooth and very shiny, with relativelly sparse and fine setiferous punctures laterally, without lateromedian longitudinal carina; in dorsal view 1.3-1.5 times as long as medially wide. Propodeal spiracle on groove separating propodeum and metapleuron. Hind leg with femur $1.1-1.2$ as long as tibia. Fore wing with vein $C u-a$ slightly basal or opposite vein $R s \& M$. Vein $2 r s-m$ shorter than half length of abscissa of $M$ between $2 r s-m$ and $2 m-c u$. Abscissa of $C u 1$ between $1 m-c u$ and $C u 1 a$ about 1.6-1.9 times as long as $C u 1 b$. Hind wing with vein $C u-a$ 0.3-0.4 times as long as abscissa of $M+C u$ between $M$ and $C u 1$. Vein $C u 1$ distinctly pigmented.

Metasoma. First tergite 1.6-1.7 times as long as posteriorly broad, smooth and shiny, with very sparse setiferous punctures laterally; spiracle near its basal 0.3. Lateromedian and lateral longitudinal carinae absent. Sternite 1 extending back about half length of tergite. Second tergite 1.2-1.3 times as long as posteriorly broad, central region finely but quite closely punctate (Fig. 5C). Ovipositor slender, at distal 0.3-0.4 evenly up-curved, matt, 2.1-2.3 times as long as hind tibia (Fig. 3E). Ovipositor sheath 1.9-2.2 times as long as hind tibia, without denticles on basal ventral side, setae slightly longer than sheath width.

Colouration. Body primarily white, black, and red (Fig. 3E). Antenna brown darkened with scape, pedicel, and basal flagellomeres white beneath. Head white, with occiput, ocellar area and frons centrally black. Face white with malar space brown. Palpi, clypeus and basal half of mandible (teeth black) white. Propleuron white. Pronotum bicoloured, mostly white with a wide longitudinal black band medially. Mesopleuron mostly white with ventral posterior corner, epicnemium, area around episternal scrobe and stripe below subalar prominence black. Metapleuron white with margin black, including the groove separating propodeum and metapleuron. Mesoscutum black with a pair of white longitudinal stripes interrupted by notauli, but lateral lobes always entirely black. Prescutellar groove black. Scutellum white, laterally black; metanotum black with postscutellum white. Propodeum white with a broad black stripe mediodorsally. Tegula and base of wings white. Wings weakly infumate, pterostigma black. Fore legs and mid legs predominantly white, femora and tibiae posterodorsally brown and 
tarsi distally infuscate. Hind legs white, coxa with anterior and posterior central black marks, trochanter basally, trochantellus apically and femur basally brown. Hind femur usually with posterodorsal and anterodorsal light brow stripes. Tibia broadly basally and apically black, tarsomeres posteriorly black. Metasoma with tergite 1 black with lateral and posterior margins white marked. Tergite 2 and following red, with posterior rim narrowly white, tergite 2 with anterolateral areas white and a pair of black marks laterally on posterior margin. Ovipositor vividly dark brown. Ovipositor sheath black.

Male. Similar to female. Body length $9.1 \mathrm{~mm}$. Fore wing length $5.0 \mathrm{~mm}$. Metapleuron 2.2 times as long as deep. Propodeum 1.1-1.2 times as long as medially wide.

Colouration. Similar in colour to female (Fig. 14B). Metasoma black with anterior and posterior margins white.

Host. Unknown.

Distribution. Neotropical: Costa Rica. Nearctic: Mexico (Tamaulipas).

Remarks. Two females collected from Gómez Farías, Mexico, previously reported as this species (Khalaim and Hernández 2008), belong to $C$. fernandezi. These two females have lateral lobes of mesoscutum black with red hue and ovipositor sheath 1.85 times as long as hind tibia.

\section{Clistopyga canadensis Provancher, 1880}

(Figs. 8C, 9E-G, 16B, 17A)

Polysphincta acuta Provancher, 1880: 44. Lectotype: + , Canada (UL).

Clistopyga canadensis Provancher, 1880: 45. Lectotype: 9 , Canada (UL).

Clistopyga sauberi Brauns, 1898: 70. Lectotype: q, Germany.

Material examined. Lectotype female, Clistopyga canadensis Provancher, "Gahan and Rohwer 15", "Barron 71”; “Clistopyga canadensis Provancher, Det. Corneaw 44" (UL). Non-type material. BELARUS. Brest: Belovezhskaya Pushcha Nature Reserve, ex spider egg sac, 1-10.VIII.1961, coll. E.P. Narchuk, $3 q q$, 3 oิ $0 \widehat{o}$ (ZISP). CANADA. Alberta: Eisenhower
Junction, Banff, $4700 \mathrm{ft}$ (=1430 m), 7.VII.1962, Malaise trap, W.R.M. Mason, 1 (CNCI); Jumping Pd. Cr., $20 \mathrm{ml}$ W. Calgary, 15-17.VIII.1962, coll. W.R.M. Mason, 1 \% (CNCI). British Columbia: Lac La Hache, 10-14.VIII.1964, 1 † (CNCI); Lakelse Lake, S. of Terrace, 5.VIII.1960, coll. B. Heming, 1 q (CNCI); Racing Riv., $2400 \mathrm{ft} \quad(=730 \mathrm{~m})$, 27.VII.1973, coll. H. and M. Townes, 1 ๙ (FSCA), 7 के $\widehat{o}$ (AEIC). Manitoba: Horton, 28.VII.1958, coll. A. \& J. Brooks, 1 \& (CNCI).

Newfoundland and Labrador: Kenemich Riv., 1/4 -1 ML. S.E. I ML. Up., 13-15.VIII.1958, B.S.E.S. Expedition. Brit. Mus. 1958-490, Vegetation on Boggy trail, 1 \& (BMNH); Port a Basques, 7.VIII.1975, 1 (AEIC); Raleigh, 4.VIII.1975, 1 \& (AEIC); South Branch, 9-17.VII.1973, coll. G. Heinrich, Malaise trap, 1 \& (CNCI); same locality and collector, VII.1974, 1 ㅇ (CNCI). Northwest Territories: Wrigley, 14.VI.1969, coll. G.E. Shewell, 1 q (CNCI). Nova Scotia: Sant Peters, 1.IX.1930, Prebble (11902-61), 1 우 (CNCI). Ontario: Brighton, 21.VII.1954, coll. John C. Martin, 1 (CNCI); Constance Bay, 9.VIII.1033, 1 ㅇ (CNCI); Island Falls, 24.VIII.1959, coll. S.M. Clark, 1 (CNCI). Québec: Beaulne, 7.VII.1942, 1 ㅇ, 1 ơ (USNM, 2053570); Meech Lake (No. 051-1079), 27.VII.1951, F.I.S. 1951, ex. Malacosoma disstria Hübner, 1 \& (CNCI); Mt. Albert, $1500 \mathrm{ft}$ (=460 m), 11.VIII.1975, coll. H. and M. Townes, 1 (FSCA). Saskatchewan: Attons Lake, Cut Knife, 17.VI.1940, coll. A.R. Brooks, 1 q (CNCI). Yukon: Dawson, 1.VIII.1973, 6 oิ oิ, 2 ㅇ ㅇ (AEIC); same locality, 2.VIII.1973, 1 oे (AEIC); Snag, 25.VII.1948, W.R. Mason, 1 \& (CNCI). GERMANY. Crefeld Rh., Ulbricht, C.F. Baker collection 1927, 1 q (USNM, 2053570). RUSSIA. Leningrad Prov.: Pushkin, 28.VII.1972, coll. D.R. Kasparyan, 2 우 (ZISP). Yaroslavl Prov.: Gedenovo, 8.VIII.1918, coll. A. Chestakow, "Clistopyga sauberi Brauns A. Shestakov det.”, 1 (ZISP); "N.Kokouyew Jaroslawl”, 1 (ZISP). Magadan Prov.: mouth of Tauy River, Okhotskoe See, 12.VII.1930, coll. M. Semen T.Sh., 1 đ (ZISP). UNITED STATES OF AMERICA. Alaska: Anchorage, 23.VII-3.VIII.1976, 1 q 1 ô (AEIC). California: Slave L. Alta, 17.VIII.1924, coll. O. Bryant, 1 (USNM). Idaho: Lowman, 3.VIII.1978, 1 q (AEIC); 
Nr. Stanley, 7.VIII.1978, 1 (AEIC). Michigan: Iosco Co., 15.VII.1939, 1 §ิ (AEIC); Huron Mts., 24.VII.1959, 1 क (AEIC); Gladwin Co., 28-30.VII.1959, 1 § (AEIC); Marquette Co., 14.VIII.1959, 1 \& (AEIC); Barage, 18.VIII.1959, 1 (AEIC); Dickinson Co., 28.VIII.1959, 1 ㅇ (AEIC); Crystal Falls, 8.VIII.1969, coll. H. and M. Townes, 1 o (AEIC); Iron Co., 13.VII.1970, coll. H. and M. Townes, 1 (AEIC). New Hampshire: Randolph, 6.VII.1946, 1 \& (AEIC). New York: Oswego, 17.VIII.1895, 1 đ (USNM, 2053570); Rome, 16.VI.1934, Homotype Polysphincta acute Prov., Homotype canadensis, 1 (AEIC). North Carolina: Highlands, 26.VIII.1957, coll. L.A. Kelton, 1 \& (CNCI). Oregon: Corvallis, 21.V.1978, 1 ; 28.VIII.1978, 1 \% 8.IX.1978, 2 $q$; 10.X.1980, 1 (all in AEIC). Grant Co., Aldrich Mts., 12.VIII.1987, 1 (AEIC); same locality, 18.VIII-18.IX.1987, 1 \& (AEIC). Pennsylvania: Spring Brook, 13.VIII.1944, 1 \& (AEIC). Virginia: Shenandoah National Park, Big meadow, $1300 \mathrm{~m}, 8$.VII-20. VIII.1987, 1 q (AEIC). Wyoming: Saratoga, Flight, 26.VIII.1938, 1 @ (USNM, 2053570).

Diagnosis. Clistopyga canadensis can be distinguished from all other North American species by combination of the following characters: metasoma black to brown, without white marks (Figs. 8C, 17A) and submetapleural carina complete. Female with mesopleuron, metapleuron, and propodeum entirely black to dark brown (Fig. 8C); metapleuron shiny and impunctate, sometimes with fine, sparse punctures on its posterior half (Fig. 9E), and ovipositor stout, uniformly upcurved from 0.4-0.5 to apex (Fig. 9G). Male with face entirely black, dark brown or dark red, and ventral part of gena with longitudinal conspicuous concavity (Fig. 16B).

Description. Female. Body length 5.2-7.0 mm. Fore wing length $4.0-5.7 \mathrm{~mm}$.

Head. In dorsal view, moderately narrowed behind eyes. Gena in anterior view, straightly and strongly constricted below eyes. Gena with dense and moderately conspicuous punctures, in dorsal view 0.4 times as long as eye. Frons shiny, transversely striate and strongly punctate. Posterior ocellus separated from eye by 1.4 times its maximum diameter. Distance between posterior ocelli 1.1-1.4 times maximum diameter of posterior ocellus. Occipital carina strong, not forming a flange dorsomedially. Occiput in dorsal view slightly concave. Face strongly and densely punctate; distance between punctures less than twice length of diameter of puncture. Clypeal suture rounded. Clypeus 1.8-1.9 times as broad as medially long, weakly convex in dorsal half and flat in ventral half. Malar space with granulate strip between eye and mandible, 0.6-0.8 times as long as basal mandibular width. Antenna with 20-22 flagellomeres, first 4.5-4.7 times as long as wide.

Mesosoma. Pronotum mostly smooth and shiny, punctate on posterior dorsal and lateral parts. Epomia strong and long. Median lobe of mesoscutum densely and strongly punctate on granulate background, especially anteriorly; lateral lobes and median lobe posteriorly, densely and strongly punctate on rugulose to smooth and shiny background. Notauli deep anteriorly, reaching about 0.6 length of mesoscutum. Mesopleuron shiny, mostly smooth, with fine and moderately dense setiferous puctures in ventral and anterior part (Fig. 9E). Epicnemial carina strong, its dorsal end slightly curved backward, ending moderately far to anterior margin of mesopleuron at level of centre of pronotum. Metapleuron smooth and shiny, sometimes with fine, sparse setiferous punctures posteriorly, 1.6 times as long as deep (Fig. 9E). Submetapleural carina strong and complete, not raised (Fig. 9E). Propodeum shiny, dorsolaterally with strong and dense punctures on rugulose to granulate background, centrally and posteriorly granulate to smooth; lateromedian longitudinal carina usually present anteriorly; propodeum in dorsal view as long as medially wide. Propodeal spiracle situated immediately above groove separating propodeum and metapleuron. Hind leg with femur as long as tibia. Fore wing with vein $\mathrm{Cu}$ - $a$ slightly distal to vein $R s \& M$; Vein $2 r s-m$ about half length of abscissa of $M$ between $2 r s-m$ and $2 m-c u$. Abscissa of $C u 1$ between $1 m-c u$ and $C u 1 a$ about twice as long as $C u 1 b$. Hind wing with vein $C u-a$ 0.4-0.7 times as long as abscissa of $M+C u$ between $M$ and $C u 1$. Vein $C u 1$ weakly pigmented.

Metasoma. First tergite $0.7-0.9$ times as long as posteriorly broad, from granulate to smooth, dorsolaterally rugulose punctate; spiracle near its basal 0.3. Lateromedian longitudinal carina strong and reaching almost posterior end of tergite, lateral longitudinal carinae strong and complete. 
Sternite 1 extending back about 0.4 of length of tergite. Second tergite $0.7-0.8$ times as long as posteriorly broad, central region very strongly and densely punctate. Ovipositor stout, weakly and evenly up-curved in apical half (Figs. 8C, 9G), matt, 1.6-1.7 times as long as hind tibia. Ovipositor sheath 1.2-1.4 times as long as hind tibia, with short, dense denticles on basal ventral margin, with numerous oblique black setae that are about as long as width of sheath.

Colouration. Body black to brown (Fig. 8C). Antenna orange. Head black with dorsal part of gena usually with two small yellow spots at level of posterior ocellus. Face red. Clypeus orange with dorsal margin slightly brown. Basal half of mandible red, apical half black, teeth orangebrown. Palpi, tegula, and posterior corner of pronotum white. Pterostigma pale brown. Legs mainly orange, fore coxa and trochanters yellow, mid tibia with white band centrally, hind tibia brown basally and apically, with central white band, and mid tarsomeres and hind tarsomeres brown, paler yellow basally. Ovipositor light brown. Ovipositor sheath brown.

Male. Body length $5.8 \mathrm{~mm}$. Fore wing length 3.9-4.9 mm. Similar to female in structure and colouration (Fig. 17A), but differs in following characters. Gena smooth with fine setiferous punctures, in dorsal view 0.3 times as long as eye. Posterior ocellus separated from eye by 1.1-1.3 times its maximum diameter. Distance between posterior ocelli 1.1-1.2 times maximum diameter of posterior ocellus. Clypeus twice as broad as medially long. Malar space $0.6-0.7$ times as long as basal mandibular width; gena below eyes with strong concavity (Fig. 16B). Antenna evenly tapered towards apex, with 19-21 flagellomeres. Pronotum smooth or slightly granulate, with puctures weaker in posterior dorsal and lateral part. Propodeum transversely strigose on granulate background. Hind leg with femur 0.9 times as long as tibia. Abscissa of $C u 1$ between $1 m-c u$ and $C u 1 a$ 1.5-1.6 times as long as $C u 1 b$. First tergite $0.7-0.9$ times as long as posteriorly broad.

Colouration. Similar to female (Fig. 17A), but with antenna entirely brown, head dark brown without yellow stripes at level of posterior ocellus. Basal half of mandible orange, apical half black, teeth orange-brown. Fore leg yellow.
Host. Townes and Townes (1960) recorded, with reservations, a specimen supposedly reared from Malacosoma disstria Hübner (Lepidoptera: Lasiocampidae). We have seen this specimen labelled "ex. Malacosoma disstria" but there are no associated host remains and, given that all reliable host records for Clistopyga are from spider egg-sacs (and possibly adult spiders), this record is questionable.

Distribution. Holarctic. Nearctic: Canada (Alberta, British Columbia, Manitoba, New Brunswick, Newfoundland and Labrador, Northwest Territories, Nova Scotia, Ontario, Prince Edward Island, Québec, Saskatchewan, Yukon Territory), United States of America (Alaska, California, Idaho, Maine, Massachusetts, Michigan, Minnesota, Montana, New Hampshire, New York, North Carolina, Oregon, Pennsylvania, Virginia, Wyoming). Palaearctic: Austria, Belarus, Belgium, former Czechoslovakia, Germany, Hungary, Latvia, Poland, Romania, Russia, and United Kingdom.

Remarks. Clistopyga sauberi was synonymised with C. canadensis by Aubert (1967, 1969). Fitton et al. (1988) considered C. sauberi to be a distinct species but did not provide any morphological differences to separate the species. In their work they only said: "However, comparison of the limited materials from Europe and North America in the BMNH collection suggests that it is better to use the European name for the European specimens, pending a more comprehensive study". Unfortunately we have not seen the lectotype of $C$. sauberi, but the study of material labelled as $C$. sauberi and C. canadensis from Belarus, Germany, and Russia, did not reveal to us any morphological differences with the numerous Nearctic specimens of $C$. canadensis we have studied (including the lectotype). Therefore, we maintain $C$. sauberi as a synonym of C. canadensis as proposed (Aubert 1967, 1969).

\section{Clistopyga chaconi Gauld, 1991}

(Figs. 3B, 4A, 4C, 14A)

Clistopyga chaconi Gauld, 1991: 295. Holotype: + , Costa Rica (INBio).

Material examined. Holotype female, COSTA RICA. Guanacaste Prov., Guanacaste 
National Park, Santa Rosa Sector, Bosque San Emilio, 300 m, XI-XII.1985, coll. D. Janzen and I.D. Gauld (INBio). Paratype. COSTA RICA. Guanacaste: Same locality and collectors as holotype, I.II.1986-1987, 1 (INBio). Non-type material. MEXICO. Yucatán: Ría Lagartos, Savannah, 23.XII.2008, coll. A. González, 1 §ิ (CER-UADY); Punto puut, tropical forest, 23-25.II.2007, 1 ㅇ (CER-UADY).

Diagnosis. Clistopyga chaconi is a very distinctive species that can be distinguished from all other North American species by combination of the following characters: occipital carina complete, strong and raised in a flange-like protuberance (Fig. 4A), submetapleural carina complete and strongly raised (Fig. 4C), and metasoma with conspicuous white marks (Figs. 3B, 14A).

Description. Female. Body length $10.0 \mathrm{~mm}$. Fore wing length $6.4 \mathrm{~mm}$.

Head. In dorsal view, strongly narrowed behind eyes. Gena in anterior view slightly rounded and strongly constricted below eyes. Gena with very few isolate fine setiferous punctures, in dorsal view 0.3 times as long as eye. Frons smooth and shiny. Posterior ocellus separated from eye by $0.8-0.9$ times its maximum diameter. Distance between posterior ocelli $0.8-0.9$ times maximum diameter of posterior ocellus. Occipital carina strong, forming a flange dorsomedially (Fig. 4A). Occiput in dorsal view flat medially. Face strongly and densely punctate; distance between punctures less than twice length of diameter of puncture. Clypeal suture very slightly rounded. Clypeus 1.9-2.2 times as broad as medially long, quite strongly convex. Malar space with deep and narrow sulcus between eye and mandible, 0.9-1.0 times as long as basal mandibular width. Antenna with 32 flagellomeres, first flagellomere about 4.1 times as long as wide.

Mesosoma. Pronotum mostly smooth and shiny, finely punctate in dorsal part (Fig. 4A). Epomia absent (Fig. 4A). Mesoscutum entirely smooth and shiny. Notauli very weak, extending from anterolateral margin of mesoscutum to about 0.4 times its length. Mesopleuron shiny, mostly smooth with moderately strong and sparse setiferous punctures except in dorsal posterior part; sometimes ventrally slightly granulate. Epicnemial carina strong, with dorsal end straight or slightly curved backward, ending far from anterior margin of mesopleuron above level of centre of pronotum. Metapleuron smooth and shiny, sometimes with sparse fine punctures, 1.5 times as long as deep (Fig. 4C). Submetapleural carina strong and complete, strongly raised and extending back to insertion of hind coxa (Fig. 4C). Propodeum smooth and shiny, with very sparse and fine punctures laterally, without lateromedian longitudinal carina; in dorsal view 0.9 times as long as medially wide. Propodeal spiracle situated immediately above groove separating propodeum and metapleuron. Hind leg with femur $0.8-0.9$ as long as tibia. Fore wing with vein $C u-a$ opposite $R s \& M$. Vein $2 r s-m$ shorter than half length of abscissa of $M$ between $2 r s-m$ and $2 m-c u$. Abscissa of $C u 1$ between $1 m-c u$ and $C u 1 a$ about 1.7 times as long as $C u 1 b$. Hind wing with vein $C u-a$ virtually confluent with abscissa of $M+C u$ between $M$ and $C u 1$. Vein $C u 1$ weakly pigmented.

Metasoma. First tergite 1.7-1.8 times as long as posteriorly broad, smooth and shiny, with very fine, sparse setiferous punctures laterally and posteriorly; spiracle near its basal 0.3. Lateromedian longitudinal carina strong, reaching about 0.2 length of tergite, lateral longitudinal carina absent. Sternite 1 extending back about 0.7 of length of tergite. Second tergite 1.2 times as long as posteriorly broad, central region with large, shallow, sparse puctures. Ovipositor slender, from the centre evenly up-curved, matt, 1.4-1.5 times as long as hind tibia (Fig. 3B). Ovipositor sheath 1.2-1.3 times as long as hind tibia, without denticles at basal ventral margin, hairs conspicuously longer than sheath width.

Colouration. Body primarily orange, black and white (Fig. 3B). Antenna brown with scape, pedicel, and basal flagellomeres in ventral part, white. Head black with ventral part of gena and inner eye orbit white. Face, palpi, clypeus, and basal half of mandible (teeth black) white. Propleuron white, dorsally infuscate. Pronotum mostly orange with anterior part and posterodorsal margin yellow. Mesopleuron mostly yellow with a large posterodorsal orange mark. Metapleuron white with ventral margin black. Mesoscutum mostly orange. Prescutellar groove orange. Scutellum yellow, centrally orange. Metanotum orange with postscutellum white. Propodeum mostly white with anterior margin, 
pleural groove and a broad central longitudinal stripe, black. Tegula and base of wings white. Wings very weakly infumate, pterostigma black brown. Fore legs and mid legs predominantly white with femora and tibiae black striped dorsally. Hind legs white with coxa anteriorly and posteriorly, trochanter proximally, femur proximally and subdistally, and tibia proximally and distally black, tarsomeres with distal apices black. Metasoma black with anterolateral corners and posterior margins of all tergites white. Ovipositor light brown. Ovipositor sheath black.

Male. Similar to female. Body length $10.0 \mathrm{~mm}$. Fore wing length $5.8 \mathrm{~mm}$. Metapleuron 1.7 times as long as deep.

Colouration. Similar in colour to female (Fig. 14A).

Host. Unknown.

Distribution. Neotropical: Costa Rica, southeastern Mexico (Yucatán).

\section{Clistopyga fernandezi Gauld, 1991}

(Figs. 3F, 4F, 14D)

Clistopyga fernandezi Gauld, 1991: 298. Holotype: q, Costa Rica (INBio).

Material examined. Holotype female, COSTA RICA. Guanacaste Prov., Guanacaste National Park, Estación Cacao (Mengo), 1100 m, VI.1988, coll. D. Janzen and I.D. Gauld (INBio). Paratypes. COSTA RICA. Guanacaste: Guanacaste National Park, Estación Mengo, Volcano Cacao, 1400 m, X-XII.1988, 2 ㅇ (INBio); same locality, $1100 \mathrm{~m}$, III-XII.1987-89, 6 우 (INBio); same locality, VIII.1989, 1 $q$; same locality, $1000 \mathrm{~m}$, VI.1989, 1 \%; same data, III-V.1989, 1 q (AEIC). Non-type material.

MEXICO. Tamaulipas: Cd. Victoria, Los Troncones (park), 18.III.2008, coll. A.I. Khalaim, 2 đิ ơ (UAT). Gómez Farías, Alta Cima, Malaise trap, coll. S. Hernández A.: 27.III-3.IV.1999, 1 q; 24.IV-1.V.1999, 1 \%; 15-22.V.1999, 1 oे; 19-26.VI.1999, 1 oे, 1 q; 21-28.VIII.1999, 1 §; 4-11.XI.2000, coll. D.R. Kasparyan, 1 q (all in UAT). Río El Cimarrón, Villa de Casas, 28.XII.1986, coll. E. Ruíz C., 1 ㅇ (UAT).

Diagnosis. Clistopyga fernandezi can be distinguished from all other North American species by combination of the following characters: submetapleural carina entirely absent or present as a vestige on anterior third of metapleuron (Fig. 4F), not raised, and occipital carina weak, not forming a flange dorsomedially. Female with lateral lobes of mesoscutum red, peripherally black; hind femur white, proximally and dorsally light brown, usually with long light brown stripe on posterolateral side; metasoma with tergite 2 and following red with posterior margins usually narrowly banded with white, tergite 2 also with a pair of small posterolateral black marks (Fig. 3F); central area of tergites finely and quite densely punctate on smooth and shiny background, distance between punctures at most equal to diameter of puncture; ovipositor sheath 1.7-1.8 times as long as hind tibia (Fig. 3F). Male with mesoscutum almost entirely red or tinged with orange, sometimes with white stripes; mesopleuron mostly orange or white with light brownish-orange marks; metapleuron extensively white; propodeum laterally extensively white (Fig. 14D); metasoma black or brown, with tergite 1 laterally, posterior margins of all tergites centrally and anterolateral corners of tergites 2-4(5) white; ventral part of gena with conspicuous longitudinal or oblique concavity.

Description. Female. Body length 9.4-11.1 mm. Fore wing length 5.0-7.0 mm.

Head. In dorsal view, strongly narrowed behind eyes. Gena in anterior view, straightly and moderately constricted below eyes. Gena finely and sparsely punctate, in dorsal view $0.2-0.3$ times as long as eye. Frons smooth and shiny. Posterior ocellus separated from eye by 0.9-1.0 times its own maximum diameter. Distance between posterior ocelli 0.7 times maximum diameter of posterior ocellus Occipital carina weak, not forming a flange dorsomedially. Occiput in dorsal view very slightly concave medially. Face finely and very sparsely punctate; distance between punctures more than twice length of diameter of puncture. Clypeal suture slightly rounded. Clypeus, 1.8-1.9 times as broad as medially long, quite strongly convex, ventral part almost flat. Malar space with deep and narrow sulcus between eye and mandible, 0.8 times as long as basal mandibular width. Antenna with 29-32 flagellomeres, first flagellomere 8.0 times as long as wide. 
Mesosoma. Pronotum smooth and shiny. Epomia discernible as a strong short tubercle. Mesoscutum virtually smooth and shiny, median lobe anteriorly with very fine and sparse setiferous punctures. Notauli deep, extending from anterolateral margin of mesoscutum to $0.4-0.5$ its length. Mesopleuron shiny, smooth, with very fine and sparse setiferous punctures in ventral part. Epicnemial carina strong, its dorsal end weakly curved backward, ending so far from anterior margin of mesopleuron at level of centre of pronotum. Metapleuron smooth and shiny, 2.5 times as long as deep (Fig. 4F). Submetapleural carina absent or discernible as vestige from anterior 0.2-0.6 length of metapleuron (Fig. 4F). Propodeum smooth and shiny, with very sparse and fine setiferous punctures laterally, without median longitudinal carina; in dorsal view moderately long, 1.3 times as long as medially wide. Propodeal spiracle on groove separating propodeum and metapleuron. Hind leg with femur $1.0-1.1$ as long as tibia. Fore wing with vein $C u-a$ opposite vein $R s \& M$. Vein $2 r s-m$ usually longer than half length of abscissa of $M$ between $2 r s-m$ and $2 m-c u$. Abscissa of $C u 1$ between $1 m-c u$ and $C u 1 a$ about 1.5 times as long as $C u 1 b$. Hind wing with vein $C u-a 0.5$ times as long as abscissa of $M+C u$ between $M$ and $C u 1$. Vein $C u 1$ weakly pigmented.

Metasoma. First tergite 1.8 times as long as posteriorly broad, smooth and shiny, with very fine, sparse setiferous punctures laterally and posteriorly; spiracle near its basal 0.3. Lateromedian and lateral longitudinal carinae absent. Sternite 1 extending back about half length of tergite. Second tergite 1.1 times as long as posteriorly broad, central finely but quite closely punctate. Ovipositor slender, at distal 0.3 evenly up-curved, matt, 1.8-1.9 times as long as hind tibia (Fig. 3F). Ovipositor sheath $1.7-1.8$ as long as hind tibia, without denticles on basal ventral margin, setae slightly longer than sheath width.

Colouration. Body mostly black, white and orange (Fig. 3F). Antenna blackish brown, scape and pedicel white ventrally, basal flagellomeres pale beneath. Head white with occiput, ocellar area and frons centrally black. Propleuron white. Pronotum bicoloured, mostly white with a wide black band medially. Mesopleuron mostly white with ventral posterior corner slightly, area around episternal scrobe and stripe below subalar prominence black. Metapleuron white with margin black, including the groove separating propodeum and metapleuron. Mesoscutum red, peripherally black with a pair of longitudinal white stripes interrupted by notauli. Scutellum white. Metanotum black with postscutellum white. Propodeum white with a broad black stripe mediodorsally. Tegula and base of wing white. Wings weakly infumate, pterostigma brown. Fore and mid leg mainly white with femora and tibia dorsally brown and tarsomeres apically infuscate. Hind leg white, with coxa anteriorly and posteriorly, trochanter basally, trochantellus apically, femur basally, dorso-anteriorly and posteriorly, tibia broadly basally and apically light brown. Metasoma with tergite 1 black to red, with lateral and posterior margins marked white, tergites 2 and following entirely red, with posterior margins usually narrowly banded with white, tergite 2 and 3 also with a pair of small posterolateral black marks. Ovipositor light brown. Ovipositor sheath black.

Male. Conspicuously smaller than female. Body length 4.1-7.1 mm. Fore wing length $2.7-4.1 \mathrm{~mm}$ Antenna with 24 flagellomeres. Metapleuron 1.9-2.1 times as long as deep. Propodeum 1.2-1.3 times as long as medially wide.

Colouration. Similar in colour to female (Fig. 14D). Dorsal genal orbit black. Mesopleuron mostly orange or white with light brown or orange marks. Metasoma with tergites 2 and following with anterolateral corners and posterior margins centrally white. Some males have mesoscutum black with white stripes, but always tinged with orange on lateral lobes. Smaller males tend to have head and mesosoma with dark marks more brown than black.

Host. Unknown.

Distribution. Neotropical: Costa Rica. Nearctic: Mexico (Tamaulipas).

\section{Clistopyga henryi Gauld, 1991}

(Figs. 3A, 14C)

Clistopyga henryi Gauld, 1991: 301. Holotype: , Costa Rica (INBio).

Material examined. Holotype female, COSTA RICA. Guanacaste Prov., Guanacaste 
National Park, Estación Cacao (Mengo), 1100 m, VI.1988, coll. P. Mitchell and I.D. Gauld (INBio). Paratypes. COSTA RICA. Guanacaste: same locality as holotype, V-IX.1987-89, 6 우 (INBio); same locality holotype, $1000 \mathrm{~m}$, VII.1988, 1 \& (AEIC); same park, Estación Pitilla, 680 m, IV.1989, 1 ㅇ (INBio); same park, Estación Maritza, Volcano Orosi, 5.VIII.1989, 1 đิ (AEIC); same park, Casa Maritza, $600 \mathrm{~m}$, VI.1989, 2 우 (INBio); same locality, V-XII.1989, 1 ㅇ (AEIC). Non-type material. COSTA RICA. Guanacaste: Guanacaste National Park, Estación Maritza, Volcano Orosi, $560 \mathrm{~m}$, I-III.1990, coll. I.D. Gauld and P. Mitchell, 1 q (UAT). MEXICO. Tamaulipas: Gómez Farías, Canindo, Malaise trap, 21-22.VII.1994, coll. J.B. Woolley, 1 (UAT). Gómez Farías, Alta Cimas, Malaise trap, 10-17.VIII.1999, coll. S. Hernández A., 1 q (UAT). Oaxaca: Santiago Comaltepec, La Esperanza, N $17.02661^{\circ}$, W 96.36.950, $1600 \mathrm{~m}$, Malaise trap, 1.VII-12.VIII.2008, coll. A. López García, 2 $q$ (UNAM).

Diagnosis. Female of $C$. henryi is very distinctive as it is the unique North American species with ovipositor long and straight, 2.7-2.8 times as long as hind tibia. Male can be distinguished from all other North American males by combination of the following characters: mesoscutum almost entirely red or orange, without white stripes; mesopleuron orange or red; metapleuron extensively red; propodeum almost entirely black or brown darkened, rarely with two small posterolateral white marks; metasoma almost entirely black with small posterolateral white marks before posterior margin (14C); submetapleural carina entirely absent or as a vestige on anterior third of metapleuron and ventral part of gena with conspicuous longitudinal or oblique concavity.

Description. Female. Body length $9.1-11.0 \mathrm{~mm}$. Fore wing length $6.0-7.3 \mathrm{~mm}$.

Head. In dorsal view, strongly narrowed behind eyes. Gena in anterior view, straightly and moderately constricted below eyes. Gena finely and sparsely punctate, in dorsal view 0.17 times as long as eye. Frons shiny, with very fine (sometimes indistinct) punctures. Posterior ocellus separated from eye by $0.8-0.9$ times its own maximum diameter. Distance between posterior ocelli 0.8 times maximum diameter of posterior ocellus. Occipital carina strong very weakly raised laterally but not forming a flange dorsomedially. Occiput in dorsal view moderately concave medially. Face finely and very sparsely punctate; distance between punctures more than twice length of diameter of puncture. Clypeal suture slightly rounded. Clypeus 1.7-1.9 times as broad as medially long, weakly convex in dorsal half, flat in ventral half. Malar space with a granulate strip between eye and mandible, about 0.5 as long as basal width of mandible. Antenna with 26 flagellomeres, first about 8.0 times as long as wide.

Mesosoma. Pronotum smooth and shiny. Epomia strong and short. Mesoscutum virtually smooth and shiny. Notauli deep, extending from anterolateral margin of mesoscutum to $0.4-0.5$ its length. Mesopleuron shiny, smooth, with very fine and sparse setiferous punctures in ventral and anterior part. Epicnemial carina weak, dorsally almost straight, ending far from anterior margin of mesopleuron, below level of centre of pronotum. Metapleuron smooth and shiny, posterior half with very fine and sparse punctures, 1.9 times as long as deep. Submetapleural carina absent or weakly present anteriorly, rarely extending to about centre of metapleuron. Propodeum smooth and shiny, with very sparse and inconspicuous setiferous punctures basally and laterally, without lateromedian longitudinal carina; in dorsal view 1.0-1.1 times as long as medially wide. Propodeal spiracle situated immediately above level of groove separating propodeum and metapleuron. Hind leg with femur $0.8-0.9$ as long as tibia. Fore wing with vein $C u-a$ opposite vein $R s \& M$. Vein $2 r s-m$ shorter than half length of abscissa of $M$ between $2 r s-m$ and $2 m-c u$. Abscissa of $C u 1$ between $1 m-c u$ and $C u 1 a$ about 1.6 times as long as $C u 1 b$. Hind wing with vein $C u-a 0.3-0.6$ times as long as abscissa of $M+C u$ between $M$ and $C u 1$. Vein $C u 1$ weakly pigmented.

Metasoma. First tergite 1.3-1.4 times as long as posteriorly broad, more or less, entirely smooth and shiny, without distinct punctures; spiracle near its basal 0.4. Lateromedian longitudinal carinae strong, reaching about $0.2-0.3$ length of tergite, lateral longitudinal carina strong and complete. Sternite 1 extending back to about half the length of tergite. Second tergite about as long as posteriorly broad, central area 
smooth and glabrous, virtually impunctate. Ovipositor shiny, slender, straight, 2.7-2.8 times as long as hind tibia (Fig. 3A). Ovipositor sheath 2.3-2.5 times as long as hind tibia, basally without denticles on ventral side, with numerous oblique black setae that are longer than sheath width.

Colouration. Body orange, black, and white (Fig. 3A). Antenna brown, paler yellowish brown proximally, scape dorsally black and ventrally white. Head black. Orbits, face, clypeus, and mouthparts entirely white. Propleuron white. Pronotum orange with anterior and dorsal anterior margin, and posterior corner white. Mesopleuron, metapleuron, mesoscutum, scutellum basally, metanotum, and propodeum orange. Scutellum distally and postscutellum white. Tegula and mesepimeron white. Wings hyaline, pterostigma brown, anteriorly black. Legs white, the coxae, trochanters, femora, and tibiae dorsally and ventrally striped with black or brown; hind tibia basally and distally brown, tarsi infuscate. Metasoma black with posterior margins broadly white marked, anterior part of tergite 1 red. Ovipositor light brown. Ovipositor sheath black.

Male. Body length $6.0-8.0 \mathrm{~mm}$. Fore wing length $4.0-7.0 \mathrm{~mm}$. Similar to female in structure and colouration except antenna with 23 flagellomeres. Distance between posterior ocelli 1.0 times maximum diameter of posterior ocellus. Ventral part of gena with strong concavity. Clypeus 1.2 times as broad as medially long. Tergite 1 with median longitudinal carina strong, reaching about 0.7 length of tergite.

Colouration. Similar in colour to female (Fig. 14C), except: genal orbit black, pronotum black centrally with dorsal and anterior margins entirely white, scutellum and postscutellum white marked, propodeum black or dark brown, rarely with two small posterolateral white marks and metasoma entirely black with posterolateral white marks before posterior margins of tergites 2-5. Hind femur also brown striped anteriorly.

Variation: Two smallest females of Costa Rica have the pronotum black centrally, like the male (Gauld 1991).

Host. Unknown.

Distribution. Neotropical: Costa Rica, Mexico (Oaxaca). Nearctic: Mexico (Tamaulipas).

\section{Clistopyga juliana Bordera and González-Moreno, new species}

\author{
(Figs. 10B, 11C, 11D)
}

Material examined. Holotype female, UNITED STATES OF AMERICA. California, Julian, 30.V.1974, coll. H. and M. Townes (AEIC). Paratypes. UNITED STATES OF AMERICA. California: Lake Wohlford, coll. H. and M. Townes: 21.IV.1974, 1 \%; 24.IV.1974, 1 \%; 27.IV.1974, 1 \%; 29.IV.1974, 1 울.V.1974, 2 우 (all in AEIC); Potrero, S.D. Co., 14.IV.1974, coll. H. and M. Townes, 1 (AEIC); Julian, 12.V.1974, coll. H. and M. Townes, G. and C. Townes, 1 \& (FSCA); Santa Ana Orange C., 27.IV.1943, collected from Diamant trap in peach, C. 1/09/y Collector, Cal. Dept. Agr. No. 43D399, 1 \& (USNM, 2053570).

Etymology. The specific name refers to Julian (California, United States of America), the locality where the holotype was collected.

Diagnosis. Female of $C$. juliana can be distinguished from all other females of North American species by combination of the following characters: metasoma from orange-brown to red or black, without white marks (Fig. 10B); ovipositor slender, tapered from base to apex, abruptly up-curved at apical 0.3 (Fig. 11D), light brown; submetapleural carina absent or weakly present anteriorly (Fig. 11C); metapleuron 2.5-2.6 times as long as deep (Fig. 11C); propodeum 1.3-1.4 times as long as wide at spiracle level.

Description. Female. Body length 5.5-7.6 mm. Fore wing length $3.8-5.3 \mathrm{~mm}$.

Head. In dorsal view, moderately narrowed behind eyes. Gena in anterior view, straightly and moderately constricted below eyes. Gena with very sparse and fine setiferous punctures, in dorsal view 0.3 times as long as eye. Frons shiny, with some fine punctures. Posterior ocellus separated from eye by 1.1-1.3 times its maximum diameter. Distance between posterior ocelli 1.1 times maximum diameter of posterior ocellus. Occipital carina strong, not forming a flange dorsomedially. Occiput in dorsal view moderately concave. Face finely and sparsely punctate; distance between punctures more than twice length of diameter of puncture. Clypeal suture straight. Clypeus shiny, with very sparse setiferous punctures, 1.9-2.0 times as broad as 
medially long. Malar space with a granulate strip between eye and mandible, 1.2-1.4 times as long as basal mandibular width. Antenna with 24-25 flagellomeres, first 5.3-5.5 times as long as wide. Mesosoma. Pronotum mostly smooth and shiny, with few short striae in ventral posterior part. Epomia weak and very short. Median lobe of mesoscutum shiny, weakly rugose, densely and finely punctate, lateral lobes more sparsely punctate. Notauli deep, extending from anterolateral margin of mesoscutum to about 0.7 times its length. Mesopleuron shiny, mostly smooth, with very sparse and fine setiferous punctures except in dorsal posterior part (Fig. 11C). Epicnemial carina strong, straight (Fig. 11C), dorsal end so far of anterior margin of mesopleuron at level of centre of pronotum. Metapleuron smooth and shiny, finely and sparsely punctate in posterior part, 2.5-2.6 as long as deep (Fig. 11C). Submetapleural carina virtually absent or weakly present anteriorly (Fig. 11C). Propodeum shiny, with sparse and moderately strong punctures in anterior half, medially granulate and transversely strigose, tending to be smooth posteriorly, without lateromedian longitudinal carina; in dorsal view 1.3-1.4 times as long as medially wide. Propodeal spiracle situated immediately above the groove separating propodeum and metapleuron. Hind leg with femur 1.0-1.1 times as long as tibia. Fore wing with vein $C u-a$ opposite vein $R s \& M$. Vein $2 r s-m$ usually shorter than half length of abscissa of $M$ between $2 r s-m$ and $2 m-c u$. Abscissa of $C u 1$ between $1 m-c u$ and $C u 1 a$ 1.4-1.7 times as long as $C u 1 b$. Hind wing with vein $\mathrm{Cu}-\mathrm{a}$ 0.3-0.4 times as long as abscissa of $M+C u$ between $M$ and $C u 1$. Vein $C u 1$ absent.

Metasoma. First tergite 1.3-1.5 times as long as posteriorly broad, smooth, with fine, sparse setiferous punctures; spiracle near its basal 0.4. Lateromedian longitudinal carina weak, reaching basal third of tergite, lateral longitudinal carina absent. Sternite 1 extending about 0.4 length of tergite. Second tergite 1.0-1.1 times as long as posteriorly broad, central region strongly and densely punctate. Ovipositor slender, strongly upcurved in apical 0.3, matt, 1.7 times as long as hind tibia (Fig. 11D). Ovipositor sheath 1.4-1.5 times as long as hind tibia, without denticles on ventral margin, with numerous oblique black setae that are usually longer than width of sheath.
Colouration. Body primarily orange and black (Fig. 10B). Antenna brown, scape and pedicel yellow ventrally, first flagellomere pale beneath. Head black with ventral part of gena with yellow stripe near mandible. Frons black. Inner eye orbit yellow, sometimes sligthly interupted opposite antennal sockets. Face white with three longitudinal brown stripes, sometimes almost entirely brown. Clypeus and basal half of mandible yellow, apical half of mandible black, teeth orange. Palpi yellow. Mesosoma orange and black. Propleuron black with ventral margin white. Pronotum black with yellow band dorsally on lateral sides. Mesopleuron mostly orange with dorsal part black and subtegular crest yellow. Metapleuron entirely orange with anterior and ventral margins black. Mesoscutum orange, peripherally and on notauli brown; scutellum orange with posterior margin yellow. Metanotum entirely black with dorsal margin yellow. Postscutellum yellow, anteriorly brown. Propodeum centrally brownish black and sublaterally reddish orange. Tegula and base of wings white. Pterostigma yellow. Fore legs and mid legs mainly yellow, trochanters, femora, and tibiae dorsally brown, tarsomeres basally brownish white. Hind leg with coxa orange, trochanters and femur orange with white stripe dorsally, tibia yellow, brown basally and apically, tarsomeres brown, tarsomeres $1-3$ basally yellow. Tergite 1 black. Metasoma behind tergite 1 entirely brown, tergites 2 and 3 with black hue posterolaterally. Ovipositor light brown. Ovipositor sheath black.

Male. Unknown.

Host. Unknown.

Distribution. Nearctic: United States of America (California).

\section{Clistopyga maculifrons Cushman, 1922}

(Figs. 8B, 9B, 9D, 15A, 16A)

Clistopyga maculifrons Cushman, 1922: 10. Holotype: $q$, United States of America (USNM).

Material examined. Holotype female, UNITED STATES OF AMERICA. Texas, Belfrage, date and collector unknown, 1 (USNM, 20058). 
Non-type material. CANADA. Ontario: Aylmer West, 17-20.VII.1972, Malaise trap, 1 \& (CNCI); Chatham, 14.VI.1929, I.E. Thomas, 1 \& (CNCI); Rondeau Prov., 31.VII.1972, Malaise trap, 1 \& (CNCI); same locality, VIII-IX.1973, Malaise trap, 1 \& (CNCI); Stittsville, 13.VII.1975, 1 \%; 19.VII.1975, coll. M. Sanborne, 1 (FSCA). UNITED STATES OF AMERICA. Michigan: Ann Arbor, Trap IV, III.1951, 1 ô (AEIC); same locality, Trap VII, 4.VI.1960, 2 우 (AEIC); same locality, Trap VI, 29-30.VI.1960, 1 \& (AEIC); same locality, Trap VIII, 13.XI.1960, 1 q (AEIC); same locality, VII.1976, coll. I.D. Gauld, 1 o (BMNH); Lake Odessa, VIII.1976, coll. I.D. Gauld, 1 đิ (BMNH); Lake Saddlebag, VII.1976, coll. I.D. Gauld, 2 đิ ô (BMNH). New York: Otsego Lake, 28.VI.1935, 1 $\delta$. North Carolina: Pisgah Mt., $4600 \mathrm{ft} \quad(=1400 \mathrm{~m})$, 2.IX.1950, 1 \& (AEIC).

Diagnosis. Clistopyga maculifrons can be distinguished from all other North American species by combination of the following characters: metasoma dark brown to black, without white marks, sometimes tergites with a narrowly white posterior margin (Figs. 8B, 15A), and submetapleural carina complete (Fig. 9B). Females with face brown with two yellow stripes below antennal insertions and yellow marks on facial orbits; mesopleuron, except in dorsoanterior part, mesosternum and metapleuron orange; propodeum entirely black or dark brown (Fig. 8B); mesosoma mostly punctate on smooth and shiny background; metasomal tergites shiny, coarsely and densely punctate on central lobes (Fig. 9D); ovipositor uniformly up-curved from $0.4-0.5$ to apex. Male with face white, sometimes black marked medially and longitudinally, and/or surrounding clypeus; ventral part of gena with deep longitudinal concavity near ventral eye margin.

Description. Female. Body length $5.8-8.0 \mathrm{~mm}$. Fore wing length $4.2-5.0 \mathrm{~mm}$.

Head. In dorsal view, moderately narrowed behind eyes. Gena in anterior view, straightly and strongly constricted below eyes. Gena finely and very densely punctate on slightly rugulose backgroud, in dorsal view 0.3-0.4 times as long as eye. Frons shiny and finely punctate. Posterior ocellus separated from eye by 1.0-1.2 times its maximum diameter. Distance between posterior ocelli 1.0-1.2 times maximum diameter of posterior ocellus. Occipital carina weak, not forming a flange dorsomedially. Occiput in dorsal view slightly concave. Face strongly and densely punctate. Distance between punctures less than twice length of diameter of puncture Clypeal suture rounded. Clypeus 1.5 times as broad as medially long, weakly convex in dorsal half and flat in ventral half. Malar space with granulate strip between eye and mandible, 1.0 times as long as basal mandibular width. Antenna with 21 flagellomeres, first about 5.0 times as long as wide.

Mesosoma. Pronotum dorsally, between epomiae, matt and densely punctate on granulate background, lateral parts below epomia smooth and shiny, punctate at posterior corner (Fig. 9B). Epomia strong and long (Fig. 9B). Anterior part of median lobe of mesoscutum densely and strongly punctate on granulate background, posterior part and lateral lobes less punctate on smooth, shiny background. Notauli deep, extending from anterolateral margin of mesoscutum to about 0.7 of its length. Mesopleuron shiny, mostly smooth, finely and sparsely punctate in ventral and anterior part (Fig. 9B). Epicnemial carina strong, its dorsal end weakly curved backward, ending moderately far from anterior margin of mesopleuron below level of centre of pronotum (Fig. 9B). Metapleuron smooth and shiny, with fine and sparse punctures in posterior part, 1.8 times as long as deep (Fig. 9B). Submetapleural carina strong and complete, not raised (Fig. 9B). Propodeum shiny, transversely strigose punctate on granulate background, medially and posteriorly less microsculptured, mediodorsally with longitudinal depression; in dorsal view about as long as medially wide. Propodeal spiracle situated immediately above groove separating propodeum and metapleuron. Hind leg with femur as long as tibia. Fore wing with vein $C u-a$ opposite vein $R s \& M$. Vein $2 r s-m$ usually shorter than half length of abscissa of $M$ between $2 r s-m$ and $2 m-c u$. Abscissa of $C u 1$ between $1 m-c u$ and $C u 1 a 1.4-1.5$ times as long as $C u 1 b$. Hind wing with vein $C u-a 0.4-0.5$ times as long as abscissa of $M+C u$ between $M$ and $C u 1$. Vein $C u 1$ weakly pigmented.

Metasoma. First tergite about as long as posteriorly broad, strongly rugose punctate on granulate background; spiracle near basal 0.4. Lateromedian longitudinal carina strong and 
reaching about 0.4 length of tergite, lateral longitudinal carinae strong and complete. Sternite 1 extending about 0.4 length of tergite. Second tergite 0.8 times as long as posteriorly broad, central region coarsely and densely punctate (Fig. 9D). Ovipositor stout, weakly and evenly up-curved in apical 0.4-0.5, matt, 1.8-2.0 times as long as hind tibia (Fig. 8B). Ovipositor sheath 1.4-1.5 times as long as hind tibia, basally with small denticles on ventral margin, with numerous long black setae which are about as long as sheath width.

Colouration. Body mostly dark brown with orange (Fig. 8B). Antenna orange, scape brown, pedicel and basal flagellomeres yellow beneath. Head black with dorsal part of gena with two small white stripes at level of posterior ocellus. Face brown with two yellow stripes below antennal insertion and yellow marks on facial orbits. Clypeus mostly yellow to orange with dorsal part brown. Mandible orange, centrally black, teeth orange. Palpi white. Mesosoma orange and black. Pronotum brown with very thin white stripe on dorsal margin. Propleuron, mesoscutum and metanotum entirely brown to black; scutellum dark brown with posterior margin brown. Mesopleuron mostly orange, its dorsal part and epicnemium dark brown. Metapleuron entirely orange with submetapleural carina brown. Propodeum dark brown. Tegula and base of wings white. Pterostigma pale brown. Legs mainly orange with fore coxa and trochanters white; mid coxae and hind coxae and femora orange, trochanters white; mid and tibiae hind tibiae brownish subbasally and apically, white basally and centrally, tarsomeres brown apically, white basally. Metasoma brown, tergites 2-4 posteriorly with small black marks. Ovipositor light brown. Ovipositor sheath brown.

Male. Body length $6.4-7.0 \mathrm{~mm}$. Fore wing length $3.6-4.7 \mathrm{~mm}$. Similar to female in structure and colouration, but differs in characters given below. Antenna filiform, with 19-20 flagellomeres, first about 3.8 times as long as wide. Face evenly convex, with strong and dense punctures (Fig. 16A). Malar space 0.6-0.7 times as long as basal mandibular width. Gena below eyes with strong concavity (Fig. 16A). Frons finely punctate, medially striate. Clypeus twice as broad as medially long (Fig. 16A). Propodeum less sculptured than in female. First tergite 1.2 times as long as posteriorly broad, with median longitudinal carinae strong, reaching about 0.8 length of tergite. Second tergite 1.0-1.1 times as long as posteriorly broad. Hind leg with femur 0.8 as long as tibia.

Colouration. Body mostly dark brown with orange (Fig. 15A). Antenna brown, red beneath. Face yellow, with very small brown spot and brown area surrounding clypeus. Genal concavity yellow. Clypeus white. Basal half of mandible yellow, apical half black, teeth orange. Propleuron brown with ventral margin white. Mesoscutum brown, sometimes with two yellow notaular stripes. Scutellum orange to orangebrown, with white posterior margin. Fore legs and mid legs mainly white. Hind leg with coxa and femur orange, trochanters white.

Host. Unknown.

Distribution. Nearctic: Canada (Ontario), United States of America (Massachusetts, Michigan, Minnesota, New York, North Carolina, Ohio, Texas, Wisconsin). First record from Canada.

\section{Clistopyga manni Cushman, 1922}

(Figs. 10C, 11E, 12A)

Clistopyga manni Cushman, 1922: 12. Holotype: $q$, United States of America (USNM).

Material examined. Holotype female, UNITED STATES OF AMERICA. California, "Pacific Grove June. Cal. W.H. Mann.Typo Cush" (USNM). Non-type material. MEXICO. Chiapas: San Cristobal de Las Casas, $7200 \mathrm{ft}$ (=2200 m), 18-25.VI.1969, Malaise trap, 1 우 (CNCI). Oaxaca: Monte Albán, Ruins, 3.VIII.1964, coll. H.V. Daly, 1 q (EMEC). UNITED STATES OF AMERICA. Arizona: Ramsey cyn., $6000 \mathrm{ft} \quad(=1830 \mathrm{~m}), \quad 15 \mathrm{ml} . \mathrm{S}$. Sierra Vista, Huachuca Mts., 23.X.1967, coll. Sternitzky, 1 q (CNCI). California: Carmel, 7.XI.1926, 1 ㅇ (AEIC); Dunlap Camground, 18 ml.E., Mendocino County, 20.VIII.1965, coll. F. Bragg, 1 \& (CNCI); Fish Canyon, "1-26-1950, 2-P/-1950, larval exuviae removed Slide no 26.VI.88a", 1 (AEIC); Lily Pond, Alpine Lake, Marin County, 15.VII.1979, coll. D.D. Monroe, Malaise trap, 1 \& (CNCI). Oregon: Mt. Hood, $3500 \mathrm{ft} \quad(=1070 \mathrm{~m})$, 24.VII.1978, 1 \& (AEIC). 
Diagnosis. Clistopyga manni can be distinguished from all other North American species by combination of the following characters: metasoma orange-brown to red or black, without white marks on tergites or sometimes with tergites narrowly white posterior margins (Fig. 10C), and submetapleural carina absent or only present anteriorly. Females with ovipositor slender, weakly and evenly up-curved in apical 0.4-0.5 (Fig. 11E), and ovipositor sheath without denticles on basal ventral margin (Fig. 12A). Male with face and ventral part of gena white; first tergite rugulose punctuate, laterally sometimes punctulate, with lateromedian longitudinal carinae sharp in basal half of tergite.

Description. Female. Body length $8.2-9.0 \mathrm{~mm}$. Fore wing length $4.0-6.9 \mathrm{~mm}$.

Head. In dorsal view, strongly narrowed behind eyes. Gena in anterior view, straightly and strongly constricted below eyes. Gena finely and sparsely punctate, in dorsal view strongly constricted behind eyes, $0.2-0.3$ times as long as eye. Frons shiny, finely punctate. Posterior ocellus separated from eye by 1.1 times its maximum diameter. Distance between posterior ocelli 1.0 times maximum diameter of posterior ocellus. Occipital carina strong, not forming a flange dorsomedially. Occiput in dorsal view deeply concave medially Face strongly and densely punctate; distance between punctures less than twice length of diameter of puncture. Clypeal suture rounded. Clypeus 1.9-2.0 times as broad as medially long, weakly convex in dorsal half and flat in ventral half. Malar space with a granulate strip between eye and mandible, 1.1 times as long as basal mandibular width. Antenna with 28 flagellomeres, first 6.4-6.7 times as long as wide.

Mesosoma. Pronotum mostly smooth and shiny, finely punctate at posterior corner. Epomia strong and moderately long. Median lobe of mesoscutum densely and finely punctate on smooth, shiny background, lateral lobes and median lobe posteriorly less punctate. Notauli deep, extending from anterolateral margin of mesoscutum to about 0.6 of its length. Mesopleuron shiny, mostly smooth with moderately strong and dense setiferous punctures except in dorsal posterior part. Epicnemial carina strong, dorsally almost straight, ending far from anterior margin of mesopleuron and above centre of pronotum. Metapleuron smooth and shiny, with moderately strong and dense setiferous punctures in dorsal posterior part, 1.6 times as long as deep. Submetapleural carina weak, present on anterior part of metapleuron. Propodeum shiny, densely and strongly punctate on a smooth background in basal half, finely and transversely strigose medially, without lateromedian longitudinal carina which is often replaced basally by median longitudinal depression; in dorsal view as long as medially wide. Propodeal spiracle situated immediately above groove separating propodeum and metapleuron. Hind leg with femur as long as tibia. Fore wing with vein $\mathrm{Cu}-a$ opposite vein $R s \& M$. Vein $2 r s-m$ shorter than half length of abscissa of $M$ between $2 r s-m$ and $2 m-c u$. Abscissa of $C u 1$ between $1 m-c u$ and $C u 1 a$ about 1.4 times as long as $C u 1 b$. Hind wing with vein $C u-a \quad 0.3$ times as long as abscissa of $M+C u$ between $M$ and $C u 1$. Vein $\mathrm{Cu} 1$ almost absent.

Metasoma. First tergite 1.0-1.1 times as long as posteriorly broad, with very fine, dense punctures; spiracle near its basal 0.4. Lateromedian longitudinal carina strong, reaching about half the length of tergite, lateral longitudinal carinae strong and complete. Sternite 1 extending back about half the length of tergite. Second tergite 0.8 times as long as posteriorly broad, central region coarsely and densely punctate. Ovipositor slender, in basal 0.6-0.7 straight and apical 0.4-0.5 weakly and evenly upcurved (Fig. 11E), matt, 1.4-1.5 times as long as hind tibia. Ovipositor sheath 1.3-1.4 times as long as hind tibia, without denticles at basal ventral margin, with numerous oblique brown setae, which are usually longer than width of sheath.

Colouration. Body black or black brown, metasoma often reddish brown (Fig. 10C). Head, apex of mandible, propleuron, pronotum (except dorsal posterior band), mark on mesopleuron, anteroventral part of metapleuron, metanotum, and basal half of propodeum (except lateral parts) black. Inner and dorsal eye orbits, face and cheek of male, spot or vertical stripe below antennal socket of female (this mark usually connected laterally with orbital mark), large mark on cheek of female, clypeus, basal 0.65 of mandible, maxilla, labium, scape and pedicel ventrally, tegula, stripe on dorsal margin of pronotum, collar, ventral part of propleurum, 
subtegular ridge, usually two short longitudinal dashes on centre of mesoscutum, scutellum posteriorly, and postscutellum white. Flagellum brown, paler beneath. Mesopleuron, mesoscutum, scutellum, metapleuron, and posterior part of propodeum orange to light brown. Pterostigma pale brown. Fore leg white, femur often light brown behind. Mid leg white, femur with stramineous or brown dorsoposterior stripe, tibia and tarsus with infuscations that faintly repeat the pattern on the hind tibia and tarsus. Hind leg with coxa red, white apically, trochanter white, brown basally, especially above, trochantellus white, femur white, basally, anteriorly and posteriorly largely light brown, tibia white with basal and apical 0.3 infuscate (basal infuscate band more or less subdivided by white band), tarsus infuscate with tarsomeres white basally. Ovipositor light brown. Ovipositor sheath and three stripes on face brown.

Male. We have not seen any male specimens. For description see Townes and Townes (1960).

Host. Reared in California from either the egg sac, or mature adult grass spider, Agelenopsis Giebel species (Araneae: Agelinidae), and from a cocoon found beside of a dead salticid spider (Araneae: Salticidae) (Townes and Townes 1960).

Distribution. Nearctic: United States of America (Arizona, California, New Mexico, Oregon). Neotropical: Mexico (Chiapas, Oaxaca).

\section{Clistopyga maya González-Moreno and Bordera, new species}

$$
\text { (Figs. 3C, 4D, 5A, 15B) }
$$

Material examined. Holotype female, Mexico, Yucatán, Ría Lagartos Reserve, Estación Rio Lagartos, savannah, 04-18.III.2009, coll. A. González (UA). Paratype. MEXICO. Yucatán: Same data as holotype, 1 $q, 1$ ô (CER-UADY); same locality, 18.II-4.III.2009, 1 † (UA).

Etymology. The name of this species refers to the place where it was found, the Mayan region of Yucatán Peninsula.

Diagnosis. Clistopyga maya can be distinguished from all other North American species by combination of the following characters: submetapleural carina complete, sometimes weak posteriorly, not raised (Fig. 4D), tergites with shallow punctures on a granulate-rugulose background (Fig. 5A). Female with mesoscutum entirely red; metasoma conspicuously whitemarked (Fig. 3C); occipital carina complete, not forming a flange dorsomedially; ovipositor up-curved, 1.9-2.0 times as long as hind tibia. Males with face white, sometimes with longitudinal median and/or surrounding clypeus black mark; metasoma orange-brown to red or black, without white marks; propodeum black with a pair of white elongate marks dorsolaterally (Fig. 15B); mesoscutum smooth and glabrous; ventral part of gena without longitudinal concavity.

Description. Female. Body length 5.3-5.8 mm. Fore wing length $3.5-4.0 \mathrm{~mm}$.

Head. In dorsal view, strongly narrowed behind eyes. Gena in anterior view, straightly and strongly constricted below eyes. Gena finely and very sparsely punctate, in dorsal view 0.3 times as long as eye. Frons smooth and shiny. Posterior ocellus separated from eye by $1.2-1.3$ times its maximum diameter. Distance between posterior ocelli 1.2 times maximum diameter of posterior ocellus. Occipital carina weak, not forming a flange dorsomedially. Occiput in dorsal view deeply concave medially. Face finely and sparsely punctate; distance between punctures more than twice length of diameter of puncture. Clypeal suture rounded. Clypeus 1.7-1.8 times as broad as medially long, weakly convex in dorsal half and slightly concave in ventral half. Malar space smooth and shiny, with very thin groove between eye and mandible, 1.2 times as long as basal mandibular width. Antenna with 23 flagellomeres, first about 5.2 times as long as wide.

Mesosoma. Pronotum smooth and shiny. Epomia absent. Mesoscutum virtually smooth and shiny, median lobe anteriorly with very fine and sparse setiferous punctures. Notauli weak extending from anterolateral margin of mesoscutum to 0.4 of its length. Mesopleuron shiny and smooth, with very sparse and inconspicuous setiferous punctures in anterior and ventral part. Epicnemial carina weak, dorsally almost straight, ending far from anterior margin of mesopleuron at level of centre of pronotum. Metapleuron smooth and shiny, 2.5-2.6 times as long as deep. Submetapleural carina complete but sometimes weak posteriorly, not raised (Fig. 4D). Propodeum shiny, slightly rugulose, with very fine sparse punctures anterolaterally, 
without lateromedian longitudinal carina; in dorsal view 1.1 times as long as medially wide. Propodeal spiracle on groove separating propodeum and metapleuron (Fig. 4D). Hind leg with femur as long as tibia. Fore wing with vein $C u-a$ opposite vein $R s \& M$. Vein $2 r s-m$ obliterated. Abscissa of $C u 1$ between $1 m-c u$ and $C u 1 a$ about 1.4 times as long as $C u 1 b$. Hind wing with vein $C u$ - $a$ confluent with abscissa of $M+C u$ between $M$ and $C u 1$. Vein $C u 1$ absent.

Metasoma. First tergite 1.3 times as long as posteriorly broad, anterodorsally smooth and shiny, strongly granulate laterally and dorsoposteriorly with fine and sparse setiferous punctures; spiracle near basal 0.3. Lateromedian longitudinal carina weak, reaching about 0.6 of length of tergite, lateral longitudinal carina absent. Sternite 1 extending back about 0.7 of length of tergite. Second tergite as long as posteriorly broad, central region strongly and densely granulate punctate (Fig. 5A). Ovipositor slender, weakly and evenly upcurved in apical 0.4, matt, 1.9-2.0 times as long as hind tibia (Fig. 3C). Ovipositor sheath 1.4-1.5 times as long as hind tibia, without denticles at basal ventral margin, with numerous oblique brown setae, which are usually longer than width of sheath.

Colouration. Body mostly red and black (Fig. 3C). Head black; antenna brown; scape at apex, pedicel, frontal and vertical orbits, mandible except apex, clypeus, maxillary and labial palpi yellow. Face white, with narrow brown stripe surrounding clypeus. Propleuron brown with ventral margin white. Pronotum black with collar and wide dorsolateral band white. Mesopleuron orange, with narrow stripe dorsally and subalar prominence yellow. Metapleuron orangebrown, black ventrally close to submetapleural carina. Mesoscutum orange. Scutellum orange, apically white. Postscutellum white. Metanotum black. Propodeum extensively black with pair of white elongate marks dorsolaterally. Tegula and bases of wings white. Wings hyaline, pterostigma brown. Fore leg with stripe on femur dorsally, tibia and tarsus brown. Mid leg white, with trochanter, dorsal stripes on femur and tibia (interrupted in the middle), and tarsomeres centrally, dark brown. Hind leg white, with coxae ventroposteriorly, trochanter basally, femur basally and subapically, tibia basally and apically and apex of tarsomeres dark brown. Metasoma black to dark brown, with dorsolateral white marks on posterior corners of all tergites. Ovipositor light brown. Ovipositor sheath black.

Male. Body length $4.2-5.5 \mathrm{~mm}$. Fore wing length $2.4-2.7 \mathrm{~mm}$. Similar to female in structure and colouration, with differences described below. Clypeus 1.8-2.0 times as broad as medially long. Gena below eyes without strong concavity. Antenna with 21-22 flagellomeres. First flagellomere about 4.6 times as long as wide. Metapleuron 2.1-2.3 times as long as deep. Fore wing with vein $C u$ - $a$ basal to vein $R s \& M$. Metasoma with first tergite 1.4 times as long as posteriorly broad, dorsally shiny and finely rugulose in basal part, rugose laterally and posteriorly, with median longitudinal carina long, reaching posterior rim of tergite. Second tergite 1.5 times as long as posteriorly broad.

Colouration. Similar in colour to female (Fig. 15B). Face almost entirely white. Scutellum and postscutellum white. Mesopleuron sometimes with diagonal yellow band. Metasoma black. Basal corners of tergites 3-5 light brown.

Host. Unknown.

Distribution. Neotropical: southeast Mexico (Yucatán).

\section{Clistopyga moraviae Gauld, Ugalde, and Hanson, 1998}

(Figs. 11H, 12D, 13A, 13C, 13E, 19A, 19C, 19E)

Clistopyga moraviae Gauld, Ugalde, and Hanson, 1998: 168. Holotype: + , Costa Rica (INBio).

Material examined. Holotype female, COSTA RICA. San Jose, Zurquí de Moravia, on edge of Braulio Carrillo National Park, $1600 \mathrm{~m}$, VII.1993, coll. I.D. Gauld (INBio). Non-type material. COSTA RICA. Puntarenas: Cerro Frantziuse, $2134 \mathrm{~m}$, Malaise trap, 29.IX-16.XI.1997, coll. R. Villalobos, 1 q (INBio); Buen Amigo, San Luis Monteverde, A.C. Arenal, 1000-1350 m, V.1994, 1 ơ (INBio). MEXICO. Veracruz: Jalapa, park near Institute de Ecología, $1260 \mathrm{~m}, 19^{\circ} 30.768^{\prime} \mathrm{N}, 96^{\circ} 56.349^{\prime} \mathrm{W}$, 17-18.II.2009, coll. A.I. Khalaim, 1 (UAT).

Diagnosis. Clistopyga moraviae can be distinguished from all other North American species by combination of the following characters: metasoma orange-brown to red or black, without 
white marks (Figs. 13A, 19A); head black with facial, frontal and vertical orbits, and two small spots below antennal sockets white (Figs. 13E, 19E); mesopleuron mostly red with black spot dorsoposteriorly; submetapleural carina absent or present as a weak tubercle on anterior part of metapleuron (Fig. 11H); hind femur mostly white with brown marks (Figs. 13A, 19A). Female with ovipositor stout, weakly and evenly up-curved in apical $0.4-0.5$; ovipositor sheath 1.5-1.7 times the length of hind tibia, basally with denticles on ventral margin (Fig. 12D); first tergite 1.2-1.4 times as long as posteriorly broad. Males with tergite 1 smooth and shiny, sometimes with very sparse setiferous punctures laterally; lateromedian longitudinal carinae absent or vestigial, reaching at most 0.2 length of tergite.

Description. For detailed description see Gauld et al. (1998). Additional characters are as follows.

Female. Body length $6.8-7.3 \mathrm{~mm}$. Fore wing length $4.5-5.5 \mathrm{~mm}$.

Head. In dorsal view, moderately narrowed behind eyes (Fig. 13C). Gena in anterior view, straightly and strongly constricted below eyes (Fig. 13E). Gena with moderately dense setiferous punctures, in dorsal view 0.43 times as long as eye (Fig. 13C). Frons smooth and shiny. Posterior ocellus separated from eye by 0.9 times its own maximum diameter (Fig. 13C). Distance between posterior ocelli $0.8-1.0$ times maximum diameter of posterior ocellus (Fig. 13C). Occipital carina weak, not forming a flange dorsomedially. Occiput in dorsal view moderately concave medially. Face strongly and densely punctate; distance between punctures less or about twice length of diameter of puncture (Fig. 13E). Clypeal suture very slightly rounded (Fig. 13E). Clypeus 2.0 times as broad as medially long, slightly convex dorsally, almost flat ventrally (Fig. 13E). Malar space with a granulate strip between eye and mandible, 1.2 times as long as basal mandibular width. Antenna with 23-24 flagellomeres, first flagellomere 5.6-5.7 times as long as wide.

Mesosoma. Pronotum smooth and shiny (Fig. 11H). Epomia absent (Fig. 11H) Median lobe of mesoscutum densely and finely punctate, lateral lobes and posterior part of median lobe more sparsely punctate on smooth and shiny background. Notauli weak, extending from anterolateral margin of mesoscutum to 0.4 its length.
Mesopleuron shiny, smooth, with very fine and sparse setiferous punctures in ventral part. Epicnemial carina weak, its dorsal end straight or weakly curved backward, ending far from anterior margin of mesopleuron slightly below of centre of pronotum. Metapleuron smooth and shiny, 2.1-2.2 times as long as deep (Fig. 11H). Submetapleural carina absent or discernible as a short vestige in anterior part of metapleuron. Propodeum smooth and shiny, with very sparse and fine punctures in basal 0.7 , without median longitudinal carina; dorsal view as long as medially wide. Propodeal spiracle on groove separating propodeum and metapleuron. Hind leg with femur as long as tibia. Fore wing with vein $C u-a$ opposite $R s \& M$. Vein $2 r s-m$ shorter than half length of abscissa of $M$ between $2 r s-m$ and $2 m-c u$. Abscissa of $C u 1$ between $1 m-c u$ and $C u 1 a 1.4-1.6$ times as long as $C u 1 b$. Hind wing with vein $C u-a$ virtually confluent with abscissa of $M+C u$ between $M$ and $C u 1$. Vein of $C u 1$ as vestige.

Metasoma. First tergite 1.2-1.4 times as long as posteriorly broad, smooth and shiny, with very shallow sparse punctures laterally and posteriorly; spiracle near its basal 0.3-0.4. Lateromedian longitudinal carina absent or vestigial, reaching at most 0.2 length of tergite, lateral longitudinal carina absent. Sternite 1 extending back about 0.6 of length of tergite. Second tergite $0.9-1.0$ times as long as posteriorly broad, central region with shallow and dense puctures. Ovipositor stout, weakly and evenly up-curved in apical 0.4, matt, 2.0 times as long as hind tibia. Ovipositor sheath 1.5-1.7 times as long as hind tibia, basally with denticles on ventral margin (Fig. 12D), setae longer than sheath width.

Colouration. Body mostly black and red (Fig. 13A, 13C, 13E). Antenna brown, darkening at distal part. Head black with dorsal part of gena white. Face black with facial, frontal and vertical orbits, two marks below antennal sockets, and basal half of mandible white. Clypeus centrally broadly white with brown surrounding clypeus. Propleuron black. Pronotum black with dorsal longitudinal white band. Mesopleuron red with black spot dorsoposteriorly. Metapleuron red with margin black. Mesoscutum and scutellum basally, reddish brown. Metanotum (except postscutellum white) and propodeum black. 
Wings hyaline, pterostigma darkened brown. Fore legs and mid leg white with femora and tibia dorsally infuscate. Hind leg white, with coxa basally red, femur basally and dorsally, tibia basally and apically brown. Metasoma brown to dark brown, tergites $2-3$ with posterolateral black marks. Ovipositor light brown. Ovipositor sheath black.

Male. Body length $6.7 \mathrm{~mm}$. Fore wing length $3.6 \mathrm{~mm}$. Similar to female in structure and colouration, but differs in characters described below. First flagellomere about 5.8 times as long as wide. Gena below eyes without concavity (Fig. 19E). Malar space 0.9 times as long as basal mandibular width. Clypeus 2.5 times as broad as medially long. Metapleuron twice as long as deep. Tergite 1 without larteromedian longitudinal carina or vestigial at most 0.2 length of tergite.

Colouration. Similar in colour to female (Fig. 19A, 19C, 19E). Metasoma brown, tergite 2 and following with black posterior margin.

Host. Unknown.

Distribution. Neotropical: Costa Rica, Mexico (Veracruz).

Remarks. A putative male was described by Gauld (1991: 169), but in the brief original description he mentioned some differences compared with the female, mainly in colour and a shorter malar space ( 0.4 times as long as basal mandibular width). We have not located the male specimen studied by Gauld but another male from Costa Rica, described here, seems more likely to be conspecific with the females as it has a longer malar space and similar colour pattern to the female.

\section{Clistopyga nigrifrons Cushman, 1922}

(Figs. 10E, 12C)

Clistopyga nigrifrons Cushman, 1922: 11. Holotype: $q$, United States of America (USNM).

Material examined. Holotype female, UNITED STATES OF AMERICA. California, Mountain View, reared from spider nest, Earhorn, VII.1898 (USNM, 20059). Non-type material. CANADA. British Columbia: Salmon
Arm, 1.VIII.1925, coll. A.S. Dennys, $1 q$ (CNCI); Robson, 8.VIII.1949, coll. H.R. Faxlee, 1 o (CNCI). MEXICO. Durango: El Salto, $10 \mathrm{ml} . \mathrm{W} ., 9000 \mathrm{ft}$ (=2745 m), 15.VI.1964, coll. W.R.M. Mason, 1 (CNCI); same locality and collector, 25.VI.1964, 1 ㅇ (CNCI). Tamaulipas: NE Miquihuana, Km 22-25, 2800 m, pine forest, 12.V.2000, coll. D.R. Kasparyan, 1 (UAT). UNITED STATES OF AMERICA. Arizona: Chiricahua Mountains, 3.VII.1956, coll. H. \& A. Howden, 1 q (CNCI); Portal, 2.IX.1987, coll. H. and M. Townes, 1 (AEIC). California: Almanor, Plumas County, $4500 \mathrm{ft}(=1370 \mathrm{~m})$, 1.VIII.1965, 1 \& (CNCI); Sequoia National Park, Giant Forest, $6500 \mathrm{ft}$ (=1980 m), VIII.1975, coll. M.G. Fitton, 1 ㅇ (BMNH). Oregon: Corvalis, 2.VIII.1978, 1 \& (AEIC); Hyatt Reserve, 29.VI.1978, 2 \& (AEIC).

Diagnosis. Female of $C$. nigrifrons can be distinguished from all other females of North American species by combination of the following characters: metasoma black to dark brow, without white marks, tergites sometimes with a fine white posterior margin; hind coxa entirely orange; hind femur red with apex white (Fig. 10E); epomia strong and long; metapleuron 1.8-2.0 times as long as deep; propodeum 0.8-0.9 times as long as wide medially; submetapleural carina strong on anterior $0.4-0.5$ of metapleuron; ovipositor stout, weakly and uniformly up-curved in apical $0.4-0.5$; ovipositor sheath basally with denticles on ventral margin (Fig. 12C), 1.2-1.3 times length of hind tibia.

Description. Female. Body length 5.8-6.8 mm. Fore wing length $4.1-5.0 \mathrm{~mm}$.

Head. In dorsal view, narrowed behind eyes. Gena in anterior view, slightly rounded and strongly constricted below eyes. Gena finely and densely punctate, in dorsal view 0.4 times as long as eye. Frons smooth and shiny. Posterior ocellus separated from eye by $0.7-0.8$ times its maximum diameter. Distance between posterior ocelli 1.0-1.1 times maximum diameter of posterior ocellus. Occipital carina weak, not forming a flange dorsomedially. Occiput in dorsal view slightly concave medially. Face strongly and densely punctate. Distance between punctures mostly less than twice length of diameter of puncture. Clypeal suture rounded. Clypeus 1.8 times as broad as medially long, convex in dorsal half and flat in ventral half. 
Malar space with granulate strip between eye and mandible, 1.1 times as long as basal mandibular width. Antenna with 23-24 flagellomeres, first 4.8-5.1 times as long as wide.

Mesosoma. Pronotum smooth and shiny. Epomia strong and long. Anterior part of median lobe of mesoscutum very densely and finely punctate on granulate or rugulose background, posterior part and lateral lobes with sparser, shallower punctures on smooth and shiny background. Notauli moderately deep, extending from anterolateral margin of mesoscutum to about half its length. Mesopleuron shiny, mostly smooth, ventrally and anterolaterally sparsely and weakly punctate. Epicnemial carina strong, its dorsal end weakly curved backward, ending moderately far from anterior margin of mesopleuron at level of centre of pronotum. Metapleuron smooth and shiny, with fine and sparse setiferous punctures posteriorly, 1.8-2.0 times as long as deep. Submetapleural carina strong on anterior half of metapleuron. Propodeum shiny, with fine and sparse setiferous punctures anteriorly on a smooth background, without lateromedian longitudinal carina; in dorsal view $0.8-0.9$ times as long as medially wide. Propodeal spiracle situated immediately above the groove separating propodeum and metapleuron. Hind leg with femur 0.8 times as long as tibia. Fore wing with vein $C u-a$ slightly distal to $R s \& M$. Vein $2 r s-m$ shorter than half length of abscissa of $M$ between $2 r s-m$ and $2 m-c u$. Abscissa of $C u 1$ between $1 m-c u$ and $C u 1 a$ 1.4-1.5 times as long as $C u 1 b$. Hind wing with vein $\mathrm{Cu}-\mathrm{a} 0.3$ times as long as abscissa of $M+C u$ between $M$ and $C u 1$. Vein $C u 1$ weakly pigmented.

Metasoma. First tergite $0.9-1.0$ times as long as posteriorly broad, smooth and shiny, with fine and dense setiferous punctures; spiracle near basal 0.3. Lateromedian longitudinal carina weak reaching 0.2 length of tergite, lateral longitudinal carina absent. Sternite 1 extending about half the length of tergite. Second tergite 0.9-1.0 times as long as posteriorly broad, central region with coarse and dense punctures. Ovipositor stout, weakly and evenly up-curved in apical $0.4-0.5$, matt, 1.2-1.3 times as long as hind tibia (Fig. 10E). Ovipositor sheath 1.2-1.3 times as long as hind tibia (Fig. 12C), basally with short denticles on ventral margin, with numerous oblique black setae which are about as long as sheath width.

Colouration. Body black (Fig. 10E). Very short orbital marks at top of eye, opposite antennal socket, longer orbital mark on frons (sometimes connected with dorsal orbital mark), sometimes spot just below antennal socket, clypeus, maxilla, labium, tegula, stripe on dorsal margin of pronotum, sometimes subtegular ridge, scutellum posteriorly, and postscutellum white. Antenna blackish brown, paler beneath. Mesosternum, mesopleuron except large quadrate mark above, lateral lobes of mesoscutum, scutellum, and metapleuron red. Prepectus black except in dorsal part. Fore leg white, femur light brown posteriorly and tarsus light brown. Mid leg with coxa apically, trochanters, femur apically and anteriorly, and tibia white, tarsomeres basally white, distally brown. Hind leg with coxa entirely orange, femur orange with apex white, trochanter and trochantellus dorsally dark brown, ventrally yellow, tibia dorsally and anteriorly white, distally and ventrally from orange to brown, tarsus light brown with tarsomeres darker apically. Ovipositor light brown. Ovipositor sheath dark brown.

Male. Unknown.

Variation. Some specimens with dark brown areas tend to have reddish colouration.

Host. Unknown.

Distribution. Nearctic: Canada (British Columbia), United States of America (Arizona, California, Oregon), Mexico (Durango, Tamaulipas).

\section{Clistopyga oaxacana González- Moreno and Bordera, new species}

(Figs. 10D, 11F-G, 12B)

Material examined. Holotype female, MEXICO. Oaxaca, Vista Hermosa, $96.5 \mathrm{~km} \mathrm{SW}$ of Tuxtepec, $1450 \mathrm{~m}, 20 . X .1962$, coll H. and M. Townes (AEIC).

Etymology. The name refers to Oaxaca, the Mexican state where the holotype was collected.

Diagnosis. Female of $C$. oaxacana can be distinguished from all other females of North American species by combination of the following characters: mesosoma dark-brown to red, without white marks, tergites with narrowly 
yellow posterior margins; hind coxa light brown, partially white; hind femur white with a dorsoposterior light brown stripe (Fig. 10D); epomia absent (Fig. 11G); metapleuron 2.3 times as long as deep; submetapleural carina strong on anterior half of metapleuron (Fig. 11G); propodeum 1.1 times as long as medially wide; ovipositor stout, weakly and uniformly up-curved in apical 0.4-0.5 (Fig. 11F); ovipositor sheath 1.4 times length of hind tibia, basally with denticles on ventral margin (Fig. 12B).

Description. Female. Body length $7.6 \mathrm{~mm}$. Fore wing length $5.6 \mathrm{~mm}$.

Head. In dorsal view, strongly narrowed behind eyes. Gena in anterior view, straightly and strongly constricted below eyes. Gena with very fine and sparse setiferous punctures, in dorsal view 0.3 times as long as eye. Frons smooth and shiny. Posterior ocellus separated from eye by 0.7 times its maximum diameter. Distance between posterior ocelli 1.0-1.1 times maximum diameter of posterior ocellus. Occipital carina weak, not forming a flange dorsomedially. Occiput in dorsal view slightly concave medially. Face strongly and densely punctate; distance between punctures less than twice length of diameter of puncture. Clypeal suture slightly rounded. Clypeus 1.6 times as broad as medially long, weakly convex. Malar space with coriaceous strip between eye and mandible, 1.0 times as long as basal mandibular width. Antenna with 24 flagellomeres, first about 6.4 times as long as wide.

Mesosoma. Pronotum mostly smooth and shiny, with fine punctures dorsally and laterally (Fig. 11G). Epomia absent (Fig. 11G). Median lobe of mesoscutum densely and finely punctate, lateral lobes and median lobe posteriorly less punctate on smooth and shiny background. Notauli deep, extending from anterolateral margin of mesoscutum to about level of tegula. Mesopleuron shiny, smooth, ventrally and anterolaterally very sparsely and weakly punctate (Fig. 11G). Epicnemial carina strong, its dorsal end strongly curved backward, ending moderately far from anterior margin of mesopleuron at level of centre of pronotum (Fig. 11G). Metapleuron smooth and shiny, with fine and very sparse setiferous punctures posteriorly, 2.3 times as long as deep (Fig. 11G). Submetapleural carina strong on anterior third of metapleuron
(Fig. 11G). Propodeum shiny, sparsely and finely punctate on a smooth background except in posterior third, without median longitudinal carina; in dorsal view 1.1 times as long as medially wide. Propodeal spiracle situated immediately above the groove separating propodeum and metapleuron (Fig. 11G). Hind leg with femur 0.85 as long as tibia. Fore wing with vein $\mathrm{Cu}-a$ slightly distal to $R s \& M$. Vein $2 r s-m$ shorter than half length of abscissa of $M$ between $2 r s-m$ and $2 m-c u$. Abscissa of $C u 1$ between $1 m-c u$ and $C u 1 a$ about 1.6 times as long as $C u 1 b$. Hind wing with vein $C u-a 0.4$ times as long as abscissa of $M+C u$ between $M$ and $C u 1$. Vein $C u 1$ virtually absent.

Metasoma. First tergite about 1.1 times as long as posteriorly broad, smooth, and shiny, weakly and densely punctate on lateral parts; spiracle near basal 0.3, Lateromedian longitudinal carina strong, reaching about 0.2 length of tergite, lateral longitudinal carina absent. Sternite 1 extending about half the length of tergite. Second tergite as long as posteriorly broad, central region with shallow and dense punctures. Ovipositor stout, weakly and evenly upcurved in apical 0.4, matt (Fig. 11F), 1.9 times as long as hind tibia. Ovipositor sheath 1.4 times as long as hind tibia, basally with distinct denticles on ventral margin (Fig. 12B), with numerous oblique black setae that are longer than sheath width.

Colouration. Body primarily orange and brown (Fig. 10D). Antenna brown, pedicel and first flagellomere white beneath. Head dark brown. Palpi, base of mandible, clypeus, inner eye orbits, and two spots below antennal socket white. Propleuron dark brown anteriorly to red and white posteriorly. Pronotum with longitudinal tricoloured band (white dorsally, orange medially, dark brown ventrally). Mesopleuron and mesosternum orange, subalar prominence white. Metapleuron orange. Mesoscutum orange. Scutellum orange basally, white apically. Metanotum brown with postscutellum white. Propodeum mostly orange, dark brown basally and apically. Legs mostly white. Fore femora and mid femora with narrow light brown stripes dorsally. Hind coxa light brown, white distally; trochanter and trochantellus white, femur white, basally and dorsoposteriorly light brown, tibia mostly white, brown apically and subbasally, all 
tarsomeres white, darkened distally. Tergites 1 and 2 of metasoma dark brown, tergites 3 and following tending to be red. Tergites $1-5$ with narrow posterolateral dark mark and yellow posterior rims. Ovipositor reddish brown. Ovipositor light brown. Ovipositor sheath brown.

Male. Unknown.

Host. Unknown.

Distribution. Neotropical: south Mexico (Oaxaca).

\section{Clistopyga recurva (Say, 1835)}

(Figs. 6B, 6C, 7B-D, 7F, 15C, 15E, 20A-D)

Anomalon recurvus Say, 1835: 243. Lectotype: 9 , designated by Cushman and Gahan (1921). Clistopyga annulipes Cresson, 1870: 150. Holotype: $q$, United States of America (ANSP).

Clistopyga pulchripicta Ashmead, 1890: 448. Holotype: $q$, United States of America (USNM).

Clistopyga covarrubiasi Khalaim and Hernández, 2008: 316. Holotype: + , Mexico (UAT). New synonym.

Material examined. Holotype female, C. pulchripicta: Collection Belfrage, Type $\mathrm{N}^{\circ}$ 2114 (USNM). Holotype female, C. annulipes: Mass. Type $\mathrm{N}^{\circ} 1443$ (ANSP). Holotype female, C. covarrubiasi: Mexico, Tamaulipas, Gómez Farías, Alta Cimas, Malaise trap, 27.II-20.III.1999, coll. S. Hernández A. (UAT). Paratypes of C. covarrubiasi: same locality as holotype, 27.II-17.VII.1999, 11 우 ㅇ, 25 oิ ô (UAT); $15 \mathrm{~km}$ SSE Cd. Victoria, El Madroño, 28.IV-25.V.1985, coll. H. and E. Ruíz-Cancino, 2 ㅇ (UAT). Non-type material. CANADA. Ontario: Leamington, Pt. Pelee N.P., 9.VI.1968, Malaise trap, $1+$ (CNCI). MEXICO. Colima: "Isla Socorro", 20-22.VIII.1987, coll. R. Medina, S. Martínez, L. Cervantes, 1 đ (UNAM). Nuevo León: Monterrey, Mesa de Chipinque, 13.VI.1975, coll. C.C. Porter, H. Weems, 1 q (FSCA); same locality, 29-30.V.1977, coll. C.C. Porter, A. Cerbone, 1 9 (FSCA). Tamaulipas: SE Cd. Victoria, Rancho Santa Elena, $23^{\circ} 37.362^{\prime} \mathrm{N}$, $99^{\circ} 12.746^{\prime} \mathrm{W}$, $970 \mathrm{~m}$, Malaise trap, 24-30.IV, 15.V-4.VI.2010, coll. E. Ruíz-Cancino, 2 우, 1 ơ (UAT). UNITED STATES OF AMERICA.
Alabama: Gulf Shores, 25.IV.1968, 1 đ (AEIC). Arizona: Portal, 19.VIII.1987, 1 †े (AEIC). Arkansas: "at large", 1.VI.1966, coll. W. Lee, 1 ९, 66-21738 (USNM, 2053570); L. Ouachita, 9-30.V.1972, Malaise trap, 4 ô $\widehat{o}$ (CNCI). Florida: Alachua Co., Gainesville, Malaise trap, III-VII.1987, coll. D.B. Wahl, 1 \& (FSCA); Gainesville, DPI Forest, 16.X.1985, coll. Gupta, 1 , 9 đ 0 (FSCA); Gainesville, Rock Cr., Malaise trap, coll. Gupta: 24-31.III.1983, 1 \%;

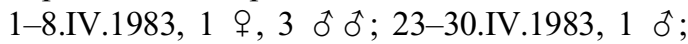
1-8.V.1983, 1 क; 16-22.V.1983, 3 q ; 10-31.X.1983, 1 ㅇ, 4 ồ ô; 1-15.XI.1983, 2 웅 I-XII.1983, 22 우, 100 ôे ô; I-VIII.1984,

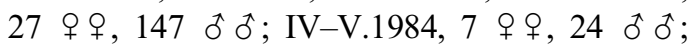
XI-XII.1984, 2 우, 1 ô (all in FSCA); S.E. Gainesville, Kincaid Rd., III-VI.1997, coll. B.D. Sutton, 10 q $q$ (FSCA); Summer Creeck, Malaise trap, 5-11.IX.1989, coll. C.C. Porter, 1 q (FSCA); Gainesville, 610 N.W., 54th Terr., Mixed Hardwood/Pine, coll. L. Stange: 20.X.1996, 6 우; I.1997, 18 o क ; III.1997, 18 ô of (all in FSCA); Gold Head Branch State Park, Clay Co., Ravine mixed wood, 21.IV-5.V.1971, coll. G. Heinrich, 1 ๙ , 2 우 (CNCI); same locality and vegetation, 10.VI.1995, 5 우 $ᄋ$, 3 ๙ิ o (FSCA); same locality and vegetation, 15.V.1996, coll. C.C. Porter, L. Stange, 4 우, 19 ๙ิ ๙ (FSCA); same locality and collectors, 1996, 4 우, 20 ôे (FSCA); same locality and collectors, Ravine Hardwoods, Malaise trap, 15.III-2.IV.1997, 1 † (FSCA); same locality, vegetation and collectors, Malaise trap, 1-15.V.1997, 8 우, 17 ઈิ Gadsden Co., Quincy NFREC, 5.VIII.1988, coll. Gupta, 2 우, 3 ô ๙ (FSCA); Polk Co., Lake Land, Malaise trap, VI.1983, coll. Gupta, 1 (FSCA); Rode Cr., Malaise trap, X.1984, coll. Gupta, 1 o (FSCA); Santa Rosa Co. Jay, AREC, 8.X.1990, coll. Gupta, 1 \& (FSCA); same locality and collector, 22.X.1990, 5 q $q$ (FSCA); Seminole, Co., Florida Fruit, Fly Trap Surv., 8.VIII.1929, coll. H. Clark, 1 o (USNM, 2053570); Sumter, Co. G.F. Wade, Sr. Coll., Steiner trap, 17.XI.1961, 1 q (FSCA). Georgia: Athens, Botanical Garden, 5.V.1983, coll. Gupta, 1 (FSCA); Forsyth, 14-22.IV.1970, coll. F.T. Naumann, Malaise trap, 1 \& (CNCI); same locality and collector, 25.X.1970, Malaise trap, 1 (CNCI). Idaho: Plummer, at light, 2.IX.1914, coll. Md. R.C.S. Bannon, 1 ㅇ (USNM, 2053570). Louisiana: Natchitoches, 8-19.VI.1971, coll. 
G. Heinrich, 1 \& (CNCI). Maryland: Laurel, 25.VI.1965, Malaise trap, 2 우 (CNCI); same locality, 28.VI.1965, Malaise trap, 1 ( $(\mathrm{CNCI})$; Lexington Park, 22.VI-20.VIII.1985, coll. Jannet Ropp, 1 ઈิ, 6 우 (AEIC); Meadowood, Subdiv. near Colesville, Mol., in house, 10.XI.1959, coll. L.M. Walkley, 1 q (USNM, 2053570); same locality and collector, IX.1966, 1 \& (USNM, 2053570); same locality, Nr. Colesville, Md., 11.IV.1964, coll. L.M. Walkley, 1 (USNM, 2053570); Takoma Park, 17.IX.1944, 1 § (AEIC); same locality, 7.X.1945, coll. H and M. Townes, $1 \lesssim \mathrm{H}$ (FSCA); same locality and collectors, 13.X.1945, 1 o (FSCA); 5 Km S Prince Frederick, 13.V.1987, 2 q $q$ (AEIC); St. Mary's Co., Bushwood, 22-28.V.1988, 1 (AEIC); same locality, 1-10.VI.1988, 2 우 (AEIC); same locality, 20.V.1988, 1 + (AEIC). St. Mary's Co., Hollywood, 5.V.1987, 2 우 (AEIC). Michigan: Gun Lake, Malaise trap, VII-VIII.1976, coll. I.D. Gauld, 3 우 (BMNH); Ann Arbor, 3-16.IX.1975, coll. M.G. Fitton, 1 \& (BMNH). Missouri: Williamsville, X-XI.1968, coll. J.T Becker, Malaise trap, 3 우 (CNCI); V.1969, 2 우 (CNCI); 12-26.V.1969, 1 우 (CNCI); 1-16.VI.1969, 2 우 (CNCI); 16-26.VI.1969, 1 ㅇ (CNCI); 26-29.VI.1969, 1 ๆ (CNCI); 5-9.VII.1969, 2 우 (CNCI). New Jersey: Anglesea, N.J., 7.IX.??, coll. F. Haimb, 1 q (USNM, 2053570); Boonton, 7.VIII.1901, coll. N.J. and G.M. Greene, 1 (USNM, 2053570); Moorestown, 16.VII.1939, 1 †े (AEIC); same locality, 14.VII.1939, 2 q (AEIC). North Carolina: Macon Co., Whiteside Mt., $1600 \mathrm{~m}$, IV-VII.1987, 1 (AEIC); Raleight, 2.IV.1950, 1 ㅇNN, 2053570); Wallace, 17.VI.1949, coll. H. Townes, 1 \& (AEIC). South Carolina: Greenville, 28.VIII.1955, 1 \& (AEIC); same locality, 27.V.1956, 2 우 (AEIC); McClellanville, 12.V.1944, 1 đิ (AEIC); same locality, 15.V.1944, 1 ㅇ (AEIC); Pendleton, 20.IX.1987, 1 $\uparrow$ (AEIC). Tennessee: Lexington, Natchez Trace S. P., 6-9.VI.1972, coll. G. Heinrich, Malaise trap, 1 \& (CNCI). Texas: Brazos, 11.IV.1941, 1 q (AEIC); Dallas, Cotx, on screen, 26.III.1951, coll. L.H. Shinners, No. 231, Lot. No. 52-11592, 1 q (USNM, 2053570); Fredericksburg, 3-19.V.1988, 24 ิㅗ ô, 6 우 (AEIC); same locality, 30.IV.1988, 1 (AEIC); Kerville, 4-18.V.1988, 15 đิ ๙ิ, 8 $ᄋ$ (AEIC); Mc Allen, 7.I.1975, coll. C.C. Porter, 1 o (FSCA); same locality and collector,
18.I.1975, 1 \& (FSCA); same locality and collector, 20.I.1975, 1 đ (FSCA); Hidaldo Co, Mc Allen Valley, Botanical Garden, 24.XII.1978, coll. C.C. Porter, 1 \& (FSCA). Utah: Farm, X.1920, coll. P.M. Hutton, 1 o (CNCI). Virginia: Arlington, 23.V.1954, coll. K.V. Krombein, 1 \% (USNM, 2053570); same locality and collector, 15.IX.1967, 1 \& (AEIC); same locality and collector, 28.VIII.1981, 1 đิ (FSCA); Mount Vernon, 16.VII.1944, 1 \& (AEIC). Washington, DC: 15.IX.1951, coll. D.G. Shappirio, 1 \& (USNM, 2053570); same locality, 7.VI.1993, coll. F.C. Pratt, 1 (USNM, 2053570).

Putative material: UNITED STATES OF AMERICA. Florida: Manatee Co., Florida Fruit, Fly Trap Surv, 22.III.1930, coll. R.F. Tinker, 1 ô (USNM, 2053570); Gold Head, Branch S.P., Clay County, 21.IV-5.V.1971, coll. G. Heinrich, 4 to $\widehat{t}$ (CNCI). Texas: Big Band N.P., Panther Junction, 3500-4000 ft $(=1070-1220 \mathrm{~m}), \quad$ 15.V.1959, coll. W.R.M. Mason, 1 ๙ (CNCI). Unknown locality: Miss., Collection Ashmead, 1 ô (USNM, 2053570).

Diagnosis. Clistopyga recurva can be distinguished from all other North American species by combination of the following characters: metasomal tergites dark brown to black, sometimes red tinged (e.g., C. pulchripicta), but always without white marks (Figs. 7B-D, 15C), and the submetapleural carina strong and complete but not raised (Fig. 6B-C). Female with mesoscutum and propodeum dark brown or black to partially or entirely red; metapleuron from black to red (Fig. 7B-D); ventral half of mesopleuron with fine but sharp and dense setiferous punctures (Fig. 6B-C); propodeum laterally, tergites 2-4 and ovipositor sheath with moderately short dense setae; central region of tergites 2-4 with small, deep and dense punctures (Figs. 7F, 15E); ovipositor strongly up-curved at distal 0.3. Male with face white, sometimes with longitudinal median dark brown mark; mesoscutum red, median lobe partly or entirely black, sometimes with a pair of longitudinal white dashes centrally; propodeum black or orange-brown, with dorsolateral red marks; gena without longitudinal concavity at its ventral part; mesoscutum with fine and dense setiferous punctures; central lobes of tergites 2-4 strongly and densely punctate on smooth background. 
Description. Female. Body length 7.0-11.0 mm. Fore wing length $3.2-8.8 \mathrm{~mm}$.

Head. In dorsal view, strongly narrowed behind eyes. Gena in anterior view, straight and moderately constricted below eyes (Fig. 20A-D). Gena with fine and moderately dense setiferous punctures, in dorsal view 0.2-0.4 times as long as eye. Frons smooth and shiny. Posterior ocellus separated from eye by $0.8-1.0$ times its maximum diameter. Distance between posterior ocelli 0.9-1.0 times maximum diameter of posterior ocellus. Occipital carina strong, not forming a flange dorsomedially. Occiput in dorsal view slightly concave medially. Face finely and densely punctate; distance between punctures usually less than twice length of diameter of puncture (Fig. 20A-D). Clypeal suture slightly rounded (Fig. 20A-D). Clypeus 1.9-2.1 times as broad as medially long, slightly convex, sometimes bent inwards in apical 0.3 (Fig. 20A-D). Malar space with a granulate strip between eye and mandible, $0.8-1.0$ times as long as basal mandibular width. Antenna with 26-32 flagellomeres, first 5.0-5.7 times as long as wide.

Mesosoma. Pronotum smooth and shiny. Epomia strong and short. Median lobe of mesoscutum finely and densely punctate, lateral lobes and median lobe posteriorly, with shallower and sparser punctures on smooth background. Notauli deep, reaching about half the length of mesoscutum. Mesopleuron shiny, mostly smooth with moderately strong and dense setiferous punctures except in dorsal posterior part (Fig. 6B-C). Epicnemial carina strong, its dorsal end straight or weakly curved backward, ending so far from anterior margin of mesopleuron at level of centre of pronotum (Fig. 6B-C). Metapleuron smooth and shiny, posterior half with fine and sparse punctures, 2.1-2.3 times as long as deep (Fig. 6B-C). Submetapleural carina strong and complete, not raised (Fig. 6B-C). Propodeum shiny with strong and dense punctures in anterior third and laterally, strongly tranversely strigose centrally, tending to be smooth posteriorly, without lateromedian longitudinal carina; in dorsal view 1.0-1.2 times as long as medially wide. Propodeal spiracle, situated immediately above groove separating propodeum and metapleuron (Fig. 6B-C). Hind femur as long as tibia. Fore wing with vein $\mathrm{Cu}$ - $a$ from opposite to slightly distal to $R s \& M$. Vein $2 r s-m$ very variable in length.
Abscissa of $C u 1$ between $1 m-c u$ and $C u 1 a$ 1.7-2.0 times as long as $C u 1 b$. Hind wing with vein $\mathrm{Cu}$ - $a$ 0.3-0.4 times as long as abscissa of $M+C u$ between $M$ and $C u 1$. Vein $C u 1$ weakly pigmented or absent.

Metasoma. First tergite 1.1-1.3 times as long as posteriorly broad, smooth and shiny dorsoanteriorly, slightly rugulose, with very weak and more or less dense punctures posteriorly; spiracle near basal 0.3-0.4. Lateromedian longitudinal carina weak to strong, reaching $0.3-0.4$ length of tergite, lateral longitudinal carina strong reaching 0.3 length of tergite. Sternite 1 extending back about 0.4 of length of tergite. Second tergite $0.9-1.0$ times as long as posteriorly broad, central region from finely and strongly densely punctate (Fig. 7F). Ovipositor stout, strongly upcurved in apical 0.3, matt, 1.5-1.7 times as long as hind tibia (Fig. 7B-D). Ovipositor sheath 1.2-1.4 times as long as hind tibia, without denticles basally on ventral margin, with numerous oblique black setae that are about as long as sheath width.

Colouration. Body primarily black (Fig. 7B-D). Antenna brown, scape, pedicel and basal flagellomeres yellow beneath. Head primarily black with inner orbits, ventral part of gena and clypeus white. Face from dark brown (with two white spots below antennal sockets) to entirely white with median dark stripe. Clypeal suture and malar space dark brown to black. Mandible tricoloured, white basally, black centrally, teeth red. Palpi white. Propleuron black with ventral margin orange or white. Pronotum mostly black with collar and dorsal longitudinal band white. Mesopleuron, mesosternum, and epicnemium dark brown or black to red with subalar prominence white. Metapleuron and propodeum from entirely black to partially or entirely red. Mesoscutum varying from brown (with two longitudinal white stripes interrupted by notauli) to entirely red. Scutellum red black, laterally black and with posterior white mark. Metanotum black with postscutellum white. Propodeum black or orange-brown, usually with dorsolateral red marks, or entirely red. Tegula and base of wings white. Pterostigma pale brown. Fore leg predominantly white with femur and tibia with dorsal brown stripe, posterior side of femur and tarsomeres apically light brown. Mid legs and hind legs with coxa, trochanters, and femur orange, mid 
tibia usually white or red, usually with brown dorsal stripe, hind tibia from entirely red to brown with median white band, mid tarsomeres and hind tarsomeres white or red, apically brown. Metasoma black, sometimes with red hue, posterior rim of tergites narrowly yellow. Ovipositor usually vividly dark brown, but sometimes brown or rarely light brown. Ovipositor sheath from brown to black.

Male. Body length $5.3-9.4 \mathrm{~mm}$. Fore wing length $3.2-6.5 \mathrm{~mm}$. Similar to female in structure and colouration (Fig. 15C) but differs in characters given below. Antenna with 21-27 flagellomeres, first about 4.6 times as long as wide. Gena below eyes without strong concavity. Clypeus 1.1 times as broad as medially long. Metapleuron 1.9-2.1 times as long as deep. Face entirely white, sometimes with median longitudinal brown stripe. Mesoscutum red, median lobe partly or entirely black, often with a pair of longitudinal white dashes centrally. Sometimes hind femur white on anterior side.

Putative males: We also have included in this species seven small males that structurally are similar to typical males of C. recurva, but they differ in their colour pattern. They have the head black with face, clypeus, mouthparts, inner eye orbits, and base of antenna white. Propleuron brown with ventral part white. Pronotum brown with dorsolateral longitudinal white band. Mesonotum, scutellum, mesopleuron (except dorsal brown part), mesosternum, and metapleuron orange. Propodeum and metasoma entirely brown. Legs white with brown marks on mid femur, dorsally, base of hind femur, strip on its posterior side, base and distal third of hind tibia and distal part of hind tarsus; hind coxa orange except distally.

Host. Unknown.

Distribution. Nearctic: Canada (Ontario), Mexico (Colima, Nuevo León, Tamaulipas), United States of America (Alabama, Arizona, Arkansas, Delaware, District of Columbia, Florida, Georgia, Idaho, Indiana, Louisiana, Maryland, Massachusetts, Michigan, Mississippi, Missouri, New Jersey, New York, North Carolina, Ohio, Pennsylvania, South Carolina, Tennessee, Texas, Utah, Virginia, West Virginia). New record from Canada.

Remarks. Clistopyga recurva is the most variable North American species of Clistopyga (varying in colour pattern and in several other morphological characters). Specimens from northern United States of America are completely black or dark brown with the face completely black, according to the original description (Townes and Townes 1960). Clistopyga covarrubiasi, described by Khalaim and Hernández (2008) from Tamaulipas (Mexico) at the boundary between the Nearctic and Neotropical regions, has a brown body with conspicuous red spots on the lobes of the mesoscutum, mesopleuron, and metapleron, as well as having a mostly white face. However, after studying a large amount of material collected from many parts of North America, we have found a gradient ranging from completely dark, to dark with red marks (e.g., C. covarrubiasi) and to mostly red specimens at the latter end of the gradient. This colour gradient is very conspicuous also in the face, ranging from entirely dark brown in dark specimens to nearly white in more red specimens (Fig. 20A-D). In addition, we found that the first metasomal tergite possesses strong dorsal carinae and considerable microsculpture in specimens collected from the north whereas specimens collected from the south of the range have the first tergite almost smooth and without carinae, resembling the C. covarrubiasi morphotype. In general, punctation is usually stronger and denser in dark specimens, with intermediate states between the two extreme forms. As we could not find a clear morphological discontinuity between specimens of these two species, we consider $C$. covarrubiasi to be a synonym of $C$. recurva, acknowledging the great variation of this species, which is probably geographical. Another possibility would be to consider C. recurva as a species complex, but in the framework of this revision we cannot distinguish discrete sibling species. The males that we tentatively identify as $C$. recurva, differ from the males of species with complete submetapleural carina, mainly by the colour pattern of the hind femur, which is mostly red in all these males. They could not be the undescribed males of $C$. aenigmatica, C. arizonica, C. juliana, C. nigrifrons, and $C$. oaxacana because all these species have the submetapleural carina incomplete or absent. They resemble $C$. moraviae males, which have this colour pattern, but they lack the 
submetapleural carina. They could belong to a new species but without more distinctive characters from $C$. recurva, which is highly variable in colour, and without females that match the colour pattern of these males, we prefer to assign them tentatively to this species.

\section{Clistopyga serricauda Khalaim and Hernández, 2008}

(Figs. 13B, 13D, 13F, 19B, 19D, 19F)

Clistopyga serricauda Khalaim and Hernández, 2008: 318. Holotype: + , Mexico (UAT).

Material examined. Holotype female, MEXICO. Tamaulipas, Miquihuana, km. 19, Aserradero, 4.XI.1988, coll. R. Thompson F. (UAT). Paratype. MEXICO. Tamaulipas: Gómez Farías, 3.5 km San Jose, 12.V.1995, S. Niño and M.H. Hernández Mtz., 1 đo (UAT). Non-type material: MEXICO. Durango: El Salto, $10 \mathrm{ml}$. W., $9000 \mathrm{ft}$ (=2745 m), 2.VII.1964, coll. W.R.M. Mason, 1 \& (CNCI).

Diagnosis. Clistopyga serricauda can be distinguished from all other North American species by combination of the following characters: metasoma orange-brown to red or black, without white marks, but with posterior margin very narrowly yellow; mesopleuron red with large sub-square black mark dorsoposteriorly (Fig. 13B, 19B); head black with four white spots in dorsal part of face (below antennal sockets and at inner eye orbits), and a pair of white spots on vertex at top of eyes (Figs. 13D, 13F, 19D, 19F); hind femur reddish brown, white at extreme base and apex (Figs. 13B, 19B); submetapleural carina absent. Female with ovipositor stout, weakly and uniformly upcurved in apical 0.4-0.5; first tergite about 1.1 times as long as posteriorly broad, ovipositor sheath 1.6 times length of hind tibia, basally with conspicuous denticles on ventral margin. Male with first tergite smooth and shiny, sometimes laterally with very sparse setiferous punctures and lateromedian longitudinal carinae absent.

Description. Female. Body length $6.5-6.7 \mathrm{~mm}$. Fore wing length $5.0 \mathrm{~mm}$.

Head. In dorsal view, moderately narrowed behind eyes (Fig. 13D). Gena in anterior view, straightly and moderately constricted below eyes (Fig. 13F). Gena with fine and moderately dense setiferous punctures, in dorsal view 0.4 times as long as eye (Fig. 13D). Frons shiny, with fine punctures. Posterior ocellus separated from eye by 0.6-0.7 times its maximum diameter (Fig. 13D). Distance between posterior ocelli subequal to 1.0 times maximum diameter of posterior ocellus (Fig. 13D). Occipital carina weak, not forming a flange dorsomedially. Occiput in dorsal view moderately concave medially. Face finely and densely punctate; distance between punctures mostly less than twice length of diameter of puncture (Fig. 13F). Clypeal suture slightly rounded (Fig. 13F). Clypeus 1.8 times as broad as medially long (Fig. 13F), weakly convex in dorsal half, flat in ventral half. Malar space with a granulate strip between eye and mandible, 1.2 times as long as basal mandibular width. Antenna with 25 flagellomeres, first flagellomere about 6.5 times as long as wide.

Mesosoma. Pronotum smooth and shiny. Epomia weak and short. Median lobe of mesoscutum finely and densely punctate, lateral lobes and median lobe posteriorly, with shallower and sparser punctures on smooth background. Notauli deep anteriorly, reaching the middle of mesoscutum. Mesopleuron shiny, mostly finely and sparsely punctate, smooth in its dorsal posterior part. Epicnemial carina strong, its dorsal end weakly curved backward, ending moderately far from anterior margin of mesopleuron at level of centre of pronotum. Metapleuron smooth and shiny, with fine and scarce punctures in posterior part, 2.2 times as long as deep. Submetapleural carina completely absent. Propodeum smooth and shiny, with relativelly sparse and fine punctures basally and laterally, without lateromedian longitudinal carina; in dorsal view as long as medially wide (holotype cannot be measured because is covered by glue). Propodeal spiracle on groove separating propodeum and metapleuron. Hind femur $0.9-1.0$ as long as tibia. Fore wing with vein $C u-a$ opposite vein $R s \& M$. Vein $2 r s-m$ shorter than half length of abscissa of $M$ between $2 r s-m$ and $2 m-c u$. Abscissa of $C u 1$ between $1 m-c u$ and $C u 1 a 1.65$ times as long as $C u 1 b$. Hind wing with vein $C u-a 0.3-0.4$ times as long as abscissa of $M+C u$ between $M$ and $C u 1$. Vein $C u 1$ weakly pigmented. 
Metasoma. First tergite about 1.1 times as long as posteriorly broad, smooth and shiny, finely and sparsely punctate posteriorly and laterally; spiracle near its basal 0.4. Lateromedian and lateral longitudinal carinae absent. Sternite 1 extending back about half the length of tergite. Second tergite about as long as posteriorly broad, central region with rather dense but shallow punctures. Ovipositor stout, weakly and evenly up-curved in apical 0.4 , matt, 1.8 times as long as hind tibia Ovipositor sheath 1.6 times as long as hind tibia, with ventral margin distinctly denticulate, with numerous oblique brown setae that are longer than sheath width.

Colouration. Body mainly black and orangebrown (Fig. 13B, D, F). Antenna brown with pedicel white beneath. Head entirely black with a pair of white marks at top of eyes. Face black with a pair or white spots in dorsal part near eye orbits and with a pair of spots below antennal sockets. Basal half of mandible, clypeus and palpi centrally and ventrally white. Propleuron black. Pronotum black with white dorsal longitudinal band. Mesopleuron mostly red with epicnemium and large sub-square dorsoposteriorly mark, black; and with white longitudinal mark in dorsal part, below tegula. Metapleuron from black anteriorly to red posteriorly, sometimes with posterior yellow mark. Mesoscutum mostly red, black peripherally, with central lobe mostly black, red anterolaterally. Scutellum red with narrow white band posteriorly. Metanotum black with postscutellum white. Propodeum black. Tegula and base of wings white. Wings hyaline, pterostigma pale brown. Legs reddish brown with fore coxa, mid coxa apically, all femora basally and apically, hind tibia medially and all tarsomeres basally, white. Fore tibia and mid tibia dorsally, hind tibia basally and apically, and all tarsomeres distally, brown. Metasoma black with brown hue, tergite 2 and following with posterior margin very narrowly yellow, tergites 2-3 with posterolateral dark marks. Ovipositor light brown. Ovipositor sheath black.

Male. Body length $6.7 \mathrm{~mm}$. Fore wing length about $5.1 \mathrm{~mm}$ (extreme apices of both wings absent). Similar to female in structure and colouration (Fig. 19B), with differences described below. Posterior ocellus separated from eye by 0.7 times its maximum diameter. Distance between posterior ocelli equal to 1.1 times maximum diameter of posterior ocellus (Fig. 19D). Malar space 1.1 times as long as basal width of mandible. Gena without longitudinal concavity in ventral part. First flagellomere about 5.5 times as long as wide. Propodeum in dorsal view 0.9 times as long as broad. Metapleuron 2.1 times as long as deep. Metasomal segments longer than in female, e.g., second tergite about 1.2 times as long as posteriorly broad. Metasomal tergites 2-4 centrally with rather large, shallow to moderately deep punctures which are mostly separated by $1.0-1.5$ puncture diameters.

Colouration. Similar in colour to female (Fig. 19B, 19D, 19F). Face black with the two pair of white marks smaller and less marked than in female. Pedicel entirely black. Tergites without posterior white band.

Host. Unknown.

Distribution. Nearctic: Mexico (Durango, Tamaulipas).

\section{Discussion}

The present study is based on a large number of specimens deposited in many important collections of Ichneumonidae. We believe we have been able to find most of the Clistopyga species present in North America, including Mexico, but certainly the geographical area covered by the present study is large. Considering that most Clistopyga species are rarely collected insects, as was noted by Townes and Townes (1960) and later by Gauld (1991), North America may still harbour some new species of Clistopyga. The scarcity of Clistopyga in field inventories was further demonstrated in the field study conducted by A. González-Moreno and S. Bordera in Yucatán where, despite a large sampling effort of 168 Malaise trap months resulting in 6567 ichneumonid specimens, only four specimens of C. maya were found in the type locality. This is in agreement with the study of Sääksjärvi et al. (2004) showing that many pimplines are found only by long-term field inventories. The species may be biologically rare or just hard to collect using common methods employed in sampling Ichneumonidae (e.g., Malaise traps).

The present study reports 19 North American species of Clistopyga. Of these, Townes and 
Townes (1960) only revised seven species from Canada and the United States of America. Khalaim and Hernández (2008) later found three new species in northern Mexico, one of which is synonymised in the present revision. Five species are here described as new and five species are new records for this region or were reported by Gauld (1991), Ruíz-Cancino et al. (2002), and Khalaim and Hernández (2008).

According to the present revision, North American Clistopyga comprises species of both Nearctic and Neotropical distributions, except for C. canadensis, which has also been recorded from cold temperate areas of Europe (Sawoniewicz 1982; Horstmann 1988; Sedivy 1989; Tereshkin 1989; Kazmierczak 1990; Zeman and Mocek 2006). The Nearctic species have been recorded from the cold temperate areas of Canada and the United States of America (excluding southern part of Florida) and the north of Mexico, whereas the Neotropical North American species have been reported from southern Mexico and the southern parts of the Floridian Peninsula and usually from Central America (Costa Rica).

Mexico is considered to be a transitional zone between Nearctic and Neotropical regions; thus, north of Mexico (Baja California, Sonora, Chihuahua, Coahuila, Nuevo León, Durango, part of Sinaloa, Tamaulipas, and Zacatecas) is considering part of Nearctic Region, whereas the Neotropical Region of Mexico covers the southern part of the country (Halffter 1978). According to this consideration, the present revision extends the distributional area of the Neotropical species C. calixtoi, C. fernandezi, and $C$. henryi to the southern part of the Nearctic region (northern parts of Mexico), and the area of the Nearctic species C. manni to the northern part of the Neotropical region (southern part of Mexico). The Nearctic species C. nigrifrons, reported also as Netropical by the records from Mexico ( $\mathrm{Yu}$ et al. 2012), is considered in this paper exclusively Nearctic because these records are from northern Mexico (Durango and Tamaulipas). The species $C$. californica, $C$. serricauda, and $C$. covarrubiasi (now a synonym of $C$. recurva), previously reported as Neotropical (Yu et al. 2012), are considered here as exclusively Nearctic, given that they have been reported from northern Mexico (Baja California, Durango, and Tamaulipas).

Considering this, the 19 North American species of Clistopyga, show the following biogeographical distribution: nine are Nearctic, four are Neotropical, four have Neotropical and Nearctic distribution, one is Holartic, and one of the new species has an unknown distribution.

From the morphological point of view, Clistopyga shows considerable interspecific variation. Recent field inventories conducted in Colombia, Ecuador, Peru, and Venezuela have revealed a plethora of undescribed species that encompass a large range of morphological variation. This is particularly pronounced in the shape, microsculpture, and size of the ovipositor, which is assumed to be related to differences in host niches. Gauld (1991) and Gauld et al. (1998) classified the Costa Rican Clistopyga in two species-groups, the $C$. calixtoi and the $C$. henryi groups, based principally on the shape of the ovipositor.

Both of these species-groups are present in North America. The C. calixtoi species-group may be identified by the relatively evenly upcurved ovipositor whereas the ovipositor of the $C$. henryi species-group is long and straight. According to this definition, all North American species, except for $C$. henryi, belong to the C. calixtoi species-group. However, as Gauld (1991) already showed, this species-group is very heterogeneous and should be subdivided into more natural species-groups in the future, when most of the undescribed tropical species have been described.

We assume that the North American species C. recurva, C. californica, C. arizonica, and C. juliana, together with some Central and South American species, might be best placed in a new species-group as the apical part of the ovipositor of these species is very strongly up-curved in relation to all other species. However, we decline to present a new species-group in the current work, considering that a revision of the Neotropical Clistopyga species is currently in preparation by E. Palacio and collaborators (including I.E. Sääksjärvi and S. Bordera). One of the main aims of that study is to define the species-groups by conducting a phylogenetic analysis that should also include at least some North American species. 


\section{Acknowledgements}

The authors are grateful to Dr. David Wahl and Dr. Hugo Kons from AEI, Dr. Ronald Zuñiga and Dr. Manuel Solis from INBio, Dr. Jim Wiley from FSCA, and Dr. Enrique Ruíz-Cancino from UAT for permitting us to study material of Clistopyga during visits to their respective institutions. Our special thanks go to the following persons for sending us type and non-type material from their institutions: Dr. Gavin Broad from BMNH, Dr. Gisèle Wagner from UL, Dr. Robert Kula from USNM, Dr. Peter T. Oboyski from EMEC, Dr. Serguei Triapitsyn from UCRC, Dr. Alejandro ZaldívarRiverón from UNAM, and Dr. Andrew Bennett from CNCI. Likewise we would like to thank Dr. Jason Weintraub from ANSP and Dr. Enrique Ruíz-Cancino for taking images of the holotypes of $C$. annulipes and $C$. serricauda, respectively. They are sincerely gratefull to Dr. G. Broad and an anonymous referee who revised the language and provided valuable comments to improve the manuscript. They are also grateful to the staff of the Ría Lagartos Biosphere Reserve (Yucatán, Mexico) for allowing access to research facilities and providing authorisation for collecting material in this protected area. This study was supported by Projects A/018089/ 08 and A/026909/09 of AECID (Ministerio de Asuntos Exteriores y de Cooperación, Spain) and by research grants from Consejo Nacional de Ciencia y Tecnología (CONACYT) (Mexico), Conselleria d'Educació (Generalitat Valenciana, Spain, Ref: BEST/2010/036) and the Russian Foundation for Basic Research (no. 13-04-00026). The work conducted in ZMUT was partly financed by the Kone Foundation (Finland) project "Biodiversity and multitrophic interactions".

\section{References}

Ashmead, W.H. 1890. Description of new Ichneumonidae in the collection of the U.S. National Museum. Proceedings of the United States National Museum, 12: 387-451.

Aubert, J.F. 1967. Première révision des ichneumonides Pimplinae Xoridinae et Acaenitinae ouest-paléarctiques (1). Annales Société Entomologique de France (N.S.), 3: 893-907.
Aubert, J.F. 1969. Les Ichneumonides ouestpaléartiques et leurs hôtes. 1 Pimplinae, Xoridinae, Acaenitinae. Laboratoire D'evolution des êtres organisés (Faculté des sciencies. Paris). Quatre feuilles Éditeur, Paris, France.

Blanchard, E.E. 1941. Nuevos parasitos del bicho de cesto Oeceticus kirbyi Guild. Revista de la Sociedad Entomológica Argentina, 11: 3-21.

Brauns, S. 1898. Neue Schlupfwespen aus Mecklenburg. Archiv des Vereins der Freunde der Naturgeschichte in Mecklenburg, 51: 58-72.

Cresson, E.T. 1870. Descriptions of new species belonging to the subfamily Pimplariae found in America north of Mexico. Transactions of the American Entomological Society, 3: 143-172.

Cushman, R.A. 1922. North American Ichneumonflies of the genera Clistopyga and Schizopyga. Proceedings of the United States National Museum, 60: $1-14$.

Cushman, R.A. and Gahan, A.B. 1921. The Thomas Say species of Ichneumonidae. Proceedings of the Entomological Society of Washington, 23: 153-171.

Eady, R.D. 1968. Some illustrations of microsculpture in the Hymenoptera. Proceedings of the Royal Entomological Society of London, 43: 66-72.

Fitton, M.G., Shaw, M.R., and Gauld, I.D. 1988. Pimpline Ichneumon-flies. Hymenoptera, Ichneumonidae (Pimplinae). Handbook for the Identification of British Insects, 7: 1-110.

Gauld, I.D. 1984. An introduction to the Ichneumonidae of Australia. British Museum (Natural History), 895: 1-413.

Gauld, I.D. 1991. The Ichneumonidae of Costa Rica, 1. Memoirs of the American Entomological Institute, 47: 1-589.

Gauld, I.D. and Dubois, J. 2006. Phylogeny of the Polysphincta group of genera (Hymenoptera: Ichneumonidae; Pimplinae): a taxonomic revision of spider ectoparasitoids. Systematic Entomology, 31: $529-564$.

Gauld, I.D., Ugalde Gómez, J.A., and Hanson, P. 1998. Guía de los Pimplinae de Costa Rica (Hymenoptera: Ichneumonidae). Revista de Biología Tropical, 46: 1-189.

Gauld, I.D., Wahl, D.B., and Broad, G.R. 2002. The suprageneric groups of the Pimplinae (Hymenoptera: Ichneumonidae): a cladistic re-evaluation and evolutionary biological study. Zoological Journal of the Linnean Society, 136: 421-485.

González-Moreno, A. and Bordera, S. 2011. New records of Ichneumonidae (Hymenoptera: Ichneumonoidea) from Mexico. Zootaxa, 2879: $1-21$.

Graf, V. 1985. Ichneumofauna do sudeste e sul do Brasil. VI. Nova espécie de Clistopyga (Ephialtinae, Hymenoptera). Revista Brasileira de Entomologia, 29: 349-350.

Gravenhorst, J.L.C. 1829. Ichneumonologia Europaea. Pars III. Published by the author, Wroclaw, Poland. 
Halffter, G. 1978. Un nuevo patrón de dispersión de la Zona de Transición Mexicana. El Mesoamericano de Montaña. Folia Entomológica Mexicana, 39-40: 219-222.

Horstmann, K. 1988. Die Schlupfwespenfauna der Nordsee-Inseln Mellum und Memmert (Hymenoptera, Ichneumonidae). Drosera, 88: 183-206.

Kasparyan, D.R. 1981. 1. Subfam. Pimplinae (Ephialtinae). In A guide to the insects of the European part of the USSR. Volume 3. Hymenoptera. Part 3. Edited by G.S. Medvedev. Nauka, St. Petersburg, Russia. Pp. 41-97 (In Russian).

Kazmierczak, T. 1990. Ichneumonidae (Hymenoptera) of the surroundings of Gastein in the Alps. Part 1. Acta Zoologica Cracoviensia, 33 (15-28), 501-512.

Khalaim, A.I. and Hernández, S.A. 2008. Review of the genus Clistopyga Grav., 1829 of Mexico (Hymenoptera: Ichneumonidae: Pimplinae). Russian Entomological Journal, 17: 315-319.

Morley, C. 1914. A revision of Ichneumonidae based on the collection in the British Museum (Natural History). Part III. Tribes Pimplides and Bassides. British Museum (Natural History), London, United Kingdom.

Nielsen, E. 1929. A second supplementary note on the life histories of the Polysphinctas. Entomologiske Meddelelser, 16: 366-368.

Porter, C.C. 1979. Ichneumonidae de Tarapacá. I. Subfamilia Ephialtinae (Hymenoptera). Idesia, 5: 157-187.

Provancher, L. 1880. Faune canadienne. Les insectes - Hyménoptères. Naturaliste Canadien, 12: 33-48.

Quicke, D.L.J., Fitton, M.G., and Ingram, S. 1992. Phylogenetic implications of the structure and distribution of ovipositor valvilli in the Hymenoptera (Insecta). Journal of Natural History, 26: 587-608.

Ruíz-Cancino, E., Kasparyan, D.R., and CoronadoBlanco, J.M. 2002. 37. Ichneumonidae. In Biodiversidad, Taxonomía y Biogeografía de Artrópodos de México: hacia una síntesis de su conocimiento. Edited by J. Llorente Bousquets and J.J. Morrone. Conabio-Ecosur-Bayer, Mexico City, Mexico. Pp. 631-646.
Sääksjärvi, I.E., Haataja, S., Neuvonen, S., Gauld, I., Jussila, R., and Salo, J. 2004. High local species richness of parasitic wasps (Hymenoptera: ichneumonidae: Pimplinae and Rhyssinae) from the lowland rainforest of Peruvian Amazonia. Ecological Entomology, 29: 735-743.

Sawoniewicz, J. 1982. Ichneumonidae (Hymenoptera) of Warsaw and Mazovia. Memorabilia Zoologica, 36: 5-39.

Say, T. 1835. Descriptions of new North American Hymenoptera, and observations on some already described. Boston Journal of Natural History, 1: 210-305.

Sedivy, J. 1989. Check list of Czechoslovak insects III (Hymenoptera). Acta Faunistica Entomologica Musei Nationalis Pragae, 19: 1-194.

Tereshkin, A.M. 1989. Ichneumon-flies of fam. Ichneumonidae (Hymenoptera) of Byelorussia. I. Subfam. Pimplinae, Xoridinae, Acaenitinae. Vyestsi Akademii Nauk Byelarusi. Seriya Biologicheskaya Nauk, 1: 1-114.

Townes, H.K. 1969. The genera of Ichneumonidae, Part 1. Memoirs of the American Entomological Institute, 11: 1-300.

Townes, H.K. and Townes, M. 1960. Ichneumon-flies of America north of Mexico: 2. Subfamilies Ephialtinae, Xoridinae, Acaenitinae. United States National Museum Bulletin, 216: Part 2: 1-676.

Uchida, T. 1941. Beiträge zur Systematik der Tribus Polysphinctini Japans. Insecta Matsumurana, 15: 112-122.

Westwood, J.O. 1840. Introduction to the modern classification of insects, volume II. Longman, Orme, Brown, Green, and Longmans, London, United Kingdom.

$\mathrm{Yu}$, D.S., van Achterberg, K., and Horstmann, K. 2012. World Ichneumonoidea 2011. Taxapad 2012. Database on flash-drive. Ottawa, Ontario, Canada.

Zeman, V. and Mocek, B. 2006. Ichneumonidae (Hymenoptera) from protected areas near Chlumec and Cidlinou (Bohemia, Czech Republic). Acta Musei Reginaehradecensis (Series A, Scientiae Naturales), 31: 105-126. 